\title{
The Development of Emergency Management Networks A Case Study of the Province of Ontario
}

\author{
by
}

\author{
Calin Deguefe
}

A thesis submitted to the Faculty of Graduate and Postdoctoral Affairs in partial fulfillment of the requirements for the degree of

\author{
Master \\ in
}

Public Policy and Administration

\author{
Carleton University \\ Ottawa, Ontario
}

(C) 2018

Calin Deguefe 


\begin{abstract}
Networks have been argued to be essential in the field of emergency management for the design of policies and delivery of programs. Networks have been theorized to be capable of becoming the dominant governance structure in sectors of society. However, how networks develop and why they are rising in prominence is a contested issue. Moreover, the increasing prominence of networks in governance has complex implications that have yet to be fully explored. This thesis uses process tracing to knit together the analysis of provincial emergency response plans, after action reports, and semi-structured interviews with twenty-three emergency management professionals in order to make inferences on the development of characteristics of emergency management networks and governance in the Province of Ontario between the years of 1991 and 2018. This thesis contributes to an understanding of how and why emergency management networks and governance in the province have developed during this time.
\end{abstract}




\section{TABLE OF CONTENTS}

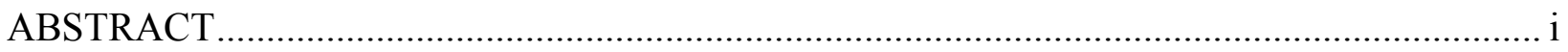

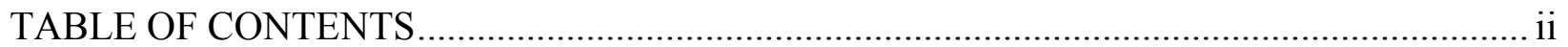

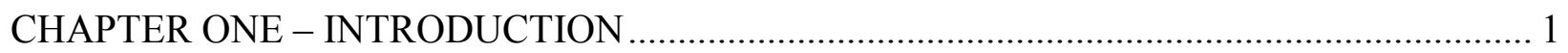

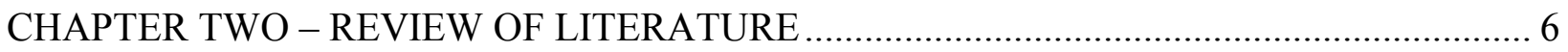

A Social Constructivist Understanding of Emergency Management......................................... 7

Emergency Management in Canada and Ontario.................................................................... 11

The Processes and Structures of Governance …………..................................................... 16

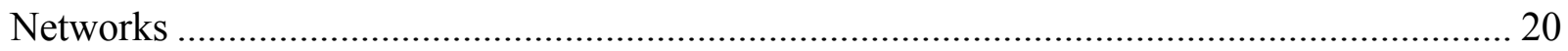

The Shift toward the Use of Networks in Emergency Management........................................ 23

The Changing Role of Government in Governance............................................................ 24

Resource Dependency and Scarcity ................................................................................ 25

The Effectiveness of Networks for Emergency Management............................................... 26

Why are Networks More Relevant Today? ............................................................................ 32

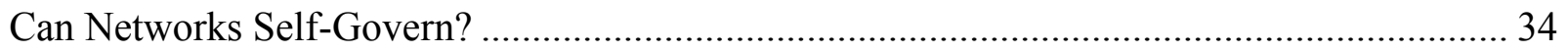

Can Networks Govern a Broader Population? ................................................................... 36

Emergency Management Policy in Ontario ........................................................................ 39

Emergency Management Networks in Ontario ………………............................................. 42

The Development of Emergency Management Networks and Governance in Ontario............. 44

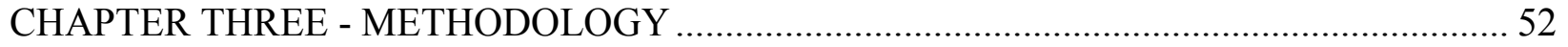

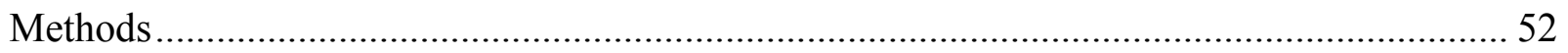

Unit of Generalization, Unit of Analysis, and Process Tracing ............................................... 52

Data Collection Techniques ............................................................................................ 55

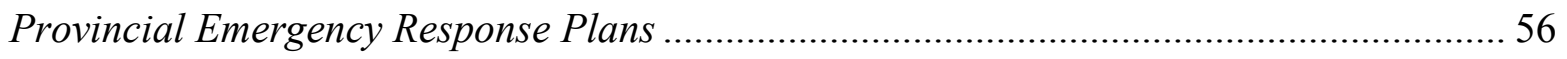

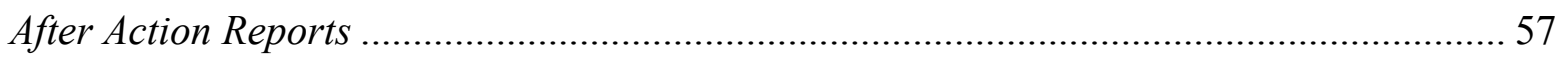

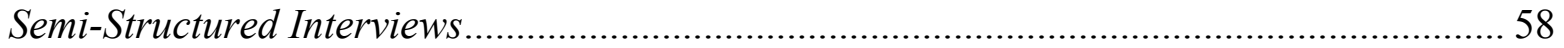

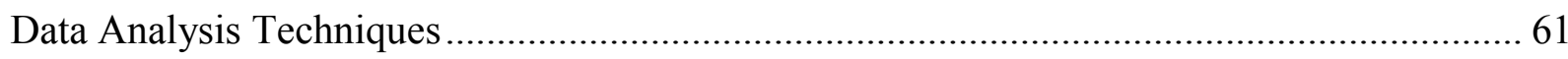

CHAPTER FOUR - DEVELOPMENTS IN THE COMPREHENSIVENESS OF

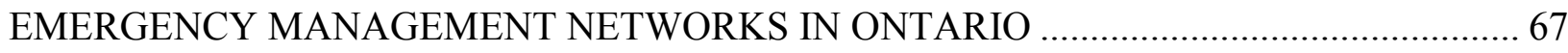


Developments in the Clarity of Roles and Responsibilities............................................ 68

Municipal and Regional/County Governments ........................................................... 68

Provincial Ministries and Federal Departments ............................................................ 72

Non-Governmental Organizations and Private Industry ............................................ 76

Developments in Information-Sharing and Communication ............................................. 79

Developments in Coordination, Collaboration and Partnerships ....................................... 88

Trust and Confidence between Emergency Management Organizations .............................. 96

CHAPTER FIVE - THE FORMALIZATION OF EMERGENCY MANAGEMENT

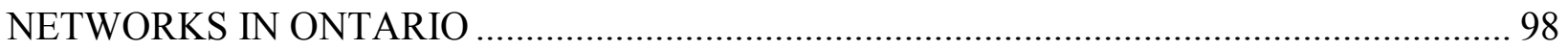

CHAPTER SIX - INFLUENCES ON THE DEVELOPMENT OF EMERGENCY MANAGEMENT NETWORKS IN ONTARIO .................................................................. 107

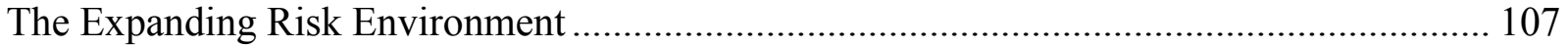

Increases in the Occurrence and Severity of Natural Disasters ......................................... 110

The Growth of the Size and Comprehensiveness of the Field ......................................... 112

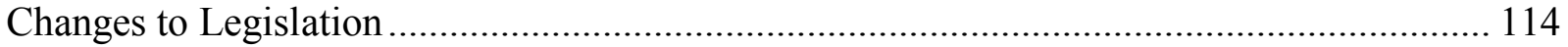

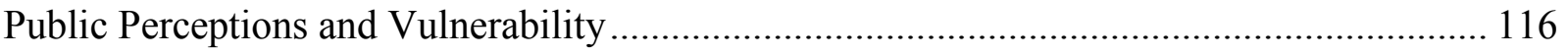

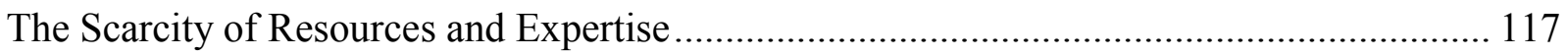

CHAPTER SEVEN - THE DEVELOPMENT OF EMERGENCY MANAGEMENT

GOVERNANCE IN ONTARIO ................................................................................... 123

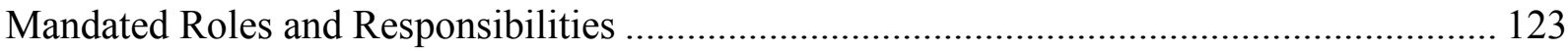

Mandated Standards and Procedures............................................................................ 126

A Reliance on Hierarchies and Top-down Decision-Making and Goal Articulation ............ 128

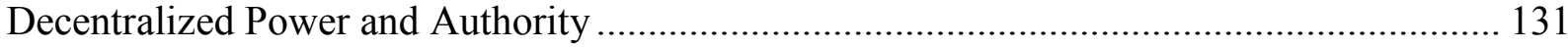

Varying Levels of Coordination and Interdependency ................................................ 136

CHAPER EIGHT - DISCUSSION AND CONCLUDING REMARKS ............................. 139

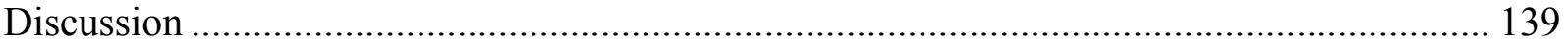

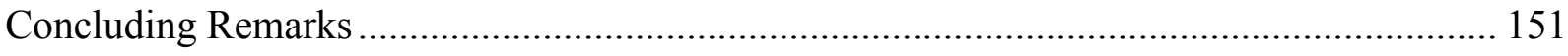

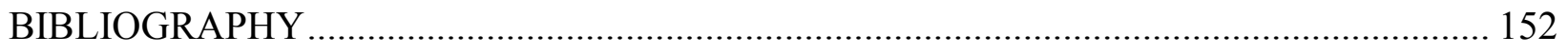




\section{CHAPTER ONE - INTRODUCTION}

There is growing recognition in emergency management (EM) literature concerning the importance of networks. An example of this recognition can be seen in Brooks et al. statement that "effective response to an emergency or other forms of crisis depends on interagency collaboration and networks - formal and informal (Brooks, Bodeau, and Fedorowicz 2013, 913).” Some argue EM networks are becoming more expansive, comprehensive, and integral to effective EM. Others have observed that the field of EM may be moving toward the use of systems of networked governance in which communication and collaboration between organizations within related domains is used achieve mutually beneficial goals (Kapucu and Garayev 2016, 932). However, there are several theories as to how and why EM networks develop, with many aspects of EM network development being unclear (S. Robinson, Murphy, and Bies 2014, 80; Kapucu and Garayev 2016,34). Analysing the development of more informal or emergent networks in EM is also difficult due to the arrangements that compromise networks not being formally discussed in plans or legislation.

The purpose of this thesis is to enhance the understanding of how governance and networks in the field of EM have developed in the Province of Ontario between 1991 and 2018. The aim is to determine whether a trend toward the development of more comprehensive EM networks can be seen in the context of Ontario and to evaluate whether EM in Ontario is characteristic of a system of bureaucratic or networked governance. This aim is achieved through the use of process tracing to knit together the findings of data gathered from Ontario's Provincial Emergency Response Plans (PERPs), after action reports (AARs) created following the responses to major crises, and the responses given by EM professionals in semi-structured 
interviews to create a coherent understanding of the development of EM networks and governance in Ontario during this period.

EM in Ontario is an important case for several reasons. The limited amount of research done on EM network development in the province has left a gap in understanding how networks in the province may have changed over time. There is also little direct evidence exists that supports a networked conceptualization of governance in the sector. Conversely, there may be evidence of a strengthening of characteristics consistent with bureaucratic governance between 1991 and 2018. Several theories of network development may also not be as applicable in the context of Ontario as in other jurisdictions due to the unique context of the province. This presents an opportunity to analyse the applicability of theories relating to EM network development abroad to the context of the province in order to help fill the gap in research that currently exists.

EM presents a wicked problem due to the cross- jurisdictional nature and wide ranging consequences of emergencies. A broad range of government agencies, non-governmental organizations (NGOs), and private sector entities may hold stake or be involved in an emergency and must be able to work together to effectively address the challenges an emergency presents (Robinson, Eller, and Gerber 2013, 346). Networks allow EM organizations to take better account of their shared resources, information, and expertise and increase their capacity, innovation, expertise, flexibility, adaptability and responsiveness (Brooks, Bodeau, and Fedorowicz 2013, 935; O’Sullivan et al. 2013, 245; Boin and 't Hart 2010, 362). A community of EM organizations that does not communicate or collaborate will have a limited knowledge of their shared capacity in the case of an emergency, leading to the development of unnecessary redundancies, failures to fill gaps in expertise, and failures to take advantage of fortuitous events 
and available resources. The impacts of large emergencies may tax the capabilities of even the most robust EM organizations and engaging in comprehensive networks expands their ability to prepare and respond to these impacts (Waugh and Streib 2006, 133).

Public Safety Canada's Report on Plans and Priorities 2016-17 highlights the importance of collaboration between EM organizations, stating "given the shifting nature and growing unpredictability of the global climate, and the corresponding rising costs of natural disasters, we need to collaborate even more with provinces and territories, Indigenous communities and municipalities to ensure Canada is prepared for any potential disaster (Public Safety Canada 2016)." Emergencies in Ontario are becoming increasingly severe and frequent due in part to the increased severity and frequency of natural disasters. Organizations like Natural Resources Canada and the Ministry of the Auditor General of Ontario have warned that climate change will continue to contribute to the increased occurrence and severity of floods and drought (Natural Resources Canada 2014, 30-31; The Office of the Auditor General of Ontario 2017, 329). The Intergovernmental Panel on Climate Change's fifth assessment report also expresses high confidence that climate hazards such as storm surges, drought and extreme heat events will continue to increase in occurrence across North America (Intergovernmental Panel on Climate Change 2013, 1443). These changes are projected to lead to increased stresses on the agricultural sector, economic activities, water systems, and rural and urban communities (Intergovernmental Panel on Climate Change 2013, 1443). A primary recommendation of Lansdowne Technologies' 2017 review of EM in Ontario is "increasing focus on supporting ministry and local emergency managers in adapting to the implications of climate change as it relates to emergencies," further illustrating the increasing impact of climate change on EM in the province (Lansdowne Technologies Inc. 2017). 
Over time new forms of hazards and risks have also been identified in communities in the province. Increased reliance on technology in the province has led to increased vulnerability to cyber-attacks (The Office of the Auditor General of Ontario 2017, 329). There has also been a heightened recognition of social emergencies in communities in Ontario (Porter 2017). The hazards faced by First Nations communities in the province has also become an area of increased focus (Lansdowne Technologies Inc. 2017). The development and recognition of new risks in the province may put a further strain on the resources of EM organizations. As the frequency and intensity of natural disasters increases and new hazards and vulnerabilities become apparent the understanding of EM networks and their development will become increasingly vital to ensuring the safety and security of the residents of Ontario.

Two major 2017 reviews of EM in Ontario highlight significant areas for development in EM that relate to the networks between EM organizations within the province. One is the report by Lansdowne Technologies Inc., which was commissioned following the Premier's 2014 mandate letter as a review of Ontario's EM systems and the other is contained in the 2017 Auditor General's Report (Lansdowne Technologies Inc. 2017; The Office of the Auditor General of Ontario 2017, 226-227). At the provincial level prominent legislation, plans, and systems are currently being reviewed, the development of which have the potential to deeply affect the way EM is carried out. EM in Ontario is changing and an understanding of the linkages between the development of the networks and governance in the field is vital to constructing a holistic understanding of why these changes are occurring and informing future policy.

The second chapter of this thesis reviews prominent literature related to EM, networks, and governance to identify major concepts and themes related to the development of EM networks and governance in Ontario and abroad and highlight gaps and contested areas in these 
fields of study. The third chapter describes and justifies the methodology used in this thesis, discusses relevant methodological and ethical considerations, and outlines the four major themes that the findings of this thesis are divided into. The fourth, fifth, sixth, and seventh chapters each discuss the findings of this thesis as they relate to one of the major themes identified in the methodology, which are respectively: developments in the comprehensiveness of emergency management networks in Ontario, the formalization of emergency management networks in Ontario, influences on the development of emergency management networks in Ontario, and the development of emergency management governance in Ontario. The eighth and final chapter discusses the findings of this thesis and their implications as they relate to the major concepts and themes analysed in the review of literature and outlines avenues for future research. 


\section{CHAPTER TWO - REVIEW OF LITERATURE}

Many academics promote the importance of comprehensive and substantive networks that include public, private, and not-for-profit organizations for emergency preparation and response (Waugh and Streib 2006, 133; Boin and 't Hart 2010, 366; Robinson, Murphy, and Bies 2014, 80-81). Several scholars argue that EM networks are rising in prominence (Kapucu and Garayev 2016, 931; Robinson, Murphy, and Bies 2014, 79; Brooks, Bodeau, and Fedorowicz 2013, 913). However, many aspects of how and why EM networks develop are still contested. Several theories of EM network development presented by various authors, such as Robinson et al.'s resource scarcity theory, may not directly map to the development of EM networks in Ontario (Robinson, Murphy, and Bies 2014, 78). There also does not appear to be sufficient evidence of characteristics of a system of networked governance, such as decentralized power and authority as well as horizontal collaboration between the public, private, and non-profit sectors, in literature discussing EM in Ontario. Some aspects of EM research in the province may support a networked conceptualization of governance in the province while others may detract from it (Henstra 2011, 416; Nirupama and Etkin 2012, 602). Lastly, the connection between the development of networks and the development of governance in the province is not wholly clear.

This chapter critically reviews the concepts and theories in the prevailing literature that relate to networks, governance, and EM in Ontario and abroad. This chapter begins by establishing the social constructivist framework of understanding used in this thesis and introducing the structure of EM in Canada and Ontario. Prominent understandings of the processes and structures of governance and the concept of networks are then discussed. This discussion is followed by an analysis of the shift towards the use of networks in EM. This 
analysis is followed by a discussion surrounding whether networks can self-govern or govern a broader population. Lastly, EM policy, networks, and the development of EM networks and governance in Ontario is discussed to begin to apply theories relating to the development of networks and governance to the context of province.

\section{A Social Constructivist Understanding of Emergency Management}

The theories and methodologies used in the field of EM are informed by the ontological and epistemological tenants to which working professionals, researchers and policy makers hold (Chipangura, Van Niekerk, and Van Der Waldt 2016, 262). An understanding of these tenants can aid in the understanding of why certain tools and techniques are used and assist in the identification of trends and anomalies. The two primary foundations of ontology and epistemology on which EM theories are erected are those of objectivism and social constructivism (Chipangura, Van Niekerk, and Van Der Waldt 2016, 262).

An objectivist understanding of EM puts emphasis on the quantifiable impact of an emergency or disaster on societies independent from social abstractions (Chipangura, Van Niekerk, and Van Der Waldt 2016, 266). From an ontological standpoint objectivism entails a belief that reality exists independently of the mind. The mind interprets nature, creating a representation of the world. One uses an objectivist approach by separating the world into subjects and objects and then focusing study on objects using methods that are universal and free from values (Chipangura, Van Niekerk, and Van Der Waldt 2016, 263). Knowledge is capable of being observed and measured because there is an objective reality outside of the individual (Chipangura, Van Niekerk, and Van Der Waldt 2016, 263). Through deductive reasoning one may discover and explain objective, universal truths. 
A social constructivist standpoint may hold that nature cannot be interpreted independently from social abstractions or even that reality does not exist independently from the mind. Two streams of thought emerge from a social constructivist standpoint. One is that nature cannot be interpreted independently from social abstractions. While a disaster may be underpinned by a physical condition, it is ultimately a shared construction influenced by the agency and constraints within a society as well as societal action and inaction (Chipangura, Van Niekerk, and Van Der Waldt 2016, 266). A disaster cannot exist without an individual to give it meaning. This means that a disaster's effects do not exist in themselves. A disaster is not defined by the physical properties that may underpin it but rather by the shared social, political, or cultural constructions of individuals. Therefore, as poignantly observed by Weichselgartner “disaster itself occurs within society and not within nature (Weichselgartner 2001, 86).” Disaster is not so much a reaction to an external force as it is a social consequence (Gilbert, 1995, 235). There is therefore a connection between the natural environment and human constructions (Perry and Quarantelli 2005, 82). Another social constructivist standpoint is that reality does not exist independently from the mind. Physical events are irrelevant and an emergency or disaster is purely a social construct (Perry and Quarantelli 2005, 82). Therefore, as stated by Aguirre "disasters are what communities define as disasters (Aguirre 2002, 114)."

In contrast to a constructivist or objectivist approach, a post-modernist approach would highlight that the strict continual adherence to a particular meta-theory hinders the scrutiny necessary in a process of interpretation (Perry and Quarantelli 2005, 82). Maintaining a consistent, precise theory or definition of what an emergency or disaster is may end up undermining the ability to come to reasonable understandings. Therefore a post-modernist 
approach may avoid the use of meta-theories altogether and focus instead on narratives tailored to the circumstances of communities.

EM from a constructivist standpoint focuses on the concept of vulnerability, the idea that social, political, and cultural factors increase the susceptibility of individuals to hazards (Chipangura, Van Niekerk, and Van Der Waldt 2016, 266). Risks and hazards reveal vulnerabilities within societies, which may lead to an emergency should they not be addressed. Reducing the susceptibility of individuals and communities may contribute to increasing their capacity, thereby reducing the chance of a crisis or disaster. EM becomes not so much the defence against external forces as it is the management of human relations in times of uncertainty and crises (Gilbert, 1995, 235).

A primary advantage of viewing EM through a constructivist lens is that the centre of attention is put on its human element (Chipangura, Van Niekerk, and Van Der Waldt 2016, 269). The cause of crises and disasters moves from being the physical phenomenon to being the vulnerability of the affected population and an onus for action is put on societal actors. The capacity and strategies of emergency managers and their organizations, the public, and the institutions of society are put to the forefront. The socially, culturally, politically, and economically disenfranchised, who are most vulnerable to the effects of crises due to dominant societal structures, become an area of focus.

The Emergency Management and Civil Protection Act (EMCPA) defines an emergency as a "situation or an impending situation that constitutes a danger of major proportions that could result in serious harm to persons or substantial damage to property and that is caused by the forces of nature, a disease or other health risk, an accident or an act whether intentional or otherwise (The Emergency Management and Civil Protection Act 1990)." The EMCPA's 
definition is incomplete in that it does not sufficiently detail the social aspects of emergencies. The social aspects of emergencies are discussed by Boin and 't Hart, who define emergencies as “threatening, urgent and uncertainty-filled disruptions of the status quo (Boin and 't Hart 2010, 358)." Emergencies disrupt the shared social constructions of societies and reveal vulnerabilities in communities. A disaster is a disruption of such a magnitude that it overwhelms the capacities of communities and has substantial social consequences for the shared constructions of the individuals within them. While an emergency or disaster may be defined by its effect on social constructions, it is important to note that it is individuals that give them meaning. A disruption may constitute a disaster for one individual and an inconvenience for another based on the meaning that they apply to it.

The EMCPA defines EM as "the prevention and mitigation of, preparedness for, response to and recovery from emergencies (The Emergency Management and Civil Protection Act 1990).” The Province of Ontario's 2008 PERP expands on this definition by stating that EM is "organized, comprehensive programs and activities taken to deal with actual or potential emergencies or disasters. These include mitigation against, preparedness for, response to and recovery from emergencies or disasters (The Ministry of Community Safety and Correctional Services 2008, 85)." Murphy states that "emergency management consists of the activities, plans, resources and skills employed to prepare and protect people and their property from emergencies and disasters (Murphy 2004, 2)." From these definitions one can elicit that EM involves planning, programming, and activities at multiple stages, the goal of which is the protection of individuals and their property. A social constructivist would expand this definition to highlight that EM entails the management of human relations during times of uncertainty and the reduction of the vulnerabilities of communities to address the social consequences of crises and disasters. 
A constructivist approach to EM is best suited to this thesis because it forms a framework through which one may understand network development. There is a reciprocal relationship between networks, actors, and structures. Actors create and change structures while structures in turn enable and constrain actors. Networks act as a mediator between actors and the structures in their environment. While networks are constrained and changed by structures they provide a substructure through which actors may negotiate to better navigate established structures. The negotiation between actors leads to the development of the network (Rhodes 1997, 11). Through the collection of data from individuals within networks, specifically regarding the development of the characteristics related to those networks, inferences can be made on the development of the networks themselves. A constructivist framework of understanding aids in the analysis of how the government's role in governance may be changing (Pierre and Peters 2000, 199). The state is charged with being capable of addressing current problems. As problems develop the position and structure of governance must develop (Pierre and Peters 2000, 198). A social constructivist framework helps understand society's role in the shifting structures of governance to ascertain how it has developed in the context of EM in Ontario.

\section{Emergency Management in Canada and Ontario}

An understanding of the EM systems in Canada at the federal, provincial, and municipal level provides a basis of understanding to begin to apply theories of network development and governance to the context of the province. EM in Canada is based on the concept of a tiered, or graduated, response system wherein higher levels of government support local governments only if local capacity is overwhelmed or if the crisis directly affects an area of their jurisdiction (Henstra 2010, 246). For instance, the Federal Government may involve itself in a provincial 
emergency if formally requested by the province for assistance or when a federal jurisdiction is clearly affected (The Ministry of Community Safety \& Correctional Services 2016). Likewise, provincial governments will usually only respond to a municipal emergency once the municipality's capacity is overwhelmed or if the municipality requires specialized resources or expertise. Action such as this is often, but not always, preluded with a municipality declaring a state of emergency (Murphy 2004, 2). Nuclear or pandemic emergencies may be examples of emergencies that are the jurisdiction of more senior levels of government, and will lead to their activation irrespectively of the actions of municipalities.

At an institutional level EM in Canada is structured by formally legislated arrangements between the different levels of government as well as the citizens of the state. EM at the federal level is dictated by the Emergency Management Act and the Emergencies Act. The Emergency Management Act clearly outlines the roles and responsibilities of federal ministers regarding emergency management, and gives authority to the Minister of Public Safety to set a clear direction for emergency management and critical infrastructure protection for the Government of Canada (The Ministry of Community Safety and Correctional Services 2008, 56). The Emergency Management Act recognizes EM as a provincial area of responsibility (Raikes and McBean 2016,13). Each province has the authority to delegate that responsibility to its municipalities through provincial legislation. Municipal governments are creatures of statue that derive their existence, authority, and responsibilities from the legislation of the province (Raikes and McBean 2016, 13). The Emergencies Act allows the federal government to invoke exceptional powers in the event of a federal emergency. Emergencies in this act are divided into four types: public welfare emergencies, public order emergencies, international emergencies, and war emergencies (The Ministry of Community Safety and Correctional Services 2008, 56). 
At the provincial level, EM legislation in Canada grants powers and authority to provincial actors to plan for, and respond to, emergencies and sets limits on civil liability in regard to the government's actions related to emergencies (Raikes and McBean 2016, 13). The Province of Ontario takes a top-down approach to the implementation of its EM strategy that measures performance and sets annual reporting requirements on its municipalities (Henstra 2011, 417). EM is framed as a matter of due diligence by the province, with local governments having a legal and moral duty to protect citizens and their property from hazards and crises (Henstra 2011, 420). Ontario's EMCPA requires its municipalities develop, implement, and annually update an EM program (The Emergency Management and Civil Protection Act 1990). The program must consist of EM planning, training programs, yearly exercises for personnel, and public education. Municipal EM programs must also identify and assess potential hazards to public safety and infrastructure that may be at risk (Raikes and McBean 2016, 14).

Municipalities are also empowered to create shared agreements with neighboring communities to better respond to crises and emergencies (The Ministry of Community Safety \& Correctional Services 2016).

The province maintains its own detailed EM plans and acts as a coordinator of the EM programs within its borders (Henstra 2011, 400). The province uses an all-hazards approach to EM focusing on five pillars:

1. Prevention - Actions taken to prevent emergencies themselves and diminish the response and recovery activities required;

2. Mitigation - Actions aimed at identifying and lessening the negative effects of an emergency or disaster;

3. Preparedness - The measures taken prior to an emergency or disaster to ensure an effective response; 
4. Response - Efforts taken to respond to an emergency and mitigate its effects on public safety, and;

5. Recovery - The restoration of affected areas in the immediate, and prolonged, aftermath of a disasters (The Ministry of Community Safety and Correctional Services 2008, 1-2).

To supplement the EMCPA, an Order in Council assigns thirteen ministries within the province responsibilities for EM in particular areas, they take the lead role in preparing and responding to the emergencies for which they are responsible (The Office of the Auditor General of Ontario 2017, 233). Some ministries have responsibilities and powers related to EM assigned in separate legislation. For example, the Forest Fires Prevention Act mandates the Minister of Natural Resources and Forestry to declare a "forest fire emergency area" if necessary and the Health Protection and Promotion Act gives the Chief Medical Officer of Health substantial powers to investigate and respond to medical risks (The Office of the Auditor General of Ontario 2017, 233). The Ministry of Municipal Affairs is responsible for Ontario’s disaster financial assistance program, which are intended for individuals, businesses, not-for-profit organizations, and municipalities (The Office of the Auditor General of Ontario 2017, 232). Within the Ministry of Community Safety and Correctional Services, Ontario's Office of the Fire Marshal and Emergency Management (OFMEM) ensures that all municipalities and ministries within the province maintain and implement their EM programs and the Provincial Emergency Operations Centre (PEOC) coordinates assistance and advice in the instance of occurring or impending emergencies. The PEOC also acts as a liaison with Ontario's ministries, other provinces, and the Federal Government (The Ministry of Community Safety \& Correctional Services 2016) . It is important to refrain from viewing the provincial government as capable of exercising complete authoritative control over its municipalities. While this top-down approach may frame EM at an 
institutional level as largely hierarchical, in reality different levels of government are often interdependent and rooted in complex relationships (Rhodes 1997, 8).

Municipal governments have differing levels of commitment to EM planning and programing due to a variety of factors, including: differing levels of pressure for effective EM by communities and elected officials, the scarcity of resources and expertise, the time constraints faced by their civil servants, and the availability of local partners. EM planning and programming often does not provide short-term rewards as the benefits of EM may not be apparent until an indeterminate point in the future. The benefits of EM are also often diffuse, and do not mobilize a great deal of broad based support (Henstra 2010, 250). Therefore, the level of emergency preparedness varies considerably from community to community (Henstra 2010, 247). While the roles and responsibilities of governmental actors are defined in the Emergency Management and Civil Protection Act, the general language used by the legislation has been argued to omit what specifically ministries and municipalities should assess to reduce risk and what crises and aspects of crises should be prepared for (Raikes and McBean 2016, 14). The lack of mandatory legislated standards to ensure preventative activities is argued by Raikes and McBean to contribute to a lack of guidance and responsibility on the part of the province and its municipalities in regard to EM (Raikes and McBean 2016, 17).

EM goes below the municipal level to the family and the individual. Families, neighbours, and community associations are part of networks within their communities that act as social resources during an emergency (Murphy 2004, 2). The first responders to an emergency are in most cases nearby residents and victims. These individuals play an important role prior to, during, and following the activation of an official government response. At first glance EM in Ontario seems to be highly structured sector driven by governmental actors with clearly defined 
roles and responsibilities and straight forward lines of authority. In order to understand how networks have developed in the province one needs to look to not only the formal role of government, but also the role of governance.

\section{The Processes and Structures of Governance}

In order to understand governance as it relates to EM it is vital to first conceptualize the processes and structures of governance. The word governance derives from the Greek verb meaning to pilot or to steer, famously used in Plato's metaphor of the ship of the state wherein he likens governing regimes to individuals in control of the chart and course of a ship (Plato and Bloom 1991, 168-69). As a concept governance is difficult to approach. There are a range of modern usages for the term, many of which retain elements from its original usage. Fasenfest describes governance as "a set of decisions and processes made to reflect social expectations through the management or leadership of the government (Fasenfest 2011, 771)." Junki refers to it as "the institutionalized politico-economic process that organizes and coordinates the activities of a variety of economic, political, and social actors (Junki 2006, 20).” Klijn describes the processes of governance as being "about reconciling different values as well as the different actors representing those values" and the "struggles about the values represented in decision making and policy outcomes (Klijn 2008, 509).” Apparent in these definitions are the concepts of authority, direction, coordination, accountability, and values. These concepts are bound to feature prominently in any study of governance.

The process of governance involves articulating the values and pursuing the collective goals of a society or community (Pierre and Peters 2000, 31). In order to achieve this one must understand the interests of the actors in that community (Pierre and Peters 2000, 12). Governance 
is therefore the connection of governing to society (Pierre and Peters 2000,32). Central to the activities of governance is the provision of direction to these actors. Governance highlights the extent to which collective goals can be articulated and direction can be given under the constraints present in the environment of those who govern (Pierre and Peters 2000, 7). As governance includes the shifting relationships between actors the concept itself is fluid (Pierre and Peters 2000, 12).

The concept of governance is valuable due to its ability to encompass the entire range of relationships and institutions that take part in the process of governing (Pierre and Peters 2000, 1). As an analytical framework governance at times challenges the idea that political institutions have the capacity to authoritatively to govern a society (Pierre and Peters 2000,24). While the state remains the key political actor in society and the dominant form of the expression of the society's collective interest, theories of governance often point out the complex linkages that are involved in the process of governing between societal actors (Pierre and Peters 2000, 32). The state remains a dominant source of legitimacy in transferring power and sanctioning the powers of those below it (Rhodes 1997, 18). However, the role of government in governance can range from it being a major coordinator, to a key actor, to marginally involved, to perhaps not involved at all (Pierre and Peters 2000,26). Society outside of the government is not only capable of articulating its needs to government but may be significantly involved with the implementation of the methods used to meet those needs (Pierre and Peters 2000, 32).

Governance may be referred to not only as a process but also as a structure. Different structures of governance may exist within a society. Some argue that styles of governance are a matter of practicality, with the type that works best in light of prevailing economic and political factors being used (Junki 2006, 21). Others point out that governance styles can be influenced by 
culture as opposed to practicality, with methods of organization and coordination being engrained in the individuals working within institutions (Brooks, Bodeau, and Fedorowicz 2013, 929). The most commonly described structures of governance are hierarchies, networks, markets and communities. The primary structures used for articulating goals and directing EM in Ontario are hierarchies and networks.

Bureaucratic governance, also known as vertical governance, flows from hierarchies. Classically tied with public government, in the Weberian model this structure of governance holds the state as the epitome of the collective interest of the society it governs. The government is seen as the legitimate embodiment of the general will of society. In a bureaucratic system of governance the bureaucracy, operating under the mandate of the executive, is kept distinct from society but imposes law and regulations upon it (Pierre and Peters 2000, 15). Power and authority are centralized in the government, which is insulated from other institutions (Pierre and Peters 2000,81$)$. The actions of government are its own policy choices. It's internal organization is characterized by mandated rules, standards, and procedures, a reliance on supervision, and scripted tasks and decisions (Considine and Lewis 2003, 133). Bureaucratic governance maintains a top-down decision making approach (Junki 2006, 21). Sectors characterized by bureaucratic governance have formalized relationships between key government and market actors based on commonly-held rules and procedures with other inter-sector and interorganizational relationships being more fragmented and ad-hoc and civil society not maintaining a substantial amount of contact with government agencies (Junki 2006, 21). Rules and procedures are mandated by higher authorities and allow for a high degree of coordination between public institutions at the cost of flexibility and innovation (Junki 2006, 21). 
In a system of networked governance the processes of governance are controlled by the networks in the sector and not by the bureaucracy. This structure is particularly important as this thesis examines the connection between EM networks and governance as well as the development of networks. Networked governance can be characterized by a decentralization of power and authority and a focus on horizontal relationships and partnerships. Interest groups in this structure elude attempts at control by the government, which is reduced to being one of many actors pursing its own interests (Pierre and Peters 2000, 39). Direction is given by a community of actors who each hold stake in the issues around which the network develops. There are complex interactions and negotiations within networks between organizations, which coordinate public and private interests as well as the resources within the network (Klijn 2008, 508; Pierre and Peters 2000,20). The communication and collaboration by actors within related domains facilitates the achievement of mutually beneficial goals (Kapucu and Garayev 2016, 932). There is a sort of "hidden hand" at work that emerges out of the shared self-interest of members of the network similar to that theorized to coordinate markets (Pierre and Peters 2000, 31). Transactions in this structure are conducted on the basis of mutual benefit, trust, and reciprocity (Junki 2006, 22).

While aspects of market mechanisms may be used internally by organizations as a method of creating incentives and market actors are certainly involved in the field, market governance is not a dominant method for articulation and direction in EM in Ontario (Pierre and Peters 2000, 19). While communities are a vital and deeply discussed aspect of EM, the field would not be accurately characterized as exhibiting communitarian governance because the mechanisms through which the public participates in governance does not ensure that all individuals affected by policy in the sector have an opportunity to contribute to the policy 
process (Pierre and Peters 2000, 21). Prior to examining the role of networks and bureaucracies in governance in EM in Ontario, it is necessary to understand the concept of the network and how it is involved in governance.

\section{Networks}

The management and governance of both the arrangements and relationships that exist between organizations is an area of increasing interest to the academic community (Brooks, Bodeau, and Fedorowicz 2013, 913). Aggregation and intermediation are essential parts governmental processes and the study of networks facilitates the analysis of these processes (Rhodes 1997, 9). An effective definition of a network is "an aggregation of structural arrangements due to the belief that structure — whether horizontal or vertical — affects outcome (Kapucu and Garayev 2016, 933)." The actors who engage in networks are rational insofar as they are aware that they are making arrangements and believe that these arrangements will affect outcomes particular to their area of interest. It is important to note that the decisions of actors are never wholly rational. There are a range of factors outside of the actor's control that can affect the structural arrangements that they form, including environmental or circumstantial factors. However, the act of engaging in a structural arrangement is still underpinned by a rational thought process. Actors make structural arrangements to affect outcomes, and the aggregation of these arrangements is the network itself.

The arrangements that comprise a network are goal-oriented policy instruments or tools (Pierre and Peters 2000, 41). The goal-oriented nature of the arrangements that form networks does not mean those networks are always predictable. Robinson et al. present the stance that networks are unpredictable and chaotic, but not wholly so. Networks are continually influenced 
by organizational, environmental, and contextual factors. The continual fluctuation of these influences over time affects their development (Kapucu and Garayev 2016, 934). The distribution of power, inter-dependency, accountability, responsibility, and the formality of the relationships between actors within a network varies depending on the network being observed (Kapucu and Garayev 2016, 938). Some networks may be more stable with persistent memberships consisting of a limited number of actors with similar values (Rhodes 1997, 44). In contrast, other networks may loosely encompass a range of interest groups with membership that fluctuates and interaction between participants that varies in frequency and intensity over time (Rhodes 1997, 44). While it may be difficult to predict what actors may participate in networks, and actors do shift over time, there is still a measure of stability and predictability to networks (Robinson, Eller, and Gerber 2013, 346). An example of EM networks in Ontario maintaining a level of stability and predictability can be seen governmental offices that maintain a mandate in sector, such as OFMEM, and NGOs that maintain an internal mandate related to the sector, such as the Salvation Army or St. John Ambulance, being consistently involved in EM networks in the province over time.

Networks exhibit varying levels of formality. Formal networks are prescribed or legislated, while informal networks are often emergent and volunteer-based (Kapucu and Garayev 2016, 939). The structural arrangements that form a formal network will be outlined in more clearly understood agreements and standards than an informal network. Public sector networks are seen by some as distinct from private sector networks in so far as they have a higher degree of formalization, more clearly defined central coordinating mechanisms, and a different levels of interaction with other societal actors (Junki 2006, 24). Public networks usually develop around lead governmental agencies that have more comprehensive resources and 
administrative means or whose position in the network is mandated through legislation (Junki 2006, 25). Multi-sector networks consist of strategic partnerships structured around the mutual interest of public sector departments and agencies, as well as private sector actors from for-profit and civil society organizations (Junki 2006, 25).

Informal networks continually evolve and shift in response to the uncoordinated individual choices of actors within the network. These networks lack the stability provided by structures arising from legislation or authoritative agreements. The coordination and collaboration between actors is more decentralized in an informal network. Given time the relationships most sought by actors will shape the structure of an informal network and ultimately influence the behaviour of the individuals and organizations within it (Berardo and Scholz 2010, 632). In informal networks reciprocal ties of cooperation are developed that lead to the cultivation of stronger relationships (Berardo and Scholz 2010, 636). The resolution of shared low-risk issues builds trust between actors, leading to a willingness to engage in more complex shared problems with greater commitment (Berardo and Scholz 2010, 645). The actors within the network are capable of coming to understandings that benefit all members of the network (G. Jordan 1990, 472). As networks develop they can therefore provide a foundation for close partnerships, the creation of specialized institutions, and the development of other mechanisms that contribute to the resolution of larger, more complex issues (Berardo and Scholz 2010, 645). An example of trust building through the resolution of shared issues can be seen in the increased confidence in inter-agency teamwork emergency responders derive from the execution of shared emergency response exercises (Perry 2004, 73).

Networks may be horizontal or vertical. Horizontal networks are clusters of organizations linked to each other through resource dependencies, characterized by an emphasis on 
coordination between relevant organizations to achieve streamlined, efficient operations (Junki 2006, 25). In horizontal networks operations are pooled and partners are interdependent. Vertical networks involve partners that are usually not engaged in the same activities along the production or policy process. In a vertical network the rolls of members lie on a sequential path. An example would be government ministries funding and designing programs for private partners to deliver. Central agencies act as coordinators between up and down stream members as opposed to a horizontal network where partners pool resources and make joint decisions (Junki 2006, 25). Networks are therefore systems of linkages between actors that address particular goals, may take a variety of forms, and are connected through varying levels of formality. Networks in EM have been observed by many to have grown in prominence and robustness over time, leading to the role they should take in governance becoming a question of increasing importance.

\section{The Shift toward the Use of Networks in Emergency Management}

There are several theories as to why networks may be becoming more prominent in EM. A transformation in governance will usually begin as a result of new political, economic, ideological, or technological imperatives (Junki 2006, 21). In the context of EM there seems to be three possible reasons for this transformation as discussed in literature on the subject. The shift may be part of a larger trend in public governance, the resources of EM organizations may be increasingly insufficient, forcing them to engage more aggressively in structural arrangements and partnerships with other entities, or networks may be increasingly seen as particularly well suited to handling the challenges that modern EM presents. 


\section{The Changing Role of Government in Governance}

The weakening position of government in many sectors of society is a widely discussed topic. Governments have often been argued to be becoming increasingly dependent on other societal actors (Pierre and Peters 2000, 5). Government's dependency on other societal actors is agued to be the result of a lack of resources, a lack of legitimacy, or as a result of societies becoming increasingly ungovernable. Some view what was once seen as the governing state to now be more accurately referred to as the enabling state (Pierre and Peters 2000, 12).

The idea of hierarchies as a defining characteristic in modern governance is often criticized. Emphasis is put instead toward the importance of informal exchanges, flexibility and small scale actors in lieu of formal control (Pierre and Peters 2000, 15). Vertical power relations are seen by many as becoming increasingly ineffective. Therefore, there is a shift in interest in the academic community away from vertical hierarchies toward horizontal agreements between actors (Hammond 1986, 379). Hammond argues that the role of hierarchies as a defining characteristic of policy making has been replaced by the process of bargaining and compromise between actors of similar power and influence. The ability for executives to dictate policy making is described as impotent as compared to the importance of the information and advice that subordinates give (Hammond 1986, 384). Therefore the focus on vertical policy making once prominent in the study of governance had been in some cases replaced by a focus on horizontal policy making (Hammond 1986, 380). Klijn supports also the idea that aspects of horizontal governance are being adopted worldwide. He argues that public-private partnership, interactive decision making, and stakeholder involvement are being increasingly experimented with by modern governments (Klijn 2008, 506). Klijn argues that an increase in horizontal governance has been primarily caused by the increasing in the complexity of the issues faced by 
governments due to the conflicting and multi-faceted nature of their roles and responsibilities (Klijn 2008, 506). Various societal actors have resources and abilities that can enable or constrain a government's pursuit of its policy goals. Therefore, collaborative action is needed to resolve societal policy problems. The rising interdependence of societal structures, rapidly growing interconnectivity and complexity facilitated by developments in information technology, and a growing variation in values among individuals are all highlighted by Klijn as factors that have contributed to making society less governable (Klijn 2008, 506). From this point of view one can argue that the expansion of networks in EM may be part of a broader trend that has been underway for some time.

It is important to recognize that while governmental actors and processes may be seen by some as inefficient, ridged, and expensive many governmental institutions are still seen as the best option to carry out their responsibilities (Pierre and Peters 2000, 5). Law enforcement, national defence, social security and other areas are still widely seen as areas in which government institutions are viable. EM may be another sector in which governments are seen as clearly the most viable choice to be formally responsible.

\section{Resource Dependency and Scarcity}

The shift to greater use of networks may also be driven by a lack of resources and considerable environmental uncertainty. Resource dependency is widely argued to be a key determinant of network development (Rhodes 1997, 13). The distribution and type of resources within networks has been used to explain the allocation of power and influence within them (Rhodes 1997, 11). Robinson et al. take the stance that resource-dependency and environmental uncertainty forces EM organizations to create collaborative networks (Robinson, Murphy, and 
Bies 2014, 92). Berardo and Scholz support this stance, arguing that organizations must engage in networking to some extent as most do not have the resources necessary to implement their desired policies, whether the resources are financial, political, technical, or regulatory. The continually emerging issues that arise for any organization ensure that new relationships and contracts will constantly be needed to deal with unexpected problems (Berardo and Scholz 2010, 637).

\section{The Effectiveness of Networks for Emergency Management}

The most touched upon reason for the greater use of networks in EM is their effectiveness in addressing areas that bureaucratic forms of governance have been argued to be deficient in. Networks have been argued to be more effective in addressing the challenges resulting from imperfect information and environmental uncertainty, increasing collaboration between EM organizations, allowing for flexibility and prompt action, and increasing the shared EM capacity of communities.

EM networks have been consistently argued to be integral to successful emergency prevention, preparation, mitigation, response, and recovery (Waugh and Streib 2006, 131). Networks are generally believed to be effective at addressing problems that require flexibility and adaptability in the face of inconsistent information, uncertain conditions, decentralized resources and knowledge that spans boundaries. High functioning networks maintain an awareness of the interdependency between actors, a clear common purpose, often an agreed upon decision-making structure at the level of the network, an absence of infighting within the network, inclusive network membership, and trust between different organizations (Boin and 't Hart 2010, 366). 
Networks have been argued to reduce uncertainty between actors, allow for the effective sharing of resources, aid in the projection of the idea of legitimacy, and make the governance process more representative (Junki 2006, 24). These benefits are particularly important at the local level due to the limited resources and volunteer-based nature of local actors (Waugh and Streib 2006, 132). Networks assist EM organizations secure and maintain an awareness of resources held by various actors within their environment. A shared understanding of the capabilities and resources of each actor is invaluable in EM when broad-based coordination is required on short notice. Networks have also been argued to expand social capital and create positive externalities on society by facilitating the formation of relationships based on trust and reciprocity (Junki 2006, 24). However, it is important to note that networks are also capable of creating negative externalities on society, such facilitating the spread of misinformation.

Ensuring efficient exchange of information is especially important to modern EM as uneven technological advances over the years have left different organizations using alternate channels of communication to obtain necessary information (Brooks, Bodeau, and Fedorowicz 2013, 922). Mandated information sharing technologies and systems along with social media, email, telephone, and paper may be used to varying extents by EM organizations (Brooks, Bodeau, and Fedorowicz 2013, 923). Boin and 't Hart provide support for the importance of information sharing in modern EM when they state "effective crisis management depends on principles and processes that assure flexibility and a smooth flow of information; formal structures play a facilitative role at best (Boin and 't Hart 2010, 358)." Boin and 't Hart argue that network failure primarily occurs when information is not communicated smoothly between organizations, leading to a reduction in reaction speed, increased misallocation of resources, and 
leading to confusion between EM organizations and other stakeholders (Boin and 't Hart 2010, 366).

Many of the traditional command and control models of governance that the government has traditionally engaged in have been argued to be ineffective in modern circumstances, leading to the implementation of more decentralized network and community-based models at local levels (Pierre and Peters 2000, 27). Kapucu and Garayev point out that the ridged nature of hierarchical command systems make them particularly deficient in emergency response due to the upward flow of information during a crisis (Kapucu and Garayev 2016, 931). High level decision making is dependent on information that comes from the lower levels, and so a system with a strict command and control structure may restrict the ability for short-term improvisation by lower level actors (Kapucu and Garayev 2016, 953-54). Brooks et al. support the need for improvisation and innovation when they state "emergency response, as coordinated by midlevel emergency managers through their articulation practices, must be improvised and carried out to meet and address contingencies as they emerge in an ad hoc fashion, rather than via rote execution of plans (Brooks, Bodeau, and Fedorowicz 2013, 935)." The flow of information that occurs during emergency response may function more effectively with a decentralized, networkbased system. It is important to note that the need for networks for information-sharing in emergency response can vary based on the scale and complexity of the emergency. The response to a small house fire may not require comprehensive information-sharing between EM organizations while the response to a forest fire that threatens and entire community may require broad-based information-sharing on the part of many EM organizations from a variety governmental, private sector, and non-profit organizations. 
Waugh and Streib take the position that networks are vital to EM because they facilitate coordination and collaboration among a broad range of stakeholders and ensure that those involved in an emergency can act rapidly, adapt, and improvise (Waugh and Streib 2006, 134). Robinson et al. support the need for inter-organizational collaboration when they state, "it is nearly impossible, then, to effectively prepare for or respond to emergencies without extensive collaboration (Robinson, Murphy, and Bies 2014, 81).” Emergency response in particular has three primary domains for coordination. These are which resources will go where, who decides which resources may go where, and how is it determined who has control over which resources (Brooks, Bodeau, and Fedorowicz 2013, 925). Without coordination and collaboration through networks these aspects of EM may be unclear and ineffective, reducing the capabilities of EM organizations.

O’Sullivan et al. highlight the importance of managing dynamic contexts and using interconnectivity and flexible planning to ensure adaptive responses. They argue that the key to unraveling complexity in EM is to understand how these key themes intersect and develop methods to enhance community capacity, promote collaborative activities, increase situational awareness and facilitate adaptive responses to dynamic, complex events (O’Sullivan et al. 2013, 245). Brooks et al. state that emergency response can be especially complicated in the case of large scale crises when multiple levels of government are activated. Coordination can be difficult as some contingencies cannot be predicted even in the case of extensive planning and preparation (Brooks, Bodeau, and Fedorowicz 2013, 919). Emergency managers must be able to stitch together information from a variety of sources during a crisis as it unfolds, otherwise known as the process of articulation (Brooks, Bodeau, and Fedorowicz 2013, 924). Articulation is used to assist in repairing organizational routines that have been disrupted during the course of an 
emergency (Brooks, Bodeau, and Fedorowicz 2013, 924). This process can be seen in emergency managers sustaining the workflow of personnel, material resources, information and other resources during the various stages of EM. An incident management system must therefore be flexible and scalable, characteristics that networked governance allows for (Brooks, Bodeau, and Fedorowicz 2013, 913).

Networks are also vital to EM as they allow for prompt action. Kapucu and Garayev argue that horizontal networks are more viable than hierarchies in EM because effective EM hinges on timely decision making (Kapucu and Garayev 2016, 954). Kapucu and Garayev found high levels of centralization in all EM networks in the two counties examined in their study and argued that it was to the detriment of these counties' EM systems. They argue that centralization leads to the reliance on relatively fewer actors in terms of resources creating a dependency that can be a threat in time-sensitive circumstance (Kapucu and Garayev 2016, 954). The importance of prompt decision making during a crisis is also stressed by Boin and ' $t$ Hart, who state that "effective responses in such extreme circumstances are necessarily improvised, flexible and networked (Boin and Hart 2010,362)." And that "any attempt on the part of strategic decisionmakers to plan and command each and every aspect of crisis response impedes flexibility and local initiative and constitutes an avoidable failure (Boin and 't Hart 2010, 362)." They argue that emergency managers must be able to make urgent decisions in the absence of full information (Boin and 't Hart 2010, 358).

Network-based systems may be more effective in EM as the central actor in a hierarchical governing system may become dysfunctional when its capacity is overwhelmed. The crisis response capacity of an EM community is determined to a large extent by the breadth and depth of the relationships between organizations in its networks (Boin and 't Hart 2010, 365). EM 
systems that share responsibility, authority, and resources have been argued to be more effective as they distribute power across available actors, increasing the individual capacity of each (Kapucu and Garayev 2016,954). To have high performing components in these networks is not enough to ensure effective EM, there must be firm linkages in order to increase resilience and capacity in the face of an emergency due to the extent to which crises and disasters strain the capacity of any organization or community involved in EM (Boin and 't Hart 2010, 365; Robinson, Murphy, and Bies 2014, 81). Kapucu and Garayev go so far as to argue that power should be spread even to actors on the very periphery of the network if their contributions may be of consequence during an emergency (Kapucu and Garayev 2016, 954). It is important to note that systems that share power and authority among a range of actors may be rendered ineffective if governance and information-sharing systems are not in place to coordinate these actors. This can be seen in the 1998 Landslides in the Sarno area of Italy, the response to which was carried out by a broad range of governmental organizations that were unable to execute an effective response during the first ten days of the emergency due to a lack of communication and coordination (Caprole 2000).

Perhaps it is not surprising that networks have become increasingly prominent in the field of EM in light of their effectiveness at overcoming issues that centralized systems seem deficient at addressing. However, it is essential to understand that the effectiveness of networks for EM is only one of several potential reasons for their rise to prominence in the field. While the scholars cited in this section provide substantive evidence that EM networks facilitate effective EM, this section is underpinned by a normative position and being such it contains normative biases. Networks in EM are often regarded positively by academics, but that does not mean that network development is necessarily a positive phenomenon. The effectiveness of networks for EM is only 
another potential influence of the rise in prominence of EM networks being explored in this section.

\section{Why are Networks More Relevant Today?}

There are several potential reasons why a shift toward a greater use of networks may be occurring in EM. It may be part of a broader trend, due to an increasing resource scarcity and growing environmental uncertainty, or the result of the realisation of the effectiveness of networks as opposed to hierarchies. However, why this shift has been occurring in recent years remains unclear. If networks are clearly more effective than hierarchies at addressing prevalent challenges in the EM domain, one would expect them to have been used for some time. If networks arise due to a lack of resources, one would expect to see EM organizations becoming increasingly undersupplied or their duties becoming increasingly expensive. Shrinking budgets of modern EM organizations due to austerity measures and the shifting interest of political officials, the fragmentation of formal authority within certain jurisdictions, gradual policy learning, focusing events, and the increasingly comprehensive nature of the field are all potential reasons why EM networks may be currently rising in prominence.

Robinson et al. assert that shrinking government budgets due to new public management practices may have contributed to a drive for increased participation by private and non-profit organizations in EM planning, leading to an emphasis on networks (Robinson, Murphy, and Bies $2014,78)$. New public management principles hold that the private sector, whether commercial or non-profit, is more effective and efficient in service delivery than the public sector and because of this the public sector's role should be limited to governance (Brinkerhoff 2002, 19). These principles also hold that the responsibility for meeting the needs of the individual should 
be held by the social entities closest to the individual. Examples of these entities could include the family, the community, and local organizations. Larger entities should only become involved when the capacity of entities closer to the individual are overwhelmed (Brinkerhoff 2002, 19). The position that government EM budgets are shrinking is supported to some extent by Henstra, who argues that EM is particularly prone to austerity measures during times of economic uncertainty as a result of its low visibility and salience (Henstra 2011, 403).

The increasingly comprehensive and expansive nature of EM may be contributing to a rise in the prominence of EM networks. EM planning in the civil defense era involved a small collection of response-related activities in the nature of designing emergency evacuation procedures and creating emergency shelters (Henstra 2011, 419). Modern EM is far more allencompassing, with a focus not only on civil defense but also natural disasters, nuclear hazards, terrorism, pandemics and health crises, as well as social emergencies. Boin and 't Hart suggest that modernisation has made societies more prone to experience large-scale disturbances due to the growingly tight and complex linkages between the social, industrial, financial, infrastructural, and administrative systems (Boin and 't Hart 2010, 358). It may be that the increasingly expansive duties and responsibilities of organizations in the EM domain are leading to cooperative and collaborative networks with NGOs, industry, and other levels of government becoming more and more necessary.

Berardo and Scholz approach the growth of networks from the context of the United States. They argue that the fragmentation of formal authority in the federal system of the United States has led to the creation of self-organizing mechanisms to coordinate action between multiple actors (Berardo and Scholz 2010, 632). Networks may therefore develop as a response to fragmentations in authority in some jurisdictions as an attempt to fill the void. 
A greater use of networks may also be caused by policy learning. EM networks are closely linked to EM policy because the course and principle of action of an actor influences the structural arrangements it will form with those in its environment. The structural arrangements an actor engages in may also influence its course of action. Events, both major and minor, can lead to policy makers re-thinking their approach and amending or changing policy as a result of greater experience (Henstra 2011, 404). The rise in the use of structural arrangements resulting in an increased prominence of networks may be the result of instrumental learning on the part of policy makers, who engage in those arrangements to better achieve policy goals (Henstra 2011, 404).

Another potential cause for a shift toward greater use of networks in EM is the occurrence of focusing events, which are unusual due to a combination of their timing, visibility, size, and impact (Kapucu and Garayev 2016, 935). Robinson et al. argue that there has been a change in public perception regarding the role and capacity of government to respond effectively in the wake of disasters such as Hurricane Katrina in 2005 and the 2001 World Trade Centre attacks (Robinson, Murphy, and Bies 2014, 78). EM policy is argued by Henstra to follow a pattern of stability with intermitted periods of rapid change in the wake of major disasters. Major disasters and emergencies draw the attention of politicians, news media, and the public, presenting an window for rapid policy change (Henstra 2011, 399-400). Networks may be increasingly pushed as an instrument to enhance EM in the wake of major crises and disasters.

\section{Can Networks Self-Govern?}

The development of networks in EM raises the question of whether networks are capable of becoming dominant systems of governance in societies. Before approaching that question it is 
important to ask whether a network of actors is capable of governing itself. In a broad sense to say a network is self-governing is to say that the network is directed by the shared goal articulation and direction of the actors within it. These actors share power and authority while exercising autonomy over their relationships, decision making, and the implementation of their plans and policies.

The existence of procedures or arrangements that organize interactions of actors in a network, described as providing "explicit managerial functions" have been argued by Klijn as being sources "of consistent guidance" to the network and therefore detracting from the idea that networks can be self-governing (Klijn 2008, 510). It should be stated that these procedures only detract from the idea of the network being self-governing if they are imposed by a source of authority, in which case the network might be better described as self-organizing rather than selfgoverning (Klijn 2008, 510). A network with common procedures and agreements interdependently created and adopted by its members is only a more formalized network.

Networks and hierarchies are not exclusive. To the contrary, it is a difficult exercise to name a system of governance that contains one and not the other. The existence of hierarchies within and between the organizations that are a part of the network does not mean that the network does not exercise self-governance. What is necessary is to determine whether an actor or actors authoritatively steer the network. Networks often interact with actors that maintain a level of authority or a mandate in the area in which the network has developed, especially in the case of networks where governmental actors maintain a mandate established through legislation that, through political processes, could be argued to be ultimately derived from the broader public that the sector affects. 
Models of governance that focus on networks may portray governmental departments and agencies as anywhere between key coordinating actors to only another component of the complex system of relationships that form the network (Pierre and Peters 2000,36). The role of governments may also be vastly different from network to network. Governmental actors may hold authoritative positions in one network and be only marginally involved in another. The complex and varied connections between structures of authority and networks leave untangling the processes of governance difficult when both are apparent. Hypothetically, should a network exist in the absence of an authority that influences its members' capacity toward articulating and pursuing shared goals, that network is capable of self-governing. In practice, the complexity of relations within a network makes it difficult to ascertain whether it is being steered by the authority of certain actors, or interdependently by the broader community of members within it.

\section{Can Networks Govern a Broader Population?}

Concepts similar to networks have been common in the study of governance for several decades. The study of iron triangles in the 1950's focused on the idea that decision making in regard to policy could be segmented into separate areas consisting of different interest groups with varying levels of influence (A. G. Jordan 1981, 96). The concept of intergovernmental relations focuses on the interdependence between the levels of government (Rhodes 1997, 8). A more recent development, is the possibility of networks themselves becoming dominant structures of governance that articulate interests and set and pursue collective goals in their sector (Pierre and Peters 2000, 20). Policy in this structure is shaped by the collective interest of the actors in the network and not the interest of the broader collective interest of the community that may hold stake in the area. Several consequences arise from this situation. First, policy change initiated by 
the government may be obstructed by the network in that particular sector. The primary role of society in governance is the expression of their interests to leadership through the political process. If this processes is enervated the traditional connection of society to policy is weakened. The network may also exude upward pressure to influence the policy choices of the actors with mandates drawn from political processes. Second, while the network maintains control of the policy sector, the citizens of the state may very well still hold their government accountable for its functioning. The mechanisms of accountability traditionally found in representative democracy are not designed to accommodate this more fragmented and emergent system of governance (Rhodes 1997, 21). Networked governance therefore, may separate the control of a sector from those who are perceived as responsible for it by the broader community who hold stake in it, potentially leading to conflict between the government and the networks in the sector (Pierre and Peters 2000, 20).

Networks are an entrenched and increasingly important part of the policy process that may wield significant expertise and represent the interests of actors of considerable importance. However, the common interests and goals of the network may not align with those of governmental actors, causing friction. The priorities of members in the network do not necessarily conflict with that of the government, they may provide the infrastructure and resources through which the government can carry out its desired policies. What is vital to note is that in a system of networked governance the network resists the influence of governmental actors and exudes pressure onto their decision-making (Pierre and Peters 2000, 39).

Trying to untangle the ideas of government authority and the interdependency of networks is difficult task. A range of provincial, municipal, regional/county, and federal actors are involved in EM networks. These actors have varying levels of authority and sources of 
mandate. To simply name this wide range of actors as the government, and regard them under a single banner is a naïve approach.

In public administration literature, effective network creation is often linked to the ability of the state to coordinate activities while maintaining the structural integrity of the governing system (Junki 2006, 23). Therefore, the agencies and departments often act as the dominant player in these networks and may use "soft" instruments of authority to steer the network and ensure compliance through the provision of incentives as opposed to the use of coercion (Pierre and Peters 2000, 105). In these networks societal actors may be more involved in the implementation of policy (Pierre and Peters 2000, 32).

The complex and changing position of governmental actors in networks has led some scholars to espouse that governance means governance networks and that separating the two is futile to begin with (Klijn 2008, 510-11). Equating governance with governance networks can be seen in Rhodes definition of governance as "self-organizing, inter-organizational networks characterized by interdependence, resource exchange, rules of the game, and significant autonomy from the state (Rhodes 1997, 15)." Klijn even goes so far as to state "in governance processes, politics is 'dissolved' or 'displaced' from the classical political institutions in a network of actors (Klijn 2008, 510). This is an ambitious statement. The weakening of structures of governmental authority often pointed out by critics has not been confirmed in legal and constitutional frameworks (Pierre and Peters 2000, 17). Government still acts as the guardian of the shared institutions that society creates and could be argued maintain the environments in which networks exist, giving the concept of the horizontalization of institutions an air of impermanence. When discussing new theories of governance it is important to understand that 
hierarchies have been dominant for some time and are not likely to disappear in the near future, though they may be accompanied by other structures in the developing processes of governance.

Whether or not a policy network can govern a sector, is a similar question to t whether or not a network can be self-governing. It can in theory, however when attempting to analyse this phenomena in actual sectors of society it becomes difficult to ascertain if networks are determining, or merely influencing processes of goal articulation and direction (Rhodes 1997, 29). The use of a framework for the analysis of governance that focuses on networks introduces a complexity and vagueness to the study due to the difficulty of forming coherent structures of authority and accountability, leading to a difficulty in understanding outcomes (Pierre and Peters 2000,37). However, complexity is not necessarily to the detriment of a study that approaches the topic. One can still analyse outcomes in sectors using a networked-based analysis of governance (Rhodes 1997, 12). It is merely more complex, which could very well be argued to be truer to the reality of governance.

\section{Emergency Management Policy in Ontario}

The theory of policymaking in EM in Ontario presented by Henstra may support the idea that the sector could be moving toward a system of networked governance (Henstra 2010, 249). In Henstra's conceptualization the issue-attention dynamics unique to the sector lead to apathy on the part of the citizens of the state and opportunities for entrepreneurial policy-making by the sector's policy community. Policies in the EM domain are described as "policies without publics," meaning they rarely attract public attention, have diffuse impacts, and present few incentives for mobilization (Henstra 2011, 401). Citizens expect their government to be prepared for the possibility of an emergency and to respond to emergencies but tend to have little direct, 
prolonged interest in the field (Henstra 2011, 401). Individual citizens pay little sustained attention to EM because emergencies are by their nature uncommon and unexpected. The costs and benefits in the EM domain are also notably diffuse, it is therefore uncommon for interest groups and stakeholders to lobby for policies in these areas (Henstra 2011, 401). However, citizens do expect EM programs and policies to be effective (Henstra 2010,248). Boin and 't Hart support this argument of general apathy toward EM on the part of the citizens of the state (Boin and 't Hart 2010, 358). When interest groups attempt to influence policy in the EM domain it is often to reduce costs. For instance, Henstra found that there was no evidence of citizens in Sarnia organizing pressure groups to increase investment in EM. However, there were several who demanded reduced municipal spending in the area to reduce property taxes (Henstra 2010, 253).

The apathetic attitude of the public and diffuse benefits of EM leaves it as a low-salience area in which policy is largely defined by experts and professionals in the field. Henstra argues that policy solutions in EM are created by a specialized policy communities comprised of actors from the federal, provincial, and municipal levels of government, private sector consultants and infrastructure managers, humanitarian organizations, and academics. At the local level community emergency management coordinators, police and fire departments, emergency medical personnel, and industry representatives organize themselves into smaller networks to discuss problems specific to their communities. The exclusive membership to local networks means that the members have substantial autonomy to develop proposals (Henstra 2010, 249).

Henstra argues EM policy follows a trend of incremental, gradual change with intermitted periods of significant, rapid change in the wake of high-visibility and rare occurrences. These events increase the salience of EM, attracting the attention of the public and 
political leaders due to an increased sense of vulnerability by the citizens of the state. Media coverage contributes to the rapid intensification and broadening of public interest following a major emergency, creating an opportunity for rapid policy change (Henstra 2011, 403). Henstra refers to these opportunities as "policy windows," which may open in the wake of major disasters (Henstra 2010, 248). Policy windows may interrupt the status quo of the policy subsystem if the salience of the issue leads to the endorsement of new policy by elected officials (Henstra 2011, 403). The opportunities that these windows present are temporary, as other objects of interest enter the public agenda EM is inevitably pushed once again into the periphery (Henstra 2011, 404). An example of a focusing event leading to a policy window in EM in Ontario can be seen in the Walkerton water supply contamination in 2000 , the reaction to which laid the foundation for rapid and broad-based provincial policy changes including the enactment of the Safe Drinking Water Act in 2002 (McCarthy, Michaels, and Goucher 2006, 989). The existence of this unique issue-attention dynamic in the field leads to sporadic and repeated attempts to address policy issues (Henstra 2011, 405). Henstra states that change in the field of EM can be caused by focusing events that attract attention to EM policy, but also by alterations in the political environment, changes in administrative leadership, and new information as a result of experiences and observations of other jurisdictions (Henstra 2011, 402). Often many of these influences contribute to notable policy developments.

Henstra's view of EM policy in Ontario in several ways reflects networked governance. Policy is argued to be driven tightly-knit networks comprised of actors from a range of organizations who take advantage of the opportunities presented by the increase in salience caused by crises to promote their desired policies. Policy communities use the issue-attention dynamics unique to the sector to influence governmental policy-making. However, a better 
understanding of the structure of EM networks in Ontario is required to make inferences on the complex relationships between the actors in these networks.

\section{Emergency Management Networks in Ontario}

The limited amount of research undertaken on EM networks in Ontario makes it difficult to make inferences regarding their structure. Given that a network is an aggregation of structural and interpersonal arrangements, it is appropriate to make observations on a range of relationships, agreements, partnerships, and other arrangements to piece together a more holistic perspective (Kapucu and Garayev 2016, 933). Structural arrangements are apparent between a variety of governmental actors in legislation at the federal and provincial level. Legislation prescribes a range of the roles, responsibilities, and relationships of governmental actors and establishes many aspects of the environment in which the networks between organizations form and develop (Pierre and Peters 2000, 17) The relationships between provincial and federal actors as seen in federal legislation particular to EM seems mainly horizontal. EM is recognized as a provincial area of responsibility in the Emergency Management Act, should a province request assistance from the federal government provincial ministries and federal departments would work horizontally with the provincial government taking the lead in the response (Raikes and McBean 2016, 13). The relationship between the province and its municipalities could be argued to be horizontal or vertical. EM in Ontario is the responsibility of the province and it delegates aspects of that responsibility to its municipalities through legislation (Raikes and McBean 2016, 13). The roles of the municipalities therefore could be considered as "downstream" from that of the province (Junki 2006, 25). However, legislation only provides a broad, highly formal view of the structural arrangements in EM in Ontario that contribute to forming EM networks. These 
actors, and others not discussed in legislation, engage in a range of other horizontal agreements, arrangements, and formal and informal relationships with one another.

Emergency managers themselves may be employed with the federal, provincial, or municipal levels of government as well as not-for-profit organizations and private industry. Emergency managers may be part of a range of local, provincial, national, and international networks for the purpose of EM (Brooks, Bodeau, and Fedorowicz 2013, 919). The relationships, arrangements, and agreements that these individuals engage in are a vital aspect of exploring networks in the province that are difficult to examine without further research. One example of EM networks at work in the Province of Ontario can be seen in the installment of four air sirens in the city of Sarnia to warn in the event of chemical vapour clouds. Sarnia's community emergency management coordinator brokered an agreement to share the $\$ 100,000$ cost of the sirens between local chemical companies and the municipality (Henstra 2010, 254). Here we see EM actors in the form of the municipality and local industry engaging in an agreement to share resources for the investment in hazard mitigation.

NGOs involved in EM often maintain it as a significant part of their mission but are also dedicated to other areas. These actors expand the capabilities of a network by contributing their expertise and resources in the various aspects of EM (Boin and 't Hart 2010, 363-364). For instance, during the Alberta Wildfires of 2016 the Canadian Red Cross accepted \$189 million from private donors, $\$ 104$ million from the Government of Canada, and $\$ 30$ million from the Government of Alberta. With those donations they held one-on-one consultations with impacted residents to identify and support their needs and provided financial assistance to a range of local stakeholders (The Canadian Red Cross 2017). Less prominent non-governmental actors such as 
local churches and community groups may also have a significant role to play in EM in their communities (S. Robinson, Murphy, and Bies 2014, 79).

The prominence and development of informal networks between EM organizations is considerably more opaque. This observation has been made in a general sense by Robinson et al. who state "despite the growing interest in cross-sector partnerships, very little is known about how these partnerships form when the collaboration is more emergent, episodic, or mutual and not necessarily contractual, normative, or instrumental in nature (S. Robinson, Murphy, and Bies 2014, 78)." The inconsistent and emergent nature of informal networks makes them more difficult to observe. Thus presenting a challenge to the analysis of networks in Ontario as the informal aspects of networks, particularly those between governmental and non-governmental actors, have been theorized to be of particular importance by some scholars (Waugh and Streib 2006, 134).

\section{The Development of Emergency Management Networks and Governance in Ontario}

While Henstra's theory of policy communities may potentially support an argument for the existence of a system of networked governance, several other aspects of development toward networked governance may not map to the context of the province. In Ontario there may be an increase in the prominence of top-down mandates, a concentration of authority, and an increased use of standardized systems and procedures as opposed to an increase in horizontal arrangements and a decentralization of authority that would be characteristic of networked governance. The bureaucratization of governance can be seen in the introduction of the provincial Emergency Management Act in 2001, which replaced the former Emergency Plans Act, and the subsequent 
regulations were passed in 2004 that mandated standards for municipal programs (Henstra 2011, 416).

Emergency managers have also expressed uncertainty regarding the role of the private sector and NGOs in EM in Ontario. In a system of networked governance one would expect to find extensive horizontal cooperation and collaboration between public, private, and not-forprofit organizations, the extent of this collaboration is unclear in the context of Ontario. Lastly, the theory of decreasing resources on the part of EM organizations leading to greater horizontal collaboration and agreements may not be as applicable in the case of Ontario as it is in other jurisdictions.

\section{The Potential Shift from a Discretionary to a Coercive Approach in Emergency Management Governance}

The introduction of the Emergency Management Act was noted by Henstra to indicate a movement in Ontario's EM planning and programming from a discretionary to a coercive approach. Ontario took a more discretionary approach to EM planning prior to the adoption of the Emergency Management Act. Municipalities created emergency plans at their own preference and to their own specifications. Emergency Management Ontario (EMO) created the Partnerships Toward Safer Communities program in 1997 in the first attempt to implement a standardized system for municipal emergency planning (Henstra 2011, 413-14). The Partnerships Toward Safer Communities Program laid out specific performance standards and publicly recognized participating communities (Henstra 2011, 415). However, participation was voluntary and many municipalities could not meet the standards set by the program.

The shift to Ontario's current approach is often cited as being in part a result of the Eastern Ontario ice storm of 1998 (Henstra 2011, 415). This event, along with the September 
$11^{\text {th }}$ World Trade Centre terrorist attacks, and the potential for disruption of electronic communications in the year 2000 (Y2K), are widely accepted to have galvanized provincial policy makers to adopt a new provincial EM program (The Office of the Auditor General of Ontario 2017, 229). The program entailed more coercive standards and procedures relating to the EM planning and programming of municipalities and ministries (Henstra 2011, 417). The lack of emergency preparedness evident prior to the adoption of the Emergency Management Act extended beyond planning to public education. A study conducted on the 2003 blackout in Ontario, which left 10 million Ontarians without power for periods of time ranging from a few hours to several days, described many respondents as believing an emergency preparedness kit was unneeded. It also reported that a 2-1 ratio of respondents were not interested in information about emergency preparedness (Murphy 2004, 8). The Emergency Management Act expanded mandated responsibilities in terms of EM planning, programming, and reporting on the part of the municipalities despite a noted hostility toward top-down mandates (Henstra 2011, 415).

The top-down institution of mandatory standards, the centralization of authority, and the mandated responsibilities created by the Act may present a view of governance in EM in Ontario as having become more bureaucratic, thus illustrating the contention between command and control and community-based approaches to EM at the institutional level. Command and control systems of EM stress standard operating procedures and top-down decision-making structures more consistent with bureaucratic governance while community-based approaches stress horizontal localized collaboration more consistent with networked governance. Nirupama and Etkin analysed the view of emergency management professionals on command and control and community-based systems of EM (Nirupama and Etkin 2012, 602). They found that some professionals believed that unless an emergency is provincial or federal in scale control of the 
situation should reside with the entity that declared the emergency, in many cases being the municipality. A community-based approach was supported in part because local actors know the area, the residents, and other important details relating to an emergency (Nirupama and Etkin 2012, 602). Other professionals expressed the significance of command and control based systems of EM, highlighting the importance of authority and legislation to ensure consistent application (Nirupama and Etkin 2012, 603).

It is important to note that the Emergency Management Act did not give authority to EMO to enforce the requirements stated in the legislation, meaning that the while standards were put in place for the programs of municipalities and ministries there are limited mechanisms to ensure compliance with those standards (The Office of the Auditor General of Ontario 2017, 238). A Cabinet Committee on Emergency Management was established that consists of the Premier, as well as eight members of the Provincial Parliament. The Committee's mandate is to provide strategic direction and ensure that the province is prepared to address emergency situations (The Office of the Auditor General of Ontario 2017, 235). However, as is reflected in the Auditor General's Report on Emergency Management in Ontario, the Cabinet Committee has not met since 2012 and has not delegated its responsibilities to any other group (The Office of the Auditor General of Ontario 2017, 235). While there have been substantial changes to legislation that point to EM in Ontario as becoming more centralized in authority and standardized in procedure, the extent to which these legislative changes are reflected in practice is not wholly clear. Further analysis is necessary on this topic to ascertain what effects the changes in EM legislation have had on governance in the sector. 


\section{Uncertainty Regarding the Role of the Private Sector}

Another contention highlighted in Nirupama and Etkin's study is concerning the role of the private sector in EM. Professionals held a mixed view of the involvement of NGOs and the private sector in EM. Some held the view that the private sector consistently meets its obligations, while others doubted the private sector's willingness to make substantial financial commitments to EM (Nirupama and Etkin 2012, 602). Brooks et al. support the positon that public-private partnerships can lead to issues. For instance, the process of deciding how much privileged information to share with telecommunications companies involved in emergency response drills and which companies should be involved is problematic (Brooks, Bodeau, and Fedorowicz 2013, 921). Supporters of private sector involvement in Nirupama and Etkin's study listed its potential role to include volunteering assistance, participation in planning, information sharing with communities, and better preparedness for long-term care facilities (Nirupama and Etkin 2012, 602). Professionals in Nirupama and Etkin's study expressed the importance of a continuing dialogue with all stakeholders to help strengthen relationships for effective and efficient emergency mitigation, risk reduction, and the enhancement of community resilience. There was a clear consensus in regard to the importance of engaging community players in the development of mitigation and preparedness strategies as well as resource allocation (Nirupama and Etkin 2012, 605).

Nirupama and Etkin's study indicates that EM professionals in Ontario support communication between EM actors but that there is less of a clear consensus regarding collaboration and power-sharing that would be indicative of networked governance. This lack of clarity is echoed by the University of Guelph's School of Environmental Design \& Rural Development, which stresses the importance of public engagement in post-disaster recovery but is less clear on the optimum extent of that engagement (Abraham et al. 2012, 7). This lack of 
clarity on the role of private actors may be a result of the differing contexts of crises and disasters. For instance, following the 2009 tornado in Vaughan, Ontario the Canadian Red Cross worked closely with the City as well as officials from the York region to reach out to affected residents. The Red Cross also worked with the City's Finance Department to collect information regarding damages to private property (Abraham et al. 2012, 20-21). Following a 1985 tornado

in Barrie, Ontario soldiers from a nearby military base, the Salvation Army, Canadian Red Cross, St. John's Ambulance, local churches and Mennonite groups, and large amounts of individual volunteers moved to aid in restoring function to the municipality (Abraham et al. 2012, 27). No two emergencies are exactly the same. Emergencies affect different stakeholders and elicit different responses from various organizations based on a broad range of factors, making the identification of streamlined roles and responsibilities for various actors difficult.

\section{Resource Dependency and Environmental Uncertainty}

The theory of dwindling budgets for EM organizations leading to greater use of networks may potentially not fit well in the context of Ontario as the adoption of the Emergency Management Act saw EMO's budget doubled (Henstra 2011, 416). In the early 2000's there was a great expansion in EMO's capabilities. However, more recently there has been a substantial decline in the resources of that office. EMO and the Office of the Fire Marshal were amalgamated in 2013 to form OFMEM. The scaling back of EMO's funding and personnel that occurred following this merger was substantial. For instance, in 2009/10 EMO’s operating expenses were 10.1 million with 84 total positions within the Office, by 2016/17 its expenses had decreased to 6.4 million with 58 total positions in the office (The Office of the Auditor General 
of Ontario 2017, 236). These large shifts in resourcing could very well be having substantial effects on the relationships and partnerships OFMEM engages in for the purpose of EM.

A lack of funding and personnel on the part of OFMEM was also commented on by the Office of the Auditor General as restricting OFMEM's ability to ensure the compliance of ministry and municipal EM programs with their legislated responsibilities (The Office of the Auditor General of Ontario 2017, 239). A shift toward more coercive legislation, while indicative of bureaucratic governance in theory, is not necessarily meaningful if the actors responsible for ensuring compliance with that legislation are rendered impotent due to resource constraints. Research is necessary to see the extent to which the more coercive nature of this legislation is reflected in the practices of municipalities and ministries.

Some scholars also argue the economic loss and societal disruption caused by hazards in Canada is increasing dramatically (Joakim and Doberstein 2013, 274). EM policy in Canada in the $21^{\text {st }}$ century has also shifted to stressing the importance of mitigation and risk reduction, which may be leading to a more holistic and costly form of EM in the case of Ontario (Joakim and Doberstein 2013, 275). It may be that OFMEM's funding for its EM-related responsibilities has been decreasing while its responsibilities are becoming more complex and the societal disruptions it acts as a central coordinator for are becoming more frequent and intense.

At the local level struggles for funding often exist. Henstra's 2010 study of EM in Sarnia found that interest groups such as The Coalition of Sarnia Taxpayers (COST) and Sarnia Taxpayers Overtaxation Protection (STOP) both criticized and fought to reduce the city's modest EM budget (Henstra 2010, 253). A lack of resources at the local level is also highlighted by Murphy, who argues that emergency preparedness support for small communities is often pushed off the agenda when the government's budget tightens or the politics of the day favours scaled 
back government services (Murphy 2004, 8-9). With this in mind, a resource dependency theory of network development may hold true in the context of Ontario, though further analysis is necessary to determine the linkages between the resources of EM actors in the province and the relationships and partnerships they form.

Laycock, Mahone, and Filson found that a disaster may temporarily enhance community engagement, capacity, and social networks in their study of the aftermath of the 2011 tornado in Goderich, Ontario (Laycock, Mahone, and Filson 2014, 39). The victims of an emergency often also act as its first responders. During an emergency family, friends, and neighbours, and to lesser extent strangers operate through their social networks to do what they can to help one another, leading to an increase in the resilience of communities in the aftermath of a disaster (Murphy 2004, 9). Laycock, Mahone, and Filson found that increase was temporary however, as the Goderich tornado did not lead to a permanent increase in social networks (Laycock, Mahone, and Filson 2014, 51). If hazards in Ontario are increasing in frequency and severity it may be that social networks in communities are continually rising to prominence in their aftermath and contributing to a trend of network development. There is some evidence of the development of EM networks and governance in Ontario. However, many of these theories are focused on other areas of EM, only partially touching on these topics. Further research is required to more comprehensively analyse these topics. 


\section{CHAPTER THREE - METHODOLOGY}

\section{Methods}

A qualitative approach grounded in social constructivist theory is used for this thesis. It is a case study of the Province of Ontario with a purpose to analyse whether there has been development in characteristics associated with networks and governance in the area of EM. A meso-level analysis is used as this case study focuses on networks, communities, and organizations. This thesis collects and analyses data from a variety micro -level sources, such as through interviews, and knits it together to make inferences on meso-level concepts. As organizations and networks are social constructs data can be collected and analysed from individuals who contribute to giving those constructs meaning in order come to a representative understanding of the constructs themselves. Ontario has unique characteristics and circumstances, therefore the study of EM network development in Ontario acts as both an instrumental and an intrinsic case (Creswell 2007, 75). The aim of this thesis is to learn more about how and why EM networks and governance develops, however the uniqueness of Ontario is also taken into account.

\section{Unit of Generalization, Unit of Analysis, and Process Tracing}

The structural arrangements between organizations that form EM networks within the Province of Ontario are the major entities being analysed in this thesis as well as the topic on which the thesis attempts to make representative inferences. Therefore, the units of analysis and generalization for this thesis is EM networks specifically within the province (Keller 2010, 2). While tentative propositions may be made about network development more generally as a concept, it is important to note that these will be limited by this thesis' focus being specifically 
on the Province of Ontario. It will therefore be difficult to apply findings from this thesis to the development of networks in other jurisdictions in Canada and abroad. The usefulness of the findings of this study does not lie in their general applicability to many jurisdictions but rather in their contribution to an understanding of the development of EM networks and governance in Ontario specifically.

Inferences are made through the analysis of data both from primary documents created or commissioned by the ministry that is now known as the Ministry of Community Safety and Correctional Services between the years of 1991 and 2018, and from semi-structured interviews with twenty-three professionals in the field of EM. This particular timeframe has been chosen for two reasons. First, it is a significant period because it was the era that the 1991 Province of Ontario Emergency Plan was adopted in accordance with the Emergency Plans Act of 1983. The implementation of a central plan signalled a prominent shift in how EM was carried out in Ontario. Likewise, the 2005 and 2008 PERPs signalled a major shift following the enactment of the Emergency Management Act in 2003. Major areas for improvement highlighted by the Premier's mandated review of Ontario's EM systems, the 2017 Auditor General of Ontario's Report, and Ontario's 2017 Emergency Management Action Plan point to another prominent shift currently being underway (The Government of Ontario Newsroom 2017).

Access to documents prior to this period is hampered by the phenomenon of disappearing public records (McNabb 2008, 378). These primary documents are not readily accessible, may be archived in confusing or unorganized manners, or may be destroyed after a certain period of time. Representatives of OFMEM have stated that departmental memory does not extend prior to this period due to it preceding the use of electronic documents, making primary documents 
created prior to 1991 difficult to access. Likewise, only a small amount of professionals in EM today worked in the field prior to the 1990s, making it difficult to collect data from this group.

Process tracing is used to construct and describe the unfolding of events over the timeframe of 1991 to 2018 as they related to the aforementioned unit of analysis. Process tracing is "the systematic examination of diagnostic evidence selected and analysed in light of research questions and hypotheses posed by the investigator (Collier 2011, 823)." It is an analytical tool used to draw descriptive and causal inferences from pieces of evidence that are understood as pieces of a temporal sequence of events (Collier 2011, 824). Process tracing allows for the identification of novel social phenomena, the evaluation of prior explanatory hypotheses, the gaining of insight into causal mechanisms, and the assessment of causal claims (Collier 2011, 824). Provincial emergency plans and AARs crafted or commissioned by the province act as the pieces of evidence used to help construct this sequence of events and the data collected from interviews with EM professionals in the province add a richness that aids in identifying trends and anomalies. The data set is knitted together from various sources to create a coherent understanding of the development of EM networks and governance in Ontario through the analysis of the unfolding of events that has taken place between 1991 and 2018.

It is important to note that during the established timeframe there have been changes to the structure of provincial ministries and federal departments and this can at times cause confusion during a longitudinal analysis. The re-structuring of relevant ministries and departments, the adoption of new legislation and regulations, and the effect of these changes is discussed throughout the analysis. Contemporary titles of provincial ministries and federal departments are not used throughout the analysis. Instead, these organizations are referred to by the titles they retained at the time of the relevant plan or report. While organizations may have 
maintained similar roles and responsibilities during the established timeframe, referring to them by contemporary titles creates the false impression that they are the same. For example, the Ministry of the Solicitor General of Ontario maintained many similar responsibilities for EM in 1991 as the Ministry of Community Safety and Correctional Services does in 2018. However, it was not the same ministry and will not be referred to as such.

\section{Data Collection Techniques}

Three primary sources for data collection are used for this thesis:

1. Emergency response plans of the Province of Ontario (PERPs);

2. After action reports (AARs) created following major emergency response events within the province, and;

3. Semi-structured interviews with EM professionals within the province.

Collecting data from these three sources allows for the analysis of structured and consistent primary documents while still capturing the richness of description necessary to investigate the development EM networks in Ontario. Robinson et al. also used multi-method research techniques in their 2013 study of EM networks. They found that media reports over-state and sensationalize the contribution of some actors, and down play that of others and that the rigidness of emergency operation plans did not capture many of the contributions of actors who do not have formally defined responsibilities (Robinson, Eller, and Gerber 2013, 351). The authors come to the conclusion that neither source is entirely accurate but when used together they present a more holistic picture (Robinson, Eller, and Gerber 2013,358). This thesis engages in a similar data collection technique by using semi-structured interviews to account for the ridged nature of PERPs and AARs. 


\section{Provincial Emergency Response Plans}

Data collected from the Province of Ontario's Emergency Plan of 1991, Emergency Response Plan of 2005, and Emergency Response Plan of 2008 are used in this thesis. These documents were obtained through a freedom of information request through Ontario's Ministry of

Community Safety \& Correctional Services. PERPs act as provincial master plans in the area of EM. The 2008 PERP is described as follows "it is designed to integrate the efforts and resources of the Province of Ontario, municipalities, the private sector, and other nongovernmental organizations. This plan includes planning assumptions, roles and responsibilities, concept of operations, and plan maintenance instructions (Ministry of Community Safety and Correctional Services 2008, 9-10)." The roles PERPs play make them an invaluable source in examining the development of EM networks in Ontario. This thesis traces the development of characteristics related to networks and governance by analysing changes in aspects of Ontario's PERPs over time. Kapucu and Garayev also used emergency plans in their study of the counties of Orange and Duval in the United States and stated that these plans provide "clear and elaborate identification of roles and responsibilities of the organizations responsible for emergency preparedness, response, and recovery in specific jurisdictions (Kapucu and Garayev 2016, 944)." Therefore emergency plans have been used effectively as a source of data in prior studies.

Several important points must be made regarding the limitations of using PERPs as source material. First, PERPs are theoretical plans and as such their translation into actual practice varies. This is discussed at length by Clarke, who argues that emergency plans serve more as symbols of control, order, and stability than actual executable schemas of response (Clarke 1999). PERPs also only discuss formal relationships and structural arrangements in EM in the province. Due to their ridged, high-level nature it is difficult to draw inferences regarding 
the informal networks that exist in the province. Next, as very high-level documents they only provide a broad overview of prominent relationships and arrangements in EM in the province. Further, PERPs focus on the roles, responsibilities, and relationships between governmental actors, putting the most emphasis on provincial and municipal actors. Non-governmental actors

are discussed to a lesser extent. Lastly, the main area of focus PERPs is emergency response. It is important to keep in mind that there are multiple aspects of EM. While the relationships outlined in PERPs are undoubtedly important, there are relationships that might exist specifically for emergency preparedness, mitigation, and recovery that are missed in the analysis of these plans.

\section{After Action Reports}

AARs are static documents created after a crisis that detail and evaluate the steps that an organization or organizations took during an emergency and outline possible avenues of improvement. AARs differ from EM plans. EM plans are continually updated schema for the mitigation, preparedness, response, and recovery from crises and disasters. Conversely, an AAR comprehensively examines the response to a particular emergency following its occurrence and makes recommendations for improvement. Where an emergency plan outlines the structural arrangements between organizations in theory, AARs analyse how these arrangements played out in practice. AARs capture aspects of the interactions within EM networks that PERPs do not. AARs used in this thesis have been either accessed online or through a freedom of information request with the Ministry of Community Safety and Correctional Services and include: the 1998 Northern Ontario Ice Storm After Action Report, the 2003 Report on the Management of the Severe Acute Respiratory Syndrome (SARS) Emergency, the 2011 Review of Ontario's 
Response to the Northern Ontario Wildfires, and the 2015 After Action Report and Improvement Plan for the James Bay Flood Evacuation.

Several points are important to take note of when collecting data from AARs. An AAR provides an outline and assessment of the preparedness and response of certain actors during a particular emergency, as such it is not a perfect representation of systems of networks and governance at work in the sector but an imperfect representation from which one can draw inferences on how those concepts were at play during a particular instance. As these AARs are all either created or commissioned by the Province, their main area of focus is on the effectiveness of provincial ministries and municipalities. While the non-governmental actors are included in these AARs the extent to which their involvement is discussed varies. The ridged scope and official nature of AARs also makes it difficult to draw inferences with respect to more informal relationships in regard to EM in the province. Lastly, as the AARs used in this thesis are all created or commissioned by the Ministry of Community Safety and Correctional Services they may contain biases specific to that ministry's interests.

\section{Semi-Structured Interviews}

Interviews with EM professionals within the province provide insight as to how the types of relationships, arrangements, and partnerships between EM organizations have developed between 1991 and 2018. Nirupama and Etkin have effectively used semi-structured interviews to collect data from EM personnel. In their 2012 study forty-three professionals were interviewed using open-ended questions to elicit detailed responses and minimize the potential influence of the researchers' bias (Nirupama and Etkin 2012, 601). O'Sullivan et al. also used interviews in their study of EM networks in five communities in Canada. They included a broad range of 
participants, from full time workers in the EM field with a high degree of expertise to volunteers from community organizations with little to no experience in EM (O'Sullivan et al. 2013, 246). Interviews have been shown to be used effectively to collect the input of EM professionals.

A comprehensive listing of community emergency management coordinators (CEMCs) in Ontario found online through the Ontario Building Officials Association was used for participant recruitment $(\mathrm{n}=13)$. Participants were also identified by representatives of organizations contacted for the purpose of recruitment for this thesis $(\mathrm{n}=10)$. These sources supplied a diverse base of interviewees associated with municipal and regional government $(\mathrm{n}=13)$, provincial government $(\mathrm{n}=4)$, federal government $(\mathrm{n}=3)$, as well as NGOs $(\mathrm{n}=3)$. Participants were professionals working in EM in Ontario. Their experience in the field ranged from three to over twenty years. Participants came from a range of backgrounds. For many EM was their primary career, some had begun working in EM as a second career, while others maintained aspects of EM as part of their broader roles. Potential interviewees were contacted through an email invitation. Organizational approval to contact potential interviewees was obtained from their respective organizations prior to recruitment as necessary.

Twenty-three semi-structured interviews were conducted over the phone to account for logistical and time restraints. The researcher aimed to create a balance between generality, availability of resources, and theoretical saturation with the set of participants. Interviews in the context of this thesis experience decreasing returns to scale. Increasing the number of interviews increases the generalizability of claims made and increases the chance to detect anomalies. However, resource and time constraints as well as the unavailability of potential interviewees were major limitations. After twenty-three interviews it was determined that time would be better spent on ensuring the proper analysis of the collected data. With these factors in mind no more 
than twenty-three interviews have been carried out for the purpose of this thesis. The collection of data through interviews was vital to the thesis findings due to the richness of description participants provided and the ability to target questioning. Interviews were semi-structured. The interview guide was comprised of questions relating to notable trends in the field of EM over time, the development of partnerships, working relationships and arrangements between EM organizations, the development of information-sharing, collaboration and resource sharing between EM organizations and professionals in the province, the divisions of roles and responsibilities for EM in communities, and other topics relating to networks and governance in EM in Ontario. Interviews with EM professionals in Ontario helped fill in the gaps that existed following the examination of primary documents, and helped to construct a coherent understanding of how the concepts explored in the formal documents relate to the lived experiences of professionals in the field. Further, conducting interviews allowed for the researcher to directly draw on the perspectives of the participants. Collecting data in this way helped capture a great deal of information that would be missed using only analysis of PERPs and AARs.

There are several limitations with this method of data collection. Data gathered through interviews can be limited as it is filtered through both the perspectives of the interviewee and the interviewer. Some interviewees also provide more articulate, robust responses than others, creating the danger of focusing on the information provided by some interviewees over others (Creswell 2003, 186). The limited nature of data collected through interviews has been addressed in this thesis by providing the interviewees opportunity to expand on their answers to elicit the greatest richness possible during the interview process. Limitations have also been addressed by creating as rich a set of interviews as possible, with a diverse range of perspectives. Interviews 
were recorded in addition to notes being taken to minimize selective note taking on the part of interviewer. Interviews were semi-structured, conducted using open, non-leading questions to filter out bias on the part of the researcher.

This thesis was carried out in compliance with the Carleton University Research Ethics Board. This thesis poses a mild risk to the economic and social wellbeing of the participants should they have chosen to be critical of their employers. With this in mind care has been taken to protect the identities of the participants. Interviews have been kept confidential and responses have been coded. Participants were made aware that they could choose to not answer any question or choose to end their interview at any time for any reason. The purpose of the interview was made clear to the interviewee prior to their agreement to participate both verbally, in the recruitment material, and in the consent form. Interviewees were given the choice to redact any response from their transcript or withdraw entirely up until four weeks after their interview, at which point identifiers were removed to ensure their anonymity.

\section{Data Analysis Techniques}

Care is needed when analysing structures of governance, particularly those that involve networks, to ensure that understanding arises from actual observable patterns and not from the frameworks that the researcher creates (Pierre and Peters 2000, 33). Accounting for the biases of the researcher, the authors of AARs, and the interview participants is also vital so as to come to representative and evidence-based conclusions. The authors of AARs as well as participants in this study have their own interests and internal biases that must be taken into account when analyzing data collected from these sources in order to construct representative patterns to apply to the province at large. Care must also be given to ensure that the frameworks used are not so 
vague as to include so wide a range of patterns that the conclusions drawn from them cannot be of use.

Order was initially brought to collected data by identifying patterns to be used to pull smaller portions of data into larger "wholes," thereby organizing it (McNabb 2008, 361). During this process careful consideration was given to seeing real added evidence in the same pattern and remaining open to disconfirming evidence (McNabb 2008, 361). The process of decoding and analysing a portion of data to decipher its core meaning was then used. Next, encoding was used to determine the appropriate code to apply to that portion of data (Saldaña 2009, 4). Open coding, a process that begins to bring the data into meaningful categories that helps structure further analysis and future data collection, was used initially (McNabb 2008, 362). Open codes are descriptive in nature and help reduce and organize the data to make it more manageable. Next, comparative analysis was used to identify similarities and contrasts in the data in order to find cases and evidence that belong together based on relevant characteristics and to locate cases that do not fit a pattern, thus aiding in categorizing similarities and develop new codes for unclassified phenomenon (McNabb 2008, 363).

Major categories were then re-examined to see if they warranted unbundling into two or more categories. A second level of coding called axial coding was then used to identify relationships among the open codes that brought order to the raw data. Axial codes are interpretive as opposed to descriptive (McNabb 2008, 364). Thematic development coding was then used to establish explanatory codes, which link larger groups of patterns into themes (McNabb 2008, 366). The interpretive nature of coding for qualitative data analysis is an important aspect of this thesis (Strauss 1987, 7). Two separate researchers may come up with very different sets of codes from the same sources of data in part due to the researcher's personal 
involvement in the study, the questions they ask, the detail and structure of notes, and the theoretical lens they apply (Saldaña 2009, 7). This interpretive and subjective character is a significant aspect of the results of this thesis. Effort has been given to ensure that the data collection, data analysis, and the theories and concepts that the thesis itself is built on are as clear and reasonable as possible so that, while the reader may not agree with the interpretation of the data or the conclusions drawn in this thesis, that they will understand how and why that interpretation was used and those conclusions were derived (Strauss 1987, 7).

Four themes became apparent following the coding of collected data. These are the comprehensiveness of EM networks, the formalization of EM networks, influences on the development of EM networks, and the development of governance in EM in Ontario. By knitting together data collected relating to the characteristics of these key themes over time, this thesis traces their development between 1991 and 2018. These key themes are discussed in four separate chapters in the findings section of the paper. Key characteristics of comprehensive and formal networks were drawn from the research of Kapucu and Garayev (2016), Junki (2006), Berardo and Scholz (2010), Perry (2004), Rhodes (1997), and Jordan (1990) in the literature review section of this thesis. These characteristics are listed in Table 1 and Table 2 respectively. 
TABLE 1, Characteristics of Comprehensive and Limited Networks

\section{Comprehensive Networks Limited Networks}

- The network's members extensively communicate and share information.

- Members of the network maintain clear roles and responsibilities.

- Members of the network coordinate, collaborate, and share resources and expertise horizontally to achieve shared goals.

- Members of the network maintain a mutual trust and confidence in one another.

- The network's members extensively communicate and share information.
- Communication and informationsharing within the network is absent or ineffective.

- Clear gaps in competencies and overlapping redundancies exist in the network.

- Members of the network do not coordinate or collaborate. Goals are conflicting or not effectively articulated. Resources are not pooled or shared within the network.

- There is a prominent lack or trust and understanding between the members of the network.

- Communication and informationsharing within the network is absent or ineffective.

Sources: Discussed in the review of literature.

TABLE 2, Characteristics of Formal and Informal Networks

\begin{tabular}{lll}
\hline Formal Networks & Informal Networks \\
\hline - $\begin{array}{l}\text { The structure of the network is } \\
\text { legislated or prescribed by } \\
\text { authoritative documents. }\end{array}$ & $\begin{array}{l}\text { The structure of the network is } \\
\text { emergent based on the needs of the } \\
\text { actors within it. }\end{array}$ \\
$\begin{array}{l}\text { Partnerships, relationships, and } \\
\text { arrangements are structured by } \\
\text { written agreements. }\end{array}$ & - $\begin{array}{l}\text { Partnerships and arrangements are } \\
\text { carried out on an ad hoc basis. }\end{array}$ \\
$\begin{array}{l}\text { The network's membership } \\
\text { maintains agreed upon standards } \\
\text { and procedures. }\end{array}$ & $\begin{array}{l}\text { The network's membership maintains a } \\
\text { range of standards and procedures. }\end{array}$ \\
\hline
\end{tabular}

Sources: Discussed in the review of literature. 
Five primary characteristics were identified from theories of bureaucratic and networked governance as discussed by Pierre and Peters (2000), Rhodes (1997), Hammond (1986), Junki (2006), Considine and Lewis (2003), Kljin (2008), and Kapucu and Graryev (2016) in the review of literature portion of this thesis. These characteristics are listed in Table 3.

TABLE 3, Characteristics of Bureaucratic and Networked Governance

\begin{tabular}{ll}
\hline Bureaucratic Governance & Networked Governance \\
\hline $\begin{array}{l}\text { Centralized power and authority } \\
\text { among relatively few actors. }\end{array}$ & $\begin{array}{l}\text { Decentralized power and authority } \\
\text { among a range of actors. }\end{array}$ \\
- Insulated policy processes. & $\begin{array}{l}\text { Horizontal policy processes or an } \\
\text { upward expression of influence. }\end{array}$ \\
$\begin{array}{l}\text { A reliance on hierarchies and top- } \\
\text { down decision-making and } \\
\text { articulation of goals. }\end{array}$ & $\begin{array}{l}\text { A reliance on horizontal partnerships } \\
\text { and relationships with shared decision- } \\
\text { making and articulation of goals. }\end{array}$ \\
$\begin{array}{l}\text { Mandated roles, responsibilities, } \\
\text { standards, and procedures. }\end{array}$ & $\begin{array}{l}\text { A lack of, or resistance to, downward } \\
\text { mandates. }\end{array}$ \\
$\begin{array}{l}\text { A high degree of coordination } \\
\text { between mandated organizations } \\
\text { and institutions. }\end{array}$ & - $\begin{array}{l}\text { Varying levels of coordination between } \\
\text { a range of interdependent actors. }\end{array}$ \\
\hline
\end{tabular}

Sources: Academics discussed in the review of literature.

Each chapter knits together the findings from this thesis' three major sources of data to trace how these characteristics have developed during the period of 1991-2018. This is done by analysing notable developments that have taken place in each of these characteristics throughout this time period and discussing the potential causes of these developments. The chapter on influences on the development of networks is separated into several inter-related but distinct sections that discuss the influences on the development of EM networks raised by participants. The discussion section summarizes the development of the characteristics of each theme and illustrates major trends in the development of each characteristic. These themes are reflected upon and compared 
to the themes discussed in the literature review. Lastly, conclusions have been drawn from the comparison of these themes to ultimately add to the understanding of how EM networks and governance have developed in the province of Ontario. 


\section{CHAPTER FOUR - DEVELOPMENTS IN THE COMPREHENSIVENESS OF EMERGENCY MANAGEMENT NETWORKS IN ONTARIO}

This chapter discusses the findings of this study as they relate to the development of the four primary characteristics of comprehensive networks. This chapter initially discusses the development of the clarity of the roles and responsibilities of EM organizations. The discussion of roles and responsibilities is followed by a discussion of the development of informationsharing and communication in EM in the province. The third section discusses the development of coordination and collaboration between EM organizations. Lastly, the fourth section entails a discussion of trust and confidence between EM organizations in the province.

The analysis of the emergency plans, AARs, and interviews with participants supports the view that characteristics of comprehensive networks are an essential component of EM in Ontario. One participant noted that "one of the key, fundamental components of emergency response or preparedness is being able to share-information and collaborate (Participant 202018 , 4)." The analysis for data collected from PERPs, AARs, and interviews with participants yields a view of EM networks in the province consistent with Junki's conceptualization of multi-sector networks (Junki 2006, 25). The characteristics of comprehensive networks as outlined in the methodology section were apparent to varying extents the three sources of data. When considered together, the findings from these sources illustrate that substantial but inconsistent developments have taken place in several of these characteristics, contributing to a view of EM networks in the province as having developed to become more comprehensive over time. 


\section{Developments in the Clarity of Roles and Responsibilities}

As is made clear through the literature review, the EM domain is not one that is dominated by a single actor but instead relies on a variety of structural arrangements between interdependent actors (Waugh and Streib 2006, 131). An important aspect comprehensive networks is the clarity of roles and responsibilities of the actors who engage in those networks (Boin and 't Hart 2010, 366). Major developments in the clarity of the roles and responsibilities of governmental organizations are apparent in the PERPs and AARs, particularly in the case of municipalities and ministries. Participants also provided a richness of description regarding the roles and responsibilities of EM organizations that is not accessible through formal documents. These developments point to an increased clarity of the roles and responsibilities of EM actors in the province, contributing to more comprehensive EM networks.

\section{Municipal and Regional/County Governments}

The roles and responsibilities of municipalities discussed in the 1991 Provincial Emergency Plan (PEP) flow from the Emergency Plans Act (The Ministry of the Solicitor General 1991, 31). The roles and responsibilities of municipalities in the 1991 PEP are loosely described by the graduate response system, which is outlined in the PEP (The Ministry of the Solicitor General 1991, 5) . Apart from the general structure of the graduated response system a few specific responsibilities are assigned to municipal actors. For example, municipalities are required to notify the Solicitor General when a municipal emergency is declare or terminated and heads of council are responsible for the declaration of municipal emergencies (The Ministry of the Solicitor General 1991, 31). The Emergency Plans Act also allowed for the creation of municipal emergency plans 
and the adoption of those plans by by-law. However, municipalities were not responsible for the creation or maintenance of emergency plans (The Ministry of the Solicitor General 1991, 31).

A lack of formally prescribed and consistent roles and responsibilities on the part of municipalities was a major issue during the 1998 Ice Storm. As discussed by Henstra many municipalities affected by the storm lacked even a consistently updated emergency response plan (Henstra 2011, 415). Likewise the roles and responsibilities of municipalities during a provincial emergency were a point of contention during the response to the 2003 SARS emergency. The 2003 SARS AAR recommends that the PEP be revised to clarify the line of authority from the province to municipalities during a provincial emergency and that municipalities have a clear understanding regarding the roles and responsibilities of each level of government during a provincial emergency (J.A. Pirie \& Associates 2003, 11).

The Emergency Plans Act was superseded by the Emergency Management Act on April 15, 2003 (J.A. Pirie \& Associates 2003, 3). The lack of clarity surrounding the roles and responsibilities of municipalities was addressed in the 2005 PERP, which was created in line with the Emergency Management Act. Municipalities were required to formulate plans to respond to emergencies and adopt these plans by by-law (The Ministry of Community Safety and Correctional Services 2005,6 ). These plans were to be reviewed annually by the municipality (The Ministry of Community Safety and Correctional Services 2005, Annex B). The Emergency Management Act also mandated that every municipality was responsible for conduction a hazard identification and risk assessment on facilities or other infrastructure they are responsible for (The Ministry of Community Safety and Correctional Services 2005, 16). It also mandated that municipalities were responsible for the adoption of an incident management system and to engage in annual exercises to ensure readiness for emergencies (The Ministry of Community 
Safety and Correctional Services 2005, 26). These and other responsibilities expanded upon, enhancing the clarity and consistency of municipal EM roles and responsibilities across the province. These responsibilities remained generally constant in the 2008 PERP, which was updated to reflect provisions included in the adoption of the EMCPA that are not pertinent to this area.

Participants affirmed the use of the graduated response system throughout the province as discussed in the 1991 PEP, 2005 PERP, and 2008 PERP. Participants widely supported the localized responsibility for emergencies that results from the graduated response system, in line with the views of participants from Nirupama and Etkin's study (Nirupama and Etkin 2012, 602). One participant stated "really in any community it's better if it's handled by the people that live there because they know what's best for their community (Participant 06 2018, 2)." Municipalities were discussed as having mandated responsibilities in regard to EM in addition to those in the EMCPA. For instance, municipalities with airports are responsible for incorporating additional planning specific to that area by Transport Canada and municipalities with senior homes are required to have additional EM planning by the Ministry of Health and Long-Term Care.

Participants expanded upon the responsibilities of local actors. Municipalities were described as being responsible for maintaining a mandated control team or program committee that oversee the municipality's program as a result of Ontario Regulation 380/04, which came into effect December 31, 2004 under the Emergency Management Act (The Ministry of Community Safety and Correctional Services 2005, 7). Control teams are comprised of municipal representatives of major local departments involved in EM in the community. CEMCs were discussed by participants as being responsible for the coordination of the EM 
responsibilities of their communities, consistent with their role as described in the 2008 PERP (The Ministry of Community Safety and Correctional Services 2008, 87). These individuals were described as the nexus of a web of relationships between their local government, local departments, other municipalities and communities, provincial ministries, NGOs, and other organizations and stakeholders engaged in EM.

The description of roles and responsibilities of the control team and CEMC varied to some extent between participants. Some participants described CEMCs as taking more of an authoritative role in emergency planning and programming in communities. Others described the control team as being much more closely involved in planning and programming, with the CEMC providing support. Participants generally supported the mandated responsibilities of municipalities to maintain a control team and CEMC as prescribed in the EMCPA and found it to be a beneficial development in EM in Ontario.

Participants provided a greater richness surrounding the roles and responsibilities of regions and counties, which are not touched on to a great extent in the 2008 PERP apart from being able to implement a regional plan and coordinate resources under their control (The Ministry of Community Safety and Correctional Services 2008, 18-19). EM at a regional and county level was discussed as being aimed at enhancing the coordination of EM planning and programming of its municipalities. Though EM goals and processes vary from between jurisdictions, regions and counties will generally assist in ensuring that their member municipalities fulfill their mandated responsibilities in regard to EM and ensure consistency of EM training, public education, and messaging. The region or county may assume a leadership role in coordinating shared working groups for the municipalities within their jurisdiction. 
The level of coordination that the region or county provides can be vital to its lower-tier municipalities at all stages of EM. Regional and county governments may also have specific responsibilities apart from that of their municipalities, such as establishing and running emergency shelters during evacuation events within their jurisdictions. Several participants commented on the role of counties and regions as having expanded considerably over time. One participant in particular noted that their county had gone from being fairly absent in regard to EM in the early 2000's to playing a substantial role in coordinating the EM planning and programming of the municipalities within its jurisdiction. The roles and responsibilities of municipalities, regions, and counties can therefore be seen to have been expanded on and clarified since 1991. The adoption of the EMCPA and Regulation 380/04 seem to have been major influences on these developments.

\section{Provincial Ministries and Federal Departments}

As is the case with municipalities the roles and responsibilities of Ministries in EM in Ontario have developed substantially since 1991 to become clearer and more consistent. The 1991 PEP exhibits a lack of clarity in regard to the descriptions of the roles and responsibilities of provincial actors. The 1991 PEP directs each ministry, agency, board, and commission to formulate their own emergency plan in line with their Minister's special responsibilities in regard to emergencies in the province assigned though an Order in Council (The Ministry of the Solicitor General 1991, 6). These plans govern the provision of necessary services along with the procedures by which Crown employees are to respond to an emergency and so constitute the initial response of the province prior to a coordinated response organized through the Office of 
the Solicitor General and the Provincial Operations Centre (POC) (The Ministry of the Solicitor General 1991, 6).

While special responsibility areas are assigned to eight ministries in the 1991 PEP the annexes expanding on these areas were not developed by the time of the PEP's release in 1991 (The Ministry of the Solicitor General 1991, iv-v). For instance, the Minister of Health is assigned responsibility to create an emergency plan for epidemics (Ministry of the Solicitor General 1991, iv-v). However, that is the extent to which the responsibilities of the Minister in this area are discussed. The 1991 PEP states that "ministry plans should identify the resources and the procedures that are necessary to recognize, contain and then resolve the cause of any emergency that falls within their area of special responsibility (The Ministry of the Solicitor General 1991, 6)." This is a relatively general stipulation for such substantial areas of responsibility.

The Ministry of the Solicitor General and the POC are two provincial actors that have their roles and responsibilities substantially described in the 1991 PEP. The 1991 PEP states that it is the Ministry of the Solicitor General's responsibility to monitor all emergency situations (The Ministry of the Solicitor General 1991, 11) . The POC, which was a part of Emergency Measures Ontario in the Ministry of the Solicitor General, monitors the status of all municipal emergencies reported to the Province, assisting in coordination between EM actors responding to the emergency as required. Should a municipality formally declare a state of emergency that continues to deteriorate, requires significant additional resources, or if the Province declare a state of emergency, the Solicitor General is required to coordinate the emergency response (The Ministry of the Solicitor General 1991, 13). Ministry Action Groups are created by ministries 
involved in the emergency to coordinate the provision of their expertise in support of the POC (The Ministry of the Solicitor General 1991, 22).

The lack of clarity regarding the roles and responsibilities of ministries became a major issue during the responses to the 1998 Ice Storm and 2003 SARS emergency. The PEP did not foresee the breadth and depth of the impact of the 1998 Ice Storm. The roles and responsibilities of ministries during such a widespread emergency were not clear, contributing to difficulties in the response. The 1998 Ice Storm AAR suggests that the roles and responsibilities of provincial ministries during an emergency should be sufficiently defined to include wide-spread events and that these responsibilities to address this lack of clarity (SAIC Canada 1998, 17). During the 2003 SARS emergency a lack of clarity surrounding the roles and responsibilities of the POC and the primary ministry action group operating under the Minister of Health and Long-term Care likewise contributed to difficulties in the response. The clarification of the responsibilities of the POC and primary action group during a provincial emergency is a major suggestion of the 2003 SARS AAR (J.A. Pirie \& Associates 2003, 23).

As with municipalities, The Emergency Management Act clarified and expanded the roles and responsibilities of ministries. In accordance with the Emergency Management Act the 2005 PERP states that certain ministries are designated the responsibility for specific types of emergencies under a 2005 Order in Council by the Lieutenant Governor, as in the case with the 1991 PEP (The Ministry of Community Safety and Correctional Services 2005, Annex A). However, these ministries are now considered to be "Full Program Ministries", and during an emergency that is assigned, the applicable ministry is expected to act as the primary response ministry. In such a case, all other ministries would be expected to act in a supporting role (The Ministry of Community Safety and Correctional Services 2005, 9). The Emergency Management 
Act and the 2005 PERP therefore clarified the roles and responsibilities of the POC and the primary ministry action group, as recommended in the 2003 SARS AAR (J.A. Pirie \& Associates 2003, 23).

Annex B of the 2005 PERP states the roles and responsibilities common to all ministries during an emergency and common to all municipalities (The Ministry of Community Safety and Correctional Services 2005, Annex B). Annex B of the 2005 PERP also states specific recommendations regarding emergency response responsibilities for each ministry (The Ministry of Community Safety and Correctional Services 2005, Annex B, Appendix 1-13). These responsibilities are much clearer than in the 1991 PEP, which stated that ministries assigned special responsibilities by the Order in Council were required to formulate emergency plans but did not specify which ministry would act as the lead in the response and did not contain annexes detailing the common responsibilities of ministries (The Ministry of the Solicitor General 1991, 29) . As with municipalities, ministries are also responsible for conducting hazard identification and risk assessments, implementing an incident management system, and engaging in yearly exercises to ensure readiness among other responsibilities.

Participants confirmed that the roles and responsibilities of Ministries in the EMCPA and 2008 PERP are observed in practice and were able to provide descriptions of the roles and responsibilities of federal departments in the province. Federal departments were described as playing a supporting role in EM in the province. Federal departments were described as providing emergency support functions, as detailed in the Federal Emergency Response Plan (FERP) (Public Safety Canada 2011, Annex A). Federal departments are assigned primary responsibility for particular aspects of emergencies in the FERP (Public Safety Canada 2011, Annex A). Federal support to emergencies within the province was discussed as being 
coordinated by Public Safety Canada's regional office, which notifies federal departments when there is an emergency relevant to their area of responsibility and coordinates the response the federal response one activated. Public Safety Canada's Government Operations Centre coordinates the response should Ontario be involved in the national response to an emergency.

Federal departments may be involved in EM outside of provincial requests for assistance as well. For instance, one participant described Environment Canada's role in setting the threshold for extreme heat incidents as playing an important part in their community's emergency preparation. Indigenous Services Canada and Health Canada were touched on by several participants as playing an integral role in EM in First Nations communities because many government services in these communities are an area of federal jurisdiction. The supporting role the federal government plays in EM in Ontario was described by participants as being fairly consistent over time.

The roles and responsibilities of provincial ministries as discussed by PERPs, AARs, and participants therefore seem to have expanded and clarified considerably over time with the adoption of the Emergency Management Act and Regulation 380/04 being a major influence on those developments. The responsibilities of federal departments as described by participants seem to have been more constant. The clearer roles and responsibilities of ministries contribute to a conceptualization of EM networks in the province of Ontario as having become more comprehensive over time.

\section{Non-Governmental Organizations and Private Industry}

Participants provided rich descriptions of the roles and responsibilities of NGOs in EM in the province that were not accessible through the analysis of PERPs and AARs. The responses given 
by participants mirrored that of Boin and ' $t$ Hart's observation that NGOs play a supporting role in EM, expanding on the capabilities of an EM networks by contributing their resources and expertise (Boin and 't Hart 2010, 363-364). NGOs were mainly seen as secondary disaster organizations in that they maintain EM as one part of their broader mission, in line with Robinson et al's study on non-profit organizations in disaster response (S. Robinson, Murphy, and Bies 2014, 78). Participants perceived NGO's in the province as supporting organizations that supplement the actions of governmental actors.

NGO's were described as taking on a range of roles and responsibilities during crises across the province, in many cases providing varieties of emergency social, medical, and physical services. One participant discussed members of Samaritan's Purse aiding in stripping down walls and pumping water out of homes following major floods. Another participant discussed the Canadian Red Cross' role in registering individuals during evacuations to emergency shelters. Other NGOs were described as providing services that enhance the emergency mitigation and preparedness of communities. For example, several participants discussed the services of St. John Ambulance as enhancing emergency preparedness both at the individual level by teaching individuals in communities how to respond to medical crises in their immediate environment, and at a community level by supplementing paramedics as medical first responders at community events. Several NGOs were discussed as being not-for-profit organizations who had no legislated responsibilities for EM in the province The Canadian Red Cross was described as being an accessory to government that has legislated responsibilities in the Red Cross Act of 1909, meaning that the organization has an obligation to act during a crisis or disaster (The Government of Canada 1909). 
The views of participants in regard to the roles and responsibilities of private industry in EM varied widely, mirroring the uncertainty regarding the role of private industry in EM expressed by the participants in Nirupama and Etkin's study (Nirupama and Etkin 2012, 602). Some participants expressed a lack of certainty regarding the proper role of private industry and how best to include private sector organizations in EM within communities. In other cases participants discussed close relationships and partnerships existing with private industry for EM in communities. Bruce Power was discussed by one participant as going above and beyond its legislated responsibilities to support local EM and be a good corporate citizen. Bell Canada was noted as aiding with the technical solutions to Ontario's newly developed public alerting program. Another participant discussed a partnership with local chemical industry to pay for specialized training for first responders in regard to chemical spills. The common perception held by participants that NGOs and private sector entities are best suited as supporting organizations in EM is in line with Pierre and Peter's statement that there are areas in which governmental actors are still perceived as the best option to have primary responsibility (Pierre and Peters $2000,5)$.

Many participants noted that communities develop varied relationships with NGOs and private industry in their jurisdiction for the purpose of EM. These different actors may be involved in EM on different scales as well. For instance, one participant described the Canadian Red Cross assisting in community evacuations as well as assisting smaller scale emergencies, such as finding accommodations for a family who had lost their home in a fire. The varying relationships that NGOs and private industry form and their fluctuating roles in communities made it difficult for participants to gauge the development of the roles and responsibilities of these actors on a provincial scale. 


\section{Developments in Information-Sharing and Communication}

The diversified roles and responsibilities of EM actors that exist as a result of the graduated response system contribute to information-sharing and communication being required between these actors in order for EM in the province to function effectively. The importance of information-sharing is noted as far back as the 1991 PEP, which states that "effective emergency response depends on receiving and sharing timely information (The Ministry of the Solicitor General 1991, 11).” The aggregation and sharing of information was expressed by participants as one of the most integral aspects of EM. The importance of the effective exchange of information between actors illustrates the importance of information-sharing within EM networks as discussed by Boin and t'Hart (Boin and 't Hart 2010, 366).

The ability to share information was expressed by participants as having developed substantially over time with the growth of the field itself, the development of formal structures and systems, and technological advancements. The continuous sharing of information between EM organizations was cited as a major reason for EM planning and programming developing to be more comprehensive and effective over time. However, while many participants believed that information-sharing and communication within the province had improved over time others pointed out major inconsistencies and gaps. Gaps in the ability to share or access information took a variety of forms. One participant discussed the confidentiality of certain emergency plans made them more difficult to share or access, another participant highlighted that academic studies are often inaccessible due to online paywalls, and another participant noted that their many substantial responsibilities made it difficult to commit time to building the networks necessary to facilitate information sharing. One participant summed this up this situation when stating "I think the information is there and available but not equally accessible (Participant 07 
2018, 5)." Sharing information in all aspects of EM was widely accepted to be difficult due to its continually evolving nature. The process of choosing what to share, when to share it, how to share it, and who to share it with was described by several participants as an ongoing challenge.

The effectiveness of information sharing during an emergency was described by several participants as being influenced by effectiveness of the established system and how it is implemented. One participant reflected "I've seen systems work extremely well because they're well understood and the means and content works well, conversely I've seen the other side of the coin where you can have emergency operations centre software precisely for information management and sharing but see it flounder because people don't have the upkeep in terms of how to understand the system and how to use it effectively (Participant 03 2018, 5)." The findings from the PERPs and AARs show the development of more effective provincial information-sharing systems over time. The sharing of information in the 1991 PEP is mainly discussed in the context of emergency response. The Solicitor General of Ontario is responsible for monitoring all emergency situations in the province (The Ministry of the Solicitor General $1991,11)$. The POC gathers and disseminates information to EM actors via the most expedient means possible (The Ministry of the Solicitor General 1991, 11) . During a municipal emergency a provincial liaison team may be dispatched to assist with the passage of information to the POC (The Ministry of the Solicitor General 1991, 13) . Information sharing outside of emergency situations is not deeply touched on by the 1991 PEP.

The provincial response to the 1998 Ice Storm led to the implementation of the PEP and the full activation of the POC for the first time since its inception (SAIC Canada 1998, Executive Summary). The Informal nature of information-sharing systems during this time meant that formal mechanisms were not in place to deal with the breadth and depth of the impact of the 
1998 Ice Storm. Apart from the statement that emergency information should be passed along as expediently as possible to the POC and that municipalities should establish an information centre during an emergency there were no formal standards or procedures for emergency communication between municipal and ministerial actors in the 1991 PEP (The Ministry of the Solicitor General 1991, 25). The capacity of the POC to communicate with the actors involved in the response to the emergency was overwhelmed. The POC's telephone system was overloaded during the crisis, requiring the installation of new lines to manage the load during the emergency (SAIC Canada 1998, 14).

The vulnerability of the provincial telecommunications network proved to be a major issue throughout the course of the 1998 Ice Storm. Ministry offices in the affected regions lost telephone service, cell phones did not function in areas where the cell net was down, and telephone communication with the Ontario Provincial Police also failed for a period (SAIC Canada 1998, 14). As discussed by Boin and 't Hart networks primarily fail when information is not communicated smoothly (Boin and 't Hart 2010, 366). Both the established system for information-sharing and the infrastructure to support that system were insufficient in light of the impact of the emergency. The importance of intercommunication between organizations during the emergency meant that the inability to effectively communicate had serious implications.

The 2005 PERP made far more extensive provisions regarding information-sharing and communication than the 1991 PEP. The 2005 PERP highlighted the importance of informationsharing amongst a multi-sector network of inter-dependent actors as opposed to focusing on information-sharing between the POC and the municipalities. The 2005 PERP states that "an effective emergency response by the Province of Ontario will depend on receiving and sharing timely information among many organizations including provincial ministries, communities, the 
federal government, and other supporting organizations and individuals (The Ministry of Community Safety and Correctional Services 2005, 48).” The importance attached by the 2005 PERP to the sharing of information among a multi-sector network of organizations indicates a greater recognition of the importance of more expansive, comprehensive networks in EM in the province. The 2005 PERP assigned responsibility for the creation and maintenance of a Provincial Emergency Information Plan to the Ministry of Community Safety and Correctional Services' Director of Communications and stated that every minister and municipality was required to designate an employee of the respective ministry/municipality as its emergency information officer, these provisions were maintained in the 2008 PERP (The Ministry of Community Safety and Correctional Services 2008, 51). Mandated requirements regarding appropriate technological and telecommunications systems in ministry emergency operations centres as well as descriptions regarding the specific functionalities ministries and municipalities should have in regard to information technology and telecommunications were also included (The Ministry of Community Safety and Correctional Services 2005, 48). These changes illustrate a movement toward systems that enhance information-sharing and communication in EM in the province.

Participants highlighted the PEOC and OFMEM's provincial system of liaison officers as two major structures for information-sharing for EM in the province. The PEOC was described as a centre point of interconnectivity for municipalities, ministries, and the federal government and was described as facilitating communication and information sharing in the province both during and outside of emergencies. The staff of the PEOC was highly regarded by participants. One participant noted "they do a tremendous job and we get daily updates from the PEOC so you know what kinds of emergencies are going on in the province at any given time (Participant 06 
2018, 10)." The PEOC's work in aggregating and distributing information was described by as becoming more effective and expansive over time by those participants who had engaged with it since the 1990s.

OFMEM's system of liaison officers was described as a direct link between the province and the municipalities. These officers directly engage in information-sharing with municipalities in order to ensure compliance with the EMCPA and to assist in EM planning and programming. The province was described by participants as separated into sectors, each of which a liaison officer is responsible for. Several participants described the sharing of information as being particularly good within these sectors of the province due to the communication between municipalities that OFMEM's liaison officers assist with. The development of this system was regarded as enhancing information-sharing throughout the province.

Views on the effectiveness of information-sharing facilitated by liaison officers varied. Several participants discussed liaison officers as being too overburdened with their work load to aid in the sharing of information between communities. Liaison officers were also discussed as lacking municipal experience or formal training in municipal affairs by multiple participants, which could lead to continual difficulties in information-sharing between CEMCs and their liaison officers. There have been shifts back and forth in this relationship over time but this was expressed by several participants as an ongoing issue since the implementation of the system.

The need for greater information-sharing and transparency on the part of the EMO during emergency preparation and response was noted by several organizations that participated to the response to the 2011 Northwestern Ontario Forest Fires. The 2011 Northwestern Ontario Forest Fires AAR acknowledges the importance of enhancing EMO's relationships with other EM organizations in the province and recommends engaging in methods to include these 
organization to a greater extent in its planning and programming in the future (The Ministry of Community Safety and Correctional Services 2012,17) . Issues relating to information-sharing on the part of OFMEM were expressed by several participants as being persistent. Municipal consultations were a particular area of contention. One participant noted "municipalities are asking for more, and what they're getting from the province is not what they're asking for. The province is putting information out to municipalities but it is perceived as frivolous information that is not contributing to the advancement of emergency management programs (Participant 11 2018, 3)." The cutbacks in EMO following its merger with the Office of the Fire Marshal in 2013 was discussed as reducing the capacity of the Office toward information sharing and communication, contributing to these issues.

Many participants noted OFMEM acknowledged in 2017 that there have been substantial deficiencies in communication and information-sharing on the part of the Office in the past and since there has been an increase information sessions, newsletters, and meetings by OFMEM with its partners and stakeholders. OFMEM held a conference focused on climate change in the fall of 2017 that participants highlighted as a particularly positive event. One participant remarked "I think there's a big push on information-sharing from the province to municipalities and being more transparent, which is really nice to see because prior to that it was sort of, twice a year communities met with field officers and get updates on what's happening. It wasn't always accurate, it wasn't always a holistic review of what was going on (Participant 07 2018, 6).” Developments like these were commented on by several participants as a beneficial step toward more open, transparent operations by OFMEM.

Some participants found that information sharing between the emergency managers themselves as having developed over time to be very strong in the province, one participant 
remarked "I've had numerous times when I've called on people and said "Would you have any information on this or that?" And I've never encountered any hesitation. Same with me, any time anyone asks me about the field or something there's no hesitation (Participant 04 2018, 5).” The participant also noted "it's grown tremendously, not because people didn't want to collaborate at first but you didn't know who has what and where to turn (Participant 04 2018, 5).” Information sharing between emergency managers was perceived as having grown over time as the field itself has grown.

Information-sharing and communication on the part of NGO's was described by several participants as having been consistently effective. One participant noted "information-sharing and collaboration between municipalities and municipalities and NGOs is always good and has always been good (Participant 11 2018, 9)." Communication with NGOs was noted as vital in the 1998 Ice Storm AAR, which states explicitly that inter-agency communication during an emergency should not be limited to government contacts (SAIC Canada 1998, 9). NGOs continually communicate and coordinate with all levels of government. The recent formation of the NGO Alliance was pointed out by participants as enhancing the communication between NGOs and between NGOs and governmental entities in recent years. The NGO Alliance was discussed by participants as being a loose coalition of many prominent NGOs involved in aspects of EM, which is chaired by Samaritan's Purse. Drawing from a system established in Alberta, the organization was discussed as providing a central mechanism for emergency managers to access information regarding which NGOs to contact for different emergency services. This development was discussed by several participants as being beneficial for information-sharing in the province. 
The views of participants support Brooks et al.'s observation that technological advancements have had a major effect on the field (Brooks, Bodeau, and Fedorowicz 2013, 923). The means through which organizations share information was described by participants as having vastly and rapidly developed since the 1990s. One participant summed this up when stating "the need has been constant but the means have evolved by leaps and bounds (Participant 17 2018, 7)." Another participant described the shift toward the use of word processors allowing for the efficient sharing and editing of emergency plans, to the widespread use of the internet providing emergency managers with a vast range of tools for engagement with other actors, to the development of technology capable of sending secure, streaming video of an incident site directly to an emergency operations centre. Another participant remarked "we used to rely almost totally on air raid sirens, word of mouth, or radio to get messages out. Now we can tap into phones and send alerts out over the phone to individuals (Participant 06 2018, 2).” The development of graphic information systems was also expressed as a major development in the sharing of information. These systems allow for the use of maps that link directly to databases containing pertinent information to specific hazards. Technological advancements have vastly improved the means through which EM actors and stakeholders can communicate over time.

Participants noted several prominent gaps in the development of information-sharing in the province. Several participants expressed that information-sharing on the part of provincial ministries could be highly siloed. One participant noted "everyone was fairly siloed in times of peace, in non-emergency times. The Ministry of the Environment would be handling environment things, the Ministry of Natural Resources would be handling natural resources things. There wasn't a great deal of cross pollination (Participant 11 2018, 4)." An inability to properly communicate between provincial ministries outside of emergencies was highlighted to 
be a result of their many priorities, which was noted as making it difficult to engage in shared initiatives in EM outside of emergency response. Policies surrounding data protection by different governmental actors and organizations was also seen by some as a major issue during the response to emergencies and the obstructions that resulted from that protection was expressed to be a limitation that needs to be continually examined.

Participants described information-sharing as particularly difficult for smaller and more geographically isolated communities. CEMCs in these communities may have fewer opportunities to share information due to their many priorities, at times restricted budgets, and geographic isolation of their communities. Information-sharing may also be a challenge in these communities during an emergency if they lack the personnel to effectively aggregate and disseminate information during an extended emergency situation. Several participants raised major concerns regarding communication and the sharing of information with First Nations communities in Northern Ontario. One participant stated "they've just been left out of the conversation so they don't know who to approach during an emergency (Participant 22 2018, 2)." These communities were described by participants as some of the most isolated and vulnerable in the province.

The lack of a centralized database for emergency managers in the province to share exercise designs, emergency plans, and other pertinent documents in was highlighted by several participants, one of whom commented "we have to do things like go to conferences, go to training, that type of thing to share information. There isn't an efficient mechanism for sharing information, it's more ad hoc (Participant 05 2018, 8)." A centralized, secure software system that would indicate the status of communities in the province was described by some participants as another major area for development. 
The development of more comprehensive information-sharing systems can therefore be seen through the analysis of PERPs and AARs. Participants also generally expressed the view that information-sharing and communication within the province had improved over time. When considered together, these findings indicate that EM networks in the province have become more comprehensive over time. However, ineffective or restrictive structures and procedures, isolation, a lack of resources, and a lack of centralized emergency information-sharing systems were described as restricting the development of information-sharing and communication between EM organizations, leading to gaps in the development of more comprehensive EM networks in the province.

\section{Developments in Coordination, Collaboration and Partnerships}

Participants expressed that emergency management at all levels is not a practice that is done in isolation. One participant described EM in Ontario as such "we're not like a civil defense construct where you have a commander directing different organizations. It is a system based on collaboration (Participant 20 2018, 4)." Another participant explained "you can't do it by yourself. It's all about partnerships, engaging stakeholders, and working together (Participant 16 2018, 1)." The importance of networks in facilitating coordination and collaboration discussed by Waugh and Streib as well as Robinson et al. was supported by participants (Waugh and Streib 2006, 134) (Robinson, Murphy, and Bies 2014, 81). Participants discussed EM organizations partnering with a wide range of organizations for EM planning and programming to enhance the capacity of the community. One participant stated: "Our perspective is that when all of our industries, agencies, and partners are prepared for an emergency that makes us a more resilient community (Participant 07 2018, 8).” EM was described by many participants as having gone 
from a field that was viewed as one that could be managed by first responders to one that requires coordination and collaboration between organizations involved in critical infrastructure, healthcare, social services, conservation and a range of other areas within the last twenty-five to thirty years.

The 1991 PEP noted that coordination in emergency response is necessary between levels of government and becomes increasingly important as multiple levels of government become involved in the response to an emergency. It stipulates that close liaison must be maintained during these instances and recommends the establishment of a joint headquarters during to coordinate decision-making (The Ministry of the Solicitor General 1991, 6). The need for horizontal collaboration between levels of government highlights the need for comprehensive networks as discussed by Kapucu and Garayev (Kapucu and Garayev 2016, 932).

In the 1991 PEP the POC acts as the central coordinator of the network of actors involved in an emergency once activated (The Ministry of the Solicitor General 1991, 13). The POC acts to focal point for the provincial response and is supported by other ministry action groups as required (The Ministry of the Solicitor General 1991, 22). The 1991 PEP demonstrates that a range of actors must coordinate, collaborate, and share resources and expertise in the response to an emergency as it escalates. It is clear that governmental departments and agencies act as key coordinating actors in the system of relationships that form the network (Pierre and Peters 2000, $36)$.

The need for coordination and collaboration can be seen in the provincial response to the 1998 Ice Storm, which was carried out by a network of government organizations centrally coordinated by the POC (SAIC Canada 1998, 8). Coordination between municipalities, ministries, professional associations, NGOs, and private industry was vital during the response. 
An example of this can be seen in the Ministry of Agriculture, Food and Rural Affairs, which coordinated with major farm organizations such as the Ontario Federation of Agriculture and Food and the Dairy Farmers of Ontario throughout the emergency (SAIC Canada 1998, 8). Coordinating the provincial response to the 1998 Ice Storm greatly strained the capacity of the POC, in part because this response marked the first full activation of the POC for the since its inception (SAIC Canada 1998, 5). The storm affected approximately eleven per cent of Ontario's population and its impacts exceeded the response capacity of many communities, leading to 65 municipalities and one First Nation community declaring a state of emergency (SAIC Canada 1998, Executive Summary).

One way in which the POC managed this strain was through the implementation of a twinning program that connected 18 municipalities outside of affected areas with 37 communities within the affected area. These municipalities directly provided aid to affected communities, thereby reducing the strain on the capacity of the POC (SAIC Canada 1998, 11). The capacity of the POC becoming overwhelmed, and its implementation of the twinning system that followed, shows the use of improvised systems to address contingencies as they emerge in an ad hoc fashion during emergency response as discussed by Brooks et al. and also shows the flexibility that Boin and ' $t$ Hart argue as necessary during the response to crises (Brooks, Bodeau, and Fedorowicz 2013, 935; Boin and Hart 2010, 362).

The lack of clarity surrounding the roles and responsibilities of provincial ministries during wide-spread events significantly limited coordination and collaboration between municipalities and ministries. The 1998 Ice Storm AAR states that "the municipal understanding of the responsibilities of the province is generally limited to two points: the province provides advice and assistance, and Department of National Defence services should be requested through 
the province. This is insufficient information to plan for provincial/municipal coordination and cooperation (SAIC Canada 1998, 17)." The AAR therefore found that the unclear roles and responsibilities of ministries limited their ability to successfully coordinate and collaborate with municipalities during the emergency.

Another major vulnerability that became apparent during the 1998 Ice Storm was the lack of coordination on the part of Ontario Hydro and local utilities companies with the province and communities in regard to the preparation and response to the emergency. This lack of coordination posed a major issue as the number of retail customers who were without electricity ranged from 230.000 to over 600,000 , with some power outages lasting up to 20 days (SAIC Canada 1998, 5). These issues illustrated that coordination and collaboration between EM organizations, while facilitated to the best of the abilities of central actors, suffered from a lack of clarity regarding roles and responsibilities and a lack of coordination in the preparation for the emergency.

The 2003 SARS Emergency AAR portrays collaboration and coordination between the representatives of the Ministry of Health and Long-Term Care and EMO initially functioning poorly during the provincial response to the emergency. A Provincial Declaration of Emergency was signed by the Premier of Ontario for the first time in the Province's history on March 26, 2003 as a response to the SARS emergency (J.A. Pirie \& Associates 2003, i). The declaration designated the Minister of Health and Long-Term Care as the executive authority in the response to the emergency, conveying to the Minister the emergency powers available to the Premier under the Emergency Plans Act (J.A. Pirie \& Associates 2003, 2). However, a system was not established in the PEP to coordinate the response of the designated Minister's primary action group and the POC, which contributed to difficulties in collaboration between the two groups 
(J.A. Pirie \& Associates 2003, 13). The SARS AAR indicates that the lack of established procedures to coordinate the actions of the POC and primary action group contributed to confusion over leadership and a breakdown in decision-making, which was made more difficult by the ad hoc structures and procedures that needed to be developed on a daily basis to react to the shifting nature of the emergency (J.A. Pirie \& Associates 2003, 14; J.A. Pirie \& Associates 2003, 21). Difficulty in coordination as a result of contingencies unforeseen in planning, as discussed by Brooks et al. can therefore be seen in the response to the 2003 SARS emergency (Brooks, Bodeau, and Fedorowicz 2013, 919). As discussed by Brooks et al. methods of organization and coordination can be engrained in the individuals working within institutions (Brooks, Bodeau, and Fedorowicz 2013, 929). The difficulty that the POC and the Ministry of Health and Long-Term Care experienced in harmonizing their procedures so as to avoid interference from one another in the course of their duties illustrates the difficulties that can arise in emergency response if standardized systems are not put in place to facilitate coordination.

The adoption of the Emergency Management Act was described by several participants as beneficial to coordination and collaboration in EM in the province because it clarified that during any emergency specific to a ministry's area of responsibility that ministry's provincial operations centre will coordinate the response. For instance, Ministry of Health and Long Term Care's provincial operations center is currently operational and is in enhanced monitoring and coordinating resources in regard to the opioid crisis. EM in the 2005 and 2008 PERPs is depicted as a system that, as in the $1991 \mathrm{PEP}$, requires partnerships, coordination, collaboration, and resource-sharing to function effectively due to the nature of the graduated response system and the varying responsibilities of EM actors (The Ministry of Community Safety and Correctional Services 2005, 3). However, whereas the PEOC still acts as a central coordinator during a 
provincial response, in addition to that role EMO also acts as an authority to ensure the programs of ministries and municipalities are in line with the regulations and guidelines that flow from the Emergency Management Act (The Ministry of Community Safety and Correctional Services 2005, 21). The Chief of EMO develops and delivers the provincial emergency management training program and provides advice and assistance to ministers and municipalities for the development of their emergency management training programs (The Ministry of Community Safety and Correctional Services 2005, 13). EMO acts as a central coordinator in the planning and programming of municipalities and ministries outside of emergencies, indicating an expansion in systems for coordination in the province.

The work of the PEOC in coordinating this wide range of EM organizations with many interwoven priorities was praised highly by participants. One participant recounted the PEOC holding teleconferences twice daily with up to twenty different communities involved during the response to the 2011 Northern Ontario Forest Fires. They stated "there's a lot of people there, there's a lot of ego, and a lot of my problem is more important than your problem mentality and they do a very good job at mitigating that and ensuring that actual work is getting done (Participant 06 2018, 10).” The response to the 2011 Northwestern Ontario Forest Fires marked the first instance of EMO inviting a NGO representative to the PEOC, which is evidence of greater collaboration between governmental and NGO (The Ministry of Community Safety and Correctional Services 2012, 26) .

However, difficulties relating to coordination during the response to the 2011 Northern Ontario Forest Fires were also experienced. The 2008 PERP lacked specific direction on the conduct of evacuation and repatriation operations, which meant that the staff of the PEOC and the Ministry of Natural Resources were required to design and develop evacuation and 
repatriation plans as the operation was taking place (The Ministry of Community Safety and Correctional Services 2012, 8). An Ontario Mass Evacuation Plan for the far north was created following the 2011 Northwestern Ontario Forest that has enhanced coordination and collaboration in subsequent evacuations. Participants also noted that the coordination provided by the PEOC has developed to become more consistent and sophisticated over the years, enhancing coordination at a provincial scale during the response to emergencies.

Many participants discussed coordination and collaboration between EM organizations as also improving over time at the community level. One of the main reasons for collaboration in EM is the different skills and expertise different groups bring to all aspects of EM. One participant noted "we may not always have the strongest plan but we have those strong working relationships and we have understandings with different community partners regarding what they can do and what their responsibilities are (Participant 07 2018, 9).” Another participant stated that "a big part of the education piece, and the training piece, and the partnerships is really coming to grips and understanding that this is what we do, this is what you do, and together we can just overall enhance the emergency management response (Participant 19 2018, 3).” The importance of partnerships and relationships expressed by participants supports the importance of enhancing community capacity for through collaborative activities discussed by O'Sullivan et al. (O'Sullivan et al. 2013, 245). Many participants expressed that a great deal of their effort was put toward fostering coordination and collaboration to improve emergency preparedness and response.

The development of collaboration between EM and other fields was touched on by a number of participants. Many participants described greater collaboration with fields such as critical infrastructure and social services over time. Collaboration between the healthcare and 
EM fields are a particular area that was touched on as having become more comprehensive. One participant remarked "we've developed a closer relationship with the health field because they realise that it's not just about proper vaccination and curing disease, there's a lot of public education, there's a lot of coordination, there's a lot of support, there's a lot of resources that come from other levels of government and municipal government and public health can't do it all (Participant 04 2018, 4).” A wider awareness of the need for coordination and collaboration between these fields in addressing shared issues was commented on by a number of participants.

Partnerships with NGOs were widely regarded as an integral part of EM in the province. One participant remarked on the expansion of their community's partnerships with NGOs "the whole volunteer and NGO aspect has grown tremendously over the last couple of years to become a lot more efficient and provide us with much more services than they used to (Participant 04 2018, 6)." The closer partnership between these organizations can be seen at the provincial level as well. While before the a representative from an NGO may have been invited into the PEOC, it was described by one participant as now a de facto practice to have a member of the NGO Alliance attend during major emergencies. The consistent practice of including an NGO representative in the PEOC is a significant development and supports Klijn's theory that partnerships with actors and stakeholders outside of government are being increasingly experimented with by modern governments (Klijn 2008, 506).

While collaboration at the local level was widely expressed as good by participants organizing a provincial-wide collaborative response was discussed as being difficult due to the decentralized nature of EM in the province. One participant discussed the lack of collaboration and inability to use a unified approach in the response to the opioid epidemic in Ontario as being in part because of the widespread and severe impact of the epidemic. It was noted that the 
breadth and depth of the epidemic has meant that EM organizations have in many cases been locked in a reactionary mode wherein they are attempting to control the deaths caused by the overdoses and are unable collaborate to take preventative measures to combat the overdoses themselves. The findings from PERPs, AARs, and interviews with participants therefore contribute to a view of coordination, collaboration, and partnerships between EM organizations as having developed substantially over time, contributing to more comprehensive EM networks in the province. However, participants noted that collaboration on a provincial scale can be difficult due to the decentralized nature of the graduated response system.

\section{Trust and Confidence between Emergency Management Organizations}

Central to the study of networks is the idea that organizations must work together to achieve their shared goals and interests (Kapucu and Garayev 2016, 932). The mutual collaboration required by actors in a network requires a basis of mutual trust and confidence, as discussed by Junki (Junki 2006, 22). Trust between EM organizations was widely expressed as being vital to the building of relationships and the effective management of emergencies by participants. The responses of participants support Berardo and Scholz's observation that resolution of shared issues builds trust between actors over time (Berardo and Scholz 2010, 645). Several participants highlighted the need to understand the capabilities of the groups they engage with, and noted that this understanding is built through the resolution of shared issues, collaborative projects, and exercises One participant noted "it builds confidence when we have training and exercises for emergencies (Participant 12 2018, 1)." Another participant stated "one thing we can take away with training with any agency is you learn so much about how they work and it's better to learn from training then when your responding to an actual emergency (Participant 06 
2018, 4)." The responses of participants support Perry's findings that shared exercises can build confidence between EM organizations (Perry 2004, 73). Some participants described situations in which trust was lost following responses that were not carried out to the standards that were expected. These could at times cause relationships to regress. Trust and confidence were expressed as vital regardless of the organization in question.

EM professionals were noted to often hold positions on a range of organizations. For instance, an EM professional may also volunteer with their local fire department or with a notfor-profit or faith-based group in their community. Some CEMCs hold responsibilities in other municipal departments. These common connections were discussed by some as contributing to the building of trust between EM organizations. An important aspect of trust between organizations perhaps more unique to EM was that expressed in regard to NGOs. Several participants expressed a trust and confidence in NGOs in part because they recognized these groups have an internal mandate to protect communities not based on legislated responsibilities but humanitarian imperatives. The common goal of helping save lives and protect communities was expressed by several participants as a major unifying force in the field.

Many participants expressed difficulty in commenting on the potential development of trust and confidence between EM actors in Ontario. The majority of participants expressed trust in the organizations and stakeholders they engage with. However, participants generally noted that it is difficult to comment on trust between organizations on a provincial scale due to the variability that exists in the relationships that different organizations hold. Trust was also commented on by many participants as a characteristic that is difficult to track over time due to many confounding variables. The development of trust and confidence was also not readily accessible through the analysis of PERPs and AARs due to the informal nature of the concept. 


\section{CHAPTER FIVE - THE FORMALIZATION OF EMERGENCY MANAGEMENT NETWORKS IN ONTARIO}

This chapter discusses the development of characteristics associated with formal and informal networks in Ontario between 1991 and 2018. The findings from the analysis of the PERPs and AARs as they relate to the formalization of EM networks in Ontario are presented in sequential order, followed by the findings from the interviews with participants. As discussed in the literature review, networks experience varying levels of formality. The arrangements that form formal networks are structured by prescriptive agreements or legislation, while informal networks are more emergent (Kapucu and Garayev 2016, 939). The analysis of the PERPs, AARs, and responses of participants show a formalization of the structural arrangements between EM organizations in the province. The once more ad hoc collaboration of EM organizations is increasingly pre-defined in plans and agreements. These agreements help formalize expectations between organizations. One participant remarked "I think we're looking at people wanting to see arrangements that are more written down and outlined with stronger terms (Participant 07 2018, 3).” An increase in formal agreements and arrangements was expressed by participants to be occurring between a range of EM organizations.

The analysis of the 1991 PEP presents a view of EM networks in Ontario that is highly informal due to the lack of common standards and procedures for actors, the lack of formally prescribed standards or procedures outside of the Ministry of the Solicitor General of Ontario, and the absence of sections of the 1991 PEP from the final copy. The 1991 PEP outlines scripted procedures for the POC and Office of the Solicitor General of Ontario during an emergency (The Ministry of the Solicitor General 1991, 31). However, other ministries and the municipalities are given a large amount of discretion regarding their activities. There is little in the 1991 PEP or the 
Emergency Plans Act that describes what municipal EM plans should entail or how they should be implemented. The Emergency Plans Act allowed municipalities to make emergency planning by-laws and allowed heads of council to declare and terminate a municipal emergency but did little to expand on those provisions, leaving EM planning and programming largely at the discretion of the municipalities (The Ministry of the Solicitor General 1991, 31). The lack of direction in the Emergency Plans Act points to the provincial EM system being highly informal in 1991.

Likewise, while special responsibility areas are assigned to eight ministries in the 1991 PEP there are few common standards or procedures outlined regarding what planning for these special areas of responsibility should entail. The 1991 PEP outlines only four general provisions for ministerial emergency plans, the interpretation of which is left to the ministries assigned special responsibilities (The Ministry of the Solicitor General 1991, 6-7). For instance, the Ministry of Energy is assigned special responsibility for "Energy Supply Matters" in the 1991 PEP (The Ministry of the Solicitor General 1991, 32). The standards and procedures for planning and programming in this area were left to the discretion of the Ministry itself, presenting a view of ministerial planning and programming that is decentralized in nature. The lack of commonly held standards and procedures in regard to the EM planning of ministries is characteristic of more informal networks (Kapucu and Garayev 2016, 939).

Several sections of the final copy of the 1991 PEP were also not developed at its time of release. Chapter six, which outlines telecommunication arrangements, chapter eight, which outlines federal assistance arrangements, and annexes E-L, which outline the responsibilities of various ministries are missing from the final copy of the 1991 PEP (The Ministry of the Solicitor General 1991, iv-v) . These sections being undeveloped in the final copy of the 1991 PEP points 
to a potential lack of clarity as to the procedures through which provincial emergency managers were supposed to communicate, how federal assistance was to be coordinated in the case of an emergency, and the specific responsibilities each ministry was to have in the event of an emergency.

Many of the issues that are highlighted by the 1998 Ice Storm and 2003 SARS Emergency AARs arise out of the informal nature of EM networks in the province during the time. Several of the most prominent recommendations made by these reports advocate the expansion of standardized systems and procedures. A primary recommendation of the 1998 Ice Storm AAR is the creation a common hazard and risk assessment, which would act as a uniform assessment for risk analysis, emergency response, and inter-agency coordination across the province (SAIC Canada 1998, 17). The creation and implementation of the municipal twinning program by the POC during the 1998 Ice Storm is an example of the emergent use of systems to address needs on an ad hoc basis, characteristic of informal networks (SAIC Canada 1998, 11). As discussed in chapter four, the POC implemented the municipal twinning system during the 1998 Ice Storm to help reduce the strain on the POC's overloaded capacity by having municipalities coordinate aid between one another. The twinning system was formally adopted and promoted in the 2005 PERP, which shows the incorporation of emergent systems formally over time, contributing to the view of an increasingly formal EM system in the province (The Ministry of Community Safety and Correctional Services 2005, 41).

A drive to formalize the structural arrangements between EM organizations in the province in 2003 SARS Emergency AAR is clear in the follow excerpt "the effective management of an emergency is too critical to public safety and security to be left to vague legislation and plans, coupled to response leadership grounded only on generalized 
management/executive experience, intuition and gut instinct (J.A. Pirie \& Associates 2003, 12).” The informal nature of EM in Ontario during the 2003 SARS Emergency and the emergent nature of standards and procedures of EM organizations that resulted from this informality are argued by the 2003 SARS Emergency AAR as being to the detriment of EM in the province (J.A. Pirie \& Associates 2003, 23). The drive for the use of more standardized systems and procedures in these AARs is characteristic of more formal networks as discussed by Kapucu and Garayev (Kapucu and Garayev 2016, 939).

The inclusion of a Provincial Hazard Identification and Risk Assessment (HIRA) in the 2005 PERP, created in line with the recommendations from the 1998 ice storm AAR, and the mandated requirement that every municipality and every minister of the Crown or other branch of government conduct a hazard identification and risk assessment on facilities or other infrastructure they are responsible for shows a further expansion of standardized systems across the network of actors in EM in Ontario (The Ministry of Community Safety and Correctional Services 2005, 16). The 2005 PERP also introduced a provincial Incident Management System (IMS) to ensure consistent, standardized responses to emergencies in the province, which is described as follows "emergency response in Ontario, irrespective of cause, size, location, complexity or duration, will be coordinated in accordance with the provincial Incident Management System (The Ministry of Community Safety and Correctional Services 2005, 26).” The provincial IMS prescribed a standardized framework for incident management in the province. The 2005 PERP also actively encouraged the establishment of arrangements with between EM organizations in order to effectively prepare for potential emergencies, indicating a push at the provincial level to adopt standardized systems and formalize the structural 
arrangements between EM organizations (The Ministry of Community Safety and Correctional Services 2005, 41).

The 2011 Northwestern Ontario Forest Fires AAR and 2015 James Bay Flood Evacuation AAR both make recommendations for the adoption upon standards and procedures to address issues identified during and following the respective emergencies. In light of the insufficient number of host communities identified prior to the 2011 Northwestern Forest Fires the AAR recommends the creation of an official roster of host communities that would engage in biannual rotations to ensure that host communities are continually available. Preparations for hosting evacuees would be part of the participating communities' annual emergency exercises and the host communities would maintain a roster of trained volunteers (The Ministry of Community Safety and Correctional Services 2012, 16). To ensure availability of accommodations for evacuees should the number of individuals exceed 5000 the 2015 James Bay Flood Evacuation AAR recommends an ongoing solicitation process be created to ensure availability of accommodations in the case of an evacuation (The Office of the Fire Marshal and Emergency Management 2015, 13). The continued development of standardized processes to identify and ensure the readiness of host communities for evacuations in the province shows a continued formalization of the structural arrangements between EM actors.

The 2015 James Bay Flood Evacuation AAR also makes reference to the Joint Emergency Management Steering Committee Standards (JEMS), which were also touched on briefly in the 2011 Northwestern Ontario Forest Fires AAR. The JEMS are a set of standards for hosting First Nations community members in the event of an evacuation. The JEMS provide guidance on allowable expenditures, hosting arrangements, feeding and personal services, health services, family reunification, among other things. These standards, developed in 2009, were 
found to be not consistently applied nor completely understood by all stakeholders (The Ministry of Community Safety and Correctional Services 2012, 31). The 2015 James Bay Flood Evacuation AAR recommends that the JEMS committee be re-convened to ensure the JEMS document is updated, understood, and fairly applied by all parties (The Office of the Fire Marshal and Emergency Management 2015, 10). The JEMS were touched on by several participants as a major success in improving collaboration between EM organizations in the province. One participant noted: "I think it was one of the better examples of how the relationships, partnerships between the three levels of government and NGOs came together to do work - I think that's because there was a clearly defined goal in mind. That being the safe, efficient, and effective evacuation of people from the James Bay coast (Participant 11 2018, 4). The continual development of these standards shows a further formalization of the structural arrangements between EM organizations in the Province.

Participants provided rich descriptions in regard to the development of agreements, standards, and procedures between EM organizations. The adoption of the Z-1600 in 2008 as a national standard for emergency management and business continuity in Canada was noted by one participant as being a major development in EM in Ontario that contributed to EM becoming a more widely recognized profession. The adoption of the Z-1600 was a major step towards the harmonization of the standards for EM programs both within the province and nationally.

Memorandums of understanding (MOUs) were described by participants as the most common form of formal agreement between EM organizations. These agreements set out, in differing levels of comprehensiveness, the conditions surrounding the provision of services between EM organizations during certain emergencies. They set out mechanisms for financial compensation, insurance, sleeping and travel arrangements for personnel, and other 
arrangements that provide structure to the provision of assistance during an emergency. Several participants discussed an increase in the use of MOUs between local organizations within communities. For instance, between local departments, local industries, and local NGO's for aid during the response to particular emergencies. MOUs between municipalities, regions, and districts were also described by several participants as increasing in prominence over time. MOUs were also discussed by participants as becoming more common between NGOs and municipalities. When discussing the increased use of MOUs by municipalities one participant stated: "They want to have those memorandums of understanding for the NGOs as they move forward, which I found was extremely different than when I first got into this - I think it's to delineate what each NGO can provide, when they can provide it, and for how long (Participant 09 2018, 6). Several participants perceived the movement toward a greater use of MOUs as not being driven by municipalities or NGOs specifically but instead by a mutual desire to have clearer, more consistent systems in place for emergency response.

Formal agreements between municipalities and ministries were also discussed as having developed over time. Formal agreements exist between provincial ministries and municipalities on a range of areas related to EM. For instance, some municipalities may maintain agreements with the Ministry of Natural Resources for the use of water bombers in response to nearby forest fires. The Ministry of Transportation maintains agreements with municipalities near major highways to respond to emergencies outside of their communities. Participants expressed that a primary reason that these agreements have developed over time was to provide clear structures for the recoup of costs. Developments in agreements between provinces were also discussed as taking place. One participant discussed the Provincial/Territorial Memorandum of Understanding for Emergency Management Assistance having been agreed upon between the provinces and 
territories in 2011, which Ontario activated during the 2017 Southern Ontario flooding. This MOU allowed emergency management personnel from Manitoba and Saskatchewan to assist in the PEOC throughout the response. Formal agreements between the federal and provincial governments in regard to EM have also been developing. One participant discussed Public Safety Canada's preparations to begin creating annex to the National Emergency Response System that would outline standard operation procedures between the federal and provincial governments in regard to emergency response. The participant expressed optimism that this annex would help clarify the operating procedures between the two levels of government.

One of the most touched-on developments in formal agreements between NGOs in Ontario has been the creation of the NGO Alliance. Several not-for-profit organizations and faith-based groups in Ontario were described by participants as engaging in a recent agreement to coordinate under a single banner to enhance their collaboration, eliminate redundancies, and fine tune their emergency response. Participants viewed the ability liaise with one coordinated group of NGO's as opposed to several separate organizations as beneficial. One participant remarked "it's nice to be working closely with them and again there is terrific support. They developed a tool where they list and identify the different services each of them provide so they are not duplicating (Participant 10 2018, 9)." The NGO Alliance was described as working closely with provincial ministries and municipalities since its inception.

Formal agreements and arrangements between commercial suppliers and municipalities and ministries were also expressed as a vital area of EM that has developed substantially. One participant stated "to have those arrangements in place beforehand helps facilitates the process. There is a vendor on record, you can go right to them, you can authorize the deployment, you don't have to go through a procurement process (Participant 20 2018, 6)." Several participants 
also commented on an increase business continuity agreements with private industry. One participant noted "I don't think that you can convince many private industries to do emergency management because it's hard to show them the cost-benefit, but if you want to save money then business continuity is the answer (Participant 07 2018, 2)." Other participants believed that private industry has been more hesitant to engage in agreements regarding EM that were not related to the realm of business continuity due to it being outside of their imperatives. The analysis of PERPs, AARs, and interviews with participants therefore widely supported a view of the structural arrangements between EM organizations becoming increasingly formalized in the province as evidenced by an expansion in prescriptive legislation and documents, an increase in commonly held standards and procedures, and an increase in agreements and MOUs. As the structural arrangements that comprise networks are goal-oriented social constructions created through the shared understanding of individuals the continued formalization of these arrangements can be understood to be the result of these actors perceiving that this formalization will contribute to them achieving their goals in regards to EM. 


\section{CHAPTER SIX - INFLUENCES ON THE DEVELOPMENT OF EMERGENCY MANAGEMENT NETWORKS IN ONTARIO}

This chapter discusses the major influences on network development in EM in Ontario apparent following the analysis of data collected from participants, PERPs, and AARs. As discussed by Kapucu and Garayev, networks are influenced a range of continually fluctuating factors (Kapucu and Garayev 2016, 934). Participants discussed a range of factors that they believe have influenced the development of characteristics related to EM networks over time. Influences on network development were supported to varying extents by the PERPs and AARs analyzed in this thesis. Once aggregated, these influences fit into several major categories: the expansion of the risk environment, the increased occurrence and severity of natural disasters, the growth in the size and comprehensiveness of the field itself, changes to legislation, public perceptions and needs, and the scarcity of resources and expertise. The factors of influence are both interwoven, and yet also distinct in their effects on the development of EM networks.

\section{The Expanding Risk Environment}

The expansion of Ontario's risk environment was noted as influencing the development of more comprehensive and formal EM networks. Participants noted the development and acknowledgement of new hazards and risks within the province over time and the adaptation and expansion of EM structures to address those developments. The acknowledgement of new risks and vulnerabilities was described as requiring greater communication, coordination, and collaboration with different sectors not traditionally associated with the field.

Participants discussed emergencies in the 1990s as being a realm that was thought of as capable of being addressed by the skill sets of individuals with military, fire, or police 
backgrounds. However, as new forms of crises occurred locally and abroad the need for new skill sets became increasingly necessary to address emergencies. The 1998 Ice Storm and 2003 Blackout were discussed by participants as indicating a need for more comprehensive planning from the perspective of critical infrastructure. The 9/11 terrorist attacks and 2005 London subway bombings were referred to as expanding the concept of risk resulting from terrorism . The SARS emergency in 2003 and H1N1 emergency in 2009 were commented on as raising the profile of epidemics that require close relationships and planning from the perspective of public health. More recently, the heightened awareness of crises resulting from suicides in First Nations communities in Ontario and the opioid epidemic have highlighted the social and mental health aspects of emergencies. Lastly, cyber security was mentioned as becoming an increasing priority with the growing societal dependence on technology and advent of attacks such as ransomware. The 2016 Syrian refugee resettlement and 2017 asylum seekers emergency were also brought up as unforeseen in provincial planning from an emergency social services perspective. Not only are new forms of emergencies becoming apparent, participants noted that established types of emergencies are constantly increasing in complexity.

Many participants referenced the identification of new forms of risks and hazards as directly contributing to the relationships, partnerships, and agreements between EM organizations in the province. As awareness of new forms of risks have become apparent EM networks have broadened to encompass a wider range of organizations and the linkages between EM organizations have formalized to allow for consistency in the management of these emergencies. The continual development and identification of new risks supports Kilgin's observation that the issues faced by modern governments are increasingly complex and multifaceted (Klijn 2008, 506). The increased expansiveness and complexity of EM in Ontario also 
supports Henstra's view that modern EM is becoming increasingly all-encompassing and Boin and ' $t$ Hart's observation that different sectors of society may be becoming increasingly interconnected (Henstra 2011, 419; Boin and 't Hart 2010, 358).

Findings from interviews and the correlating support from the literature are supported by the analysis of the AARs. Emergencies with unforeseen or unprepared for impacts have consistently led to the development of more comprehensive and formalized structural arrangements between EM organizations. For instance, the lack of coordination on the part of Ontario Hydro and utilities with the province and communities is a major observation of the 1998 Ice Storm (SAIC Canada 1998, 13). Several participants noted that following the 1998 Ice Storm hydro-electric and other utilities companies have worked much more closely with communities and provincial ministries in their emergency planning and preparation. Likewise, the initial dysfunction between the Ministry of Health and Long-term Care's primary action group and EMO discussed in the 2003 SARS Emergency AAR was addressed in the expansion and clarification of roles and responsibilities in the 2005 PERP (J.A. Pirie \& Associates 2003, 21). The difficulty coordinating a mass evacuation as a response to the 2011 Northwestern Ontario Forest Fires was addressed through the creation of standardized evacuation and repatriation procedures in the Ontario Mass Evacuation Plan for the Far North (The Ministry of Community Safety and Correctional Services 2012, 8). The expanding of Ontario's risk environment would therefore seem to have contributed to more expansive, comprehensive, and formalized EM networks. 


\section{Increases in the Occurrence and Severity of Natural Disasters}

Climate change and the corresponding increase in occurrence and severity of natural disasters was identified by many participants as a principle driver behind development of EM programming and planning in Ontario. One participant noted "I think through major experiences throughout the province, Goderich, the ice storm; I think that's how people realise that these events aren't going away. It's not an every one hundred year storm now. It's when the storm is going to come (Participant 02 2018, 2-3)." The increase in frequency and severity of natural disasters was corroborated by a number of participants, who had noticed a rise in medium to large scale natural disasters in Ontario in the span of their careers. Some EM professionals described a sharp increase in natural disasters following the turn of the century. Whereas emergency situations that required a broad-based community response were described as sparse prior to the 2000's, following the turn of the century ice storms, tornados, and flood events were described as increasing in frequency. These findings are in line with the Intergovernmental Panel on Climate Change's fifth assessment report, which expects with high confidence that climate hazards like storm surges, drought and extreme heat events will continue to increase in occurrence across North America (Intergovernmental Panel on Climate Change 2013, 1443). Participants commented on flooding occurring after major draughts, co-current flooding and wildfires, and other simultaneous natural disasters also becoming more common in the province.

Several participants noted that natural disasters in Ontario and Canada have a major impact on EM planning and programming in the province in part because of their relatability. One participant expressed that the development of EM programming in Ontario is "definitely a reaction to the emergencies that are occurring Canada and Ontario and are relatable (Participant 07 2018, 2)." Regarding the relatability of these emergencies to the public, another participant 
stated "many of them will talk about their experiences with things like the blackout or ice storm or other things that have taken place that makes it more real for them (Participant 10 2018, 3)." Natural disasters that occur within the province may have a heightened effect on EM not only because they directly affect EM organizations and stakeholders in the province but also because they relate to the circumstances of those living in the province that may have not been directly affected. These disasters are more meaningful to the public and enhance their perceived vulnerability, making it more likely for them to pursue action. The idea that the relatability of domestic emergencies to policy makers and the public has had a significant effect on EM policy and programming ties into the issue-attention dynamics characteristic of the field discussed by Henstra (Henstra 2011, 399-400).

The increased frequency and severity of natural disasters was discussed by participants as contributing to a shift from reactive planning to proactive planning in the province since the early 1990s, as noted in Joakim and Doberstein's study (Joakim and Doberstein 2013, 275). The movement to a more preventative approach requires not only planning but also training, exercises, and public education. These aspects of EM require the development of partnerships, the sharing of resources, and communication and coordination outside of emergency response, increasing the connectivity between EM organizations and contributing to more comprehensive networks. The increased severity of natural disasters has required the development of structural arrangements to facilitate coordination and collaboration between a more expansive number of organizations in order to effectively manage to their impact, these findings are supported by Henstra's discussion regarding policy learning leading to EM actors re-thinking their approach as a result of greater experience (Henstra 2011, 404). 
Participants noted that climate change itself is a cross-sectoral issue. One participant noted "climate change I think is coming from not just emergency management. We're seeing it with the Ministry of Environment and Climate Change; we're seeing it with the Ministry of Natural Resources and Forestry. I think it's a priority of so many different areas that that's why we're seeing it in emergency management (Participant 07 2018, 2)." Climate change is not an issue specific to the field of EM but one that has broad and deep implications for many aspects of Canadian society. Climate change therefore requires collaboration across a range of fields and sectors in the province.

While participants did not comment on the increase in social networks in communities following major disasters, discussed in Laycock et al.'s study, several participants did discuss that major emergency response events in the province being beneficial to building relationships between EM organizations (Laycock, Mahone, and Filson 2014, 39). One participant stated "I think another major disaster that impacts Ontario or another part of the world that Ontario could relate to would help the relationships as well. We need an event that would draw us together instead of projects that push us apart (Participant 11 2018, 7)." Several participants noted that major emergency response events tended to have a beneficial effect on the linkages between EM organizations. Increases in the number and severity of natural disasters can therefore be seen to have contributed to the increased comprehensiveness of EM networks.

\section{The Growth of the Size and Comprehensiveness of the Field}

Aspects contributing to the development in comprehensiveness and formalization in EM networks in Ontario were described by many participants as in part driven by the increase in size and prominence of the field itself. Several participants discussed EM positions in the 1990s as 
primarily involved in creating and maintaining emergency plans, usually tailored to response. One participant noted "the field has evolved exponentially. When I started we were called emergency planners and all we did was write plans and hope that somebody would use them (Participant 04 2018, 2)."An explosion of interest in the field during the early to mid-2000's was described by a number of participants, who witnessed the development of new legislation, specialized programs at the provincial and municipal levels, and a heightened interest from the public, elected officials, and civil servants.

EM was described by several participants as having gone from being seen as a second career or something that could be worked on off the side of one's desk to one entailing specialized education and training and requiring full-time commitment. One participant noted "it is more widely accepted as a legitimate and distinct field separate from first response agency fields (Participant 11 2018, 1)." Some participants expressed EM as having evolved from a reactive environment to also being a preventative environment, which entailed a shift in focus toward public education, the preparation and execution of exercises, the management and coordination of resources, personnel and expertise, and other activities. Several participants stated that these more expansive duties required a greater time commitment, greater resources, and a greater level of expertise.

These developments were seen as contributing to the growth of academia focused on disaster and emergency management in Ontario. One participant discussed their education in the field in the mid 1990s "there wasn't anything really in Canada so I took a course from FEMA, there was no online at the time. We're talking about twenty-five years ago when the internet didn't exist so I had to write to get books and course manuals - I wrote the tests, got them back, and got their certificates. That's really how I got my training and education in emergency 
management (Participant 04 2018, 1)." The Ontario Association of Emergency Managers was discussed as engaging with EMO and the Ministry of Training, Colleges, and Universities during the years 0f 2003-2004 to develop programs with educational institutions in Ontario. By 20072008 the first graduates of these new programs began to enter the workforce. Today there are a number of academic programs in the province from institutions such as York University, George Brown College, Fleming College, and Sheridan College.

The rapid development in the field and the change in perception as to what an emergency manager's career entails described as taking place in the early to mid-2000's illustrates how quickly the shared understandings of a society can shift and the effects that these shifts can have on network development. As the field has become more sophisticated, expansive, and respected networks in the field seem to have become more comprehensive and formalized. The heightened number of EM professionals has meant that there are more individuals to communicate and collaborate amongst one another and the more substantial responsibilities and expansive focus of the field has meant EM professionals need to engage in more substantial relationships and partnerships to forward their policies and deliver their programs.

\section{Changes to Legislation}

Several participants noted changes in legislation to be a central factor in the development of EM in Ontario. The mandate and standards derived from legislation serves to coordinate the programing, planning, and training of EM organizations on a provincial scale, allowing for increased levels of coordination between these organizations and contributing to the environment in which they build relationships. One participant stated "certainly the legislation which governs program activities at the municipal and provincial level, the Emergency Management and Civil 
Protection Act, was a major driver in the development and formalization of emergency management programs (Participant 10 2018, 4).” The growth in the size and comprehensiveness of the field in 2003-2004 was cited by many as due in part to the adoption of the Emergency Management Act. Many participants cited the requirements of the Emergency Management Act for emergency programming by ministries and municipalities as the reason they obtained their first position in the field due to the mandated requirement for each municipality to have a CEMC. There is therefore appears to be connection between the perceptions of society, societal constructions like legislative structures, and the development of EM networks. The requirement for mandatory CEMC positions in municipalities was described by participants as contributing to the development of relationships and partnerships in regard to the EM of communities in the province. The greater role and responsibilities of EMO also led to an expansion of its staffing and the compliance/reporting relationship the Act established between the EMO and the municipalities and ministries added to the formal structure of networks in the province and strengthened EMO's position as the central coordinator of EM programming in the province.

While participants widely agreed that the adoption of the Emergency Management Act in Ontario was a step in the right direction for EM in the province a few noted that it also caused strain on the relationship between the province and the municipalities. One participant stated "they rolled it out at the same time there was a downloading from the provincial government to the municipalities including things like accessibility requirements, land ambulance services, social services programs, so the perceptions for most municipalities was "sure we have to do this and there's no funding (Participant 05 2018, 4)." Participants noted that there haven't been significant changes in a legislative or regulative standpoint since the adoption of the EMCPA. It was speculated that changes may be coming soon due to the development of a new Provincial 
Emergency Management Action Plan and the opening up of the Act by the Ministry of Community Safety and Correctional Services. These changes could potential cause further developments in the comprehensiveness and formalization of EM networks in the province.

\section{Public Perceptions and Vulnerability}

The perceptions and needs of the public were discussed by participants as having influenced the increased comprehensiveness and formalness of EM networks in Ontario in a variety of ways. The response of participants support Henstra and Boin and t' Hart's observations that the public expects EM planning and programming to be effective (Henstra 2010, 248; Boin and 't Hart 2010, 358).One participant noted the effect that the increased needs of individuals moving into smaller communities is having on EM planning and programming "the public's perspective is that they're all looked after. So when you have that mindset and people moving out of bigger cities and into rural communities they expect that those services will be the same as in bigger cities. So you have to try and be more creative with your resources and figure out better ways of doing things (Participant 02 2018, 5)." Smaller communities are expected to do more without increased resources, and this contributes to the need for coordination and collaboration by those communities.

Other participants noted that the public is becoming more dependent on governments in a broader sense. One participant stated "I think it's because society itself is more dependent on the infrastructure provided by various levels of government. People are less independent (Participant 11 2018, 2)." A major factor influencing this increased dependency was remarked on by one participant as the aging of Canada's population. As the population ages they become more dependent on government services, particularly in emergency events as the elderly may be more 
vulnerable to hazards. Another participant noted that changes in emergency planning of individual citizens have also contributed to their increased reliance on the government for EM. They noted that during 1977 blizzard in Southern Ontario some individuals were snowed in for as long as two weeks. However, it was common practice for individuals in the area to maintain a large amount of food in their pantry, which lowered the vulnerability of communities to the effects of emergencies of this nature. It was observed that individuals no longer maintain such large stores of food, increasing the vulnerability of communities in a more modern context.

The increased formalization of EM networks has also been influenced by the perceptions and needs of the public. The increased creation of MOUs by local governments was discussed by one participant as arising out of a desire to demonstrate to the public that their government has solid and formalized working relationships with their neighbors and other organizations. They noted "the municipality wants its citizens to believe it is strong and can handle these things (Participant 09 2018, 6).” Another participant expressed that while MOUs were helpful in ensuring there was a consistent agreement in place in the case of an emergency these arrangements were often informally in place beforehand. Therefore the increased expectations of the public on governments, their increased dependency on government infrastructure and services, and the desire of governments to be perceived as capable by its residents are potentially factors that have contributed to the development of more comprehensive and formalized EM networks in the province.

\section{The Scarcity of Resources and Expertise}

Resource dependency was a common characteristic of EM organizations expressed by participants. Many EM professionals are civil servants whose agencies compete to obtain the 
resources to develop and implement their programs. One participant remarked "we're all at the table trying to get the taxpayer to pay for things and more money only goes so far (Participant 06 2018, 11)." Obtaining resources can be a struggle because, as discussed by Henstra, the benefits of EM are particularly diffuse and are often not apparent until an indeterminate point in the future (Henstra 2011, 401). Participants did not hold the view that EM was prioritised to a greater extent than other areas of government. The opposite was often the case, with participants expressing a scarcity of resources. Participants noted the scarcity of resources could be in the form of funding, physical resources, staffing, expertise, or time, is in line with the Berado and Scholz's discussion surrounding the variety of forms resource dependency can take (Berardo and Scholz 2010, 637).

The scarcity of resources and expertise, theorized to be a major factor in the development of networks by Rhodes as well as Robinson et al., was discussed by participants as being a factor in the development of the relationships, partnerships, and arrangements between EM organizations in two key ways (Rhodes 1997, 13; Robinson, Murphy, and Bies 2014, 92). First, the scarcity of resources on the part of EM organizations means that they need to coordinate, collaborate, and share resources and expertise to effectively engage in EM. When asked if they believe the organization they work with have the resources necessary to carry out their responsibilities one participant answered "within the organizations themselves, no. Collectively do we have everything? Probably not but we have a lot more resources at our disposal to help us carry out what we need to do in emergencies (Participant 01 2018, 9).” As discussed by Robinson et al., the scarcity of resources that EM organizations experience makes it necessary for them to share resources to engage in EM (Robinson, Murphy, and Bies 2014, 92). Second, those organizations with greater resources are capable of engaging in more comprehensive and 
formalized partnerships and arrangements than those that experience a greater scarcity of resources. The more scarce the resources of the organization the more difficult it becomes to engage in the building of resource-sharing networks. Therefore the scarcity of resources and expertise has contributed to disparities in the development of EM networks in the province.

Municipal emergency managers share a range of intellectual resources with one another to strengthen their programming. Municipalities may also share physical resources and personnel with one another during emergencies. Ministries and municipalities were also discussed as continually sharing resources with one another. Emergency managers also engage with NGOs and faith-based groups to share resources. One participant commented "we're working now to go to more faith-based groups in our communities to take on certain roles and help us with some of the resources. Particularly they have the man power, they have the people factor. If we provide them with the training they can provide us with that resource (Participant 04 2018, 8).” Engagement extends to the individuals within communities as well, the participant commented "we've put a lot of work in the last five to ten years to get the community to listen and recognize that they have a responsibility to take care during emergencies - we need to do better on that side of things in order to be able to make better use of the resources that exist in our communities already (Participant 04 2018, 9)." The expansion of community engagement shows the importance of drawing on the resources of individuals and families within communities for EM preparation discussed by Murphy (Murphy 2004, 2). This increased collaboration with individuals and NGOs may support Pierre and Peter's observation that governments increasingly need to collaborate with other societal actors (Pierre and Peters 2000, 5).

Participants expressed that the networking process is made more difficult as resources become scarcer. The responses of participants affirmed the limited resources of local actors 
discussed by Waugh and Streib (Waugh and Streib 2006, 132). Several participants described large discrepancies in resourcing and funding between different communities or organizations, one of which noted "the bulk of the municipalities don't have the resources and don't have the money to be able to provide what we need to be able to do our work (Participant 04 2018, 8)." Another participant stated: "it's a waste of time and an addition to our work and we don't have time to do the work. I don't have any resources to do emergency management work. It's always something we're putting on the side (Participant 08 2018, 1)." Some CEMCs maintain substantial responsibilities in their community apart from their CEMC duties, which can lead to emergency management becoming a very minor part of their overall work and lead to an inability to spend the time needed to develop and enhance the relationships required for resource-sharing.

Many participants noted that one of the roles of OFMEM's liaison officers is to assist those municipalities that suffer from a lack of resources. One participant noted that: "field officers may not need to do anything with a city like Toronto but can spend their time with the less sophisticated communities and assist them with their HIRA and plans, assist in the creation of mutual aid agreements, and help develop table top exercises (Participant 20 2018, 7).” However, cutbacks by the province were discussed as restricting OFMEM's ability to engage with other EM organizations and stakeholders. Speaking on the topic, one participant said "as the field officers have diminished in number their ability to get to know their municipalities, the people that work in them, and provide them with assistance has been limited (Participant 18 2018, 7)." When discussing their relationship with their liaison officer another participant noted “they've been here once in two years, and again not through any fault of their own. The willingness is there it's just a matter of getting enough people in place that you can make those commitments once a year. They've cut back their staff so much (Participant 06 2018, 4)." Several 
participants discussed these cutbacks as making it difficult to establish meaningful relationships with individuals representing OFMEM and attain resources to supplement their EM programming. One participant remarked "the province has cut back funding and there have been huge impacts on day to day operations. You know if you're going to do a field exercise, if you're going to do a training session, or if you need to bring in somebody with specialized skills to develop your IMS-based emergency management plan. There's no funding (Participant 05 2018, 11)." A lack of resources on the part of OFMEM was also noted to affect the ability of emergency managers in the province to share information. One participant stated "a number of years ago Emergency Management Ontario would run their conferences free of charge with the exception of hotel expenses. That was an opportunity for me to stay up to date with what's going on and obtain pertinent information (Participant 09 2018, 10). The lack of resources on the part of OFMEM limiting its capabilities is consistent with the findings of the 2017 Auditor General's Report (The Office of the Auditor General of Ontario 2017, 239).

Participants also noted cutbacks in EM at the federal level. Several participants discussed the closing of the Canadian Emergency Management College in Ottawa in 2012 as being a major blow to the ability to obtain job specific training. One participant recounted the benefits of the college "all the courses were free and they were assuming the cost - they took a leadership on emergency management that was great at the time (Participant 08 2018, 3).” The discontinuation of the Joint Emergency Preparation Fund in 2013 was likewise regarded by one participant as increasing the difficulty of properly preparing for and responding to emergencies. Another participant expressed concerns that the Government of Canada had announced that the National Emergency Stockpile System would also no longer be replenished as of 2017, which removes another avenue for communities to attain resources. 
The scaling back of provincial and federal assistance experienced by participants supports Henstra's observation that EM is particularly prone to austerity measures (Henstra 2011, 403). The scaling back of provincial and federal support has in some cases led to communities working together to fill in that void through increased partnerships with private industry and other municipalities for cost-sharing arrangements to invest in specialized equipment and other shared resources. Some participants also noted increased collaboration between municipalities to update training materials and deliver training. However, it has had a particularly negative effect on communities whose resource scarcity inhibits their ability to engage in relationship-building, partnerships, and arrangements. Resource scarcity seems to have spurred on the development of structural arrangements between certain EM organizations in the province while also contributing to notable disparities in that development.

One participant noted that governmental funding for EM goes through periods of growth and cutbacks, stating "you go through cycles where emergency management is a priority for a particular government where you get resources and are in a growth mode. Then you get another government and begin to go back and you're dealing with cuts and are losing people (Participant 20 2018, 7)."'OFMEM was described by several participants as currently entering a period of growth following several years of cutbacks, who were optimistic that these increased resources would enhance the Office's capability to engage with EM organizations and stakeholders. One participant noted "I think there's a lot more outreach now from a communications perspective compared to a few years ago but I think that's more of just a turn back to how it used to be (Participant 10 2018, 9)." Many participants expressed optimism with respect to the Office's future. 


\section{CHAPTER SEVEN - THE DEVELOPMENT OF EMERGENCY MANAGEMENT GOVERNANCE IN ONTARIO}

This chapter discusses the development of the major characteristics of governance in EM in Ontario between 1991 and 2018. The findings in this chapter show that some characteristics associated with bureaucratic governance have strengthened during this time period while characteristics associated with networked governance have remained constant or become less prominent. This presents of view of EM governance becoming more bureaucratic in some ways while remaining networked in others. The first three sections of this chapter discuss characteristics related to bureaucratic governance. The first section is a discussion of the development of more extensively mandated roles and responsibilities in the sector, which is followed by a discussion of the increase in mandated standards and procedures. These discussions are followed by a section on the reliance on hierarchies and top-down decisionmaking and goal articulation in EM organizations in the province. The last two sections discuss the continued decentralization of power and authority in the sector as well as the varying levels of coordination between EM organizations, showing that prominent characteristics of networked governance also exist in the sector.

\section{Mandated Roles and Responsibilities}

The Emergency Management Act and Regulation 380/04, which came into effect December 31 , 2004 under its authority, expanded and clarified the roles and responsibilities of municipalities and ministries, two of the most prominent EM actors in the province (J.A. Pirie \& Associates 2003, 3). The increase in mandated roles and responsibilities is evidence of a bureaucratization of governance in the EM in Ontario. The Emergency Plans Act loosely prescribed the roles and 
responsibilities of municipalities and ministries apart from the roles and responsibilities of Ministry of the Solicitor General. There are few stipulations as to what ministerial plans must actually entail and nothing touching on EM programming (The Ministry of the Solicitor General 1991, 6) . Likewise, municipalities were authorized to put into place emergency planning bylaws but apart from having to notify the Ministry if the Solicitor General when an emergency has been declared or terminated there were few formal responsibilities on the part of municipalities (The Ministry of the Solicitor General 1991, 6) . There were also no formal mechanisms established by the act to ensure compliance. This decentralization and lack of top-down mandates would appear characteristic of networked governance (Pierre and Peters 2000, 39).

The 1998 Ice Storm AAR discusses the legal authority of the Emergency Plans Act was generally understood and respected by provincial government organizations participating in the preparedness and response to the storm (SAIC Canada 1998, 6). The AAR cites a lack of authority in several areas as a major area of improvement for the province (SAIC Canada 1998, 13). Ontario Hydro and other local utilities were not required by the Emergency Plans Act or any other provincial legislation to formulate an emergency plan despite the vital role of these organizations during an emergency (SAIC Canada 1998, 13). The 1998 Ice Storm AAR also noted that the roles and responsibilities of provincial ministries during an emergency should were not sufficiently defined to include wide-spread events (SAIC Canada 1998, 17).

The Emergency Management Act's clarified and expanded the roles and responsibilities of ministries and municipalities through a top-down mandate. Full program ministries are designated responsibility for specific types of emergencies under a 2005 Order in Council by the Lieutenant Governor of Ontario (The Ministry of Community Safety and Correctional Services 2005, 9). Roles and responsibilities common to all ministries during an emergency and common 
to all municipalities are also assigned (The Ministry of Community Safety and Correctional Services 2005, Annex B). The requirement for municipalities to formulate plans to respond to emergencies, adopt these plans by by-law, and review these plans annually is also mandated (The Ministry of Community Safety and Correctional Services 2005, 6). The clarification and expansion of roles and responsibilities of EM actors via a top-down mandate supports the view of EM in Ontario as shifting toward a more bureaucratic style of governance as discussed by Junki and Considine and Lewis (Considine and Lewis 2003, 133; Junki 2006, 21).

The structure of EM in the province lay out by EMCPA, while not regarded as perfect, was widely respected by participants. Several participants noted the importance of legislation in ensuring consistency in EM across the province. One participant stated "in Ontario the structure has been here for years. Even it's not as strong as everyone might want it to be it's one of the strongest for emergency management systems in Canada. They have training, they have field officers, they have resources to support, or try to support, CEMCs. They have a compliance system for emergency management and municipalities try their best to be compliant (Participant $082018,7)$." Municipalities and ministries were widely expressed by participants as taking their legislated responsibilities seriously.

A few participants expressed a desire to see the EMCPA expanded to include mechanisms to ensure compliance with its stipulations in regard to EM. One participant highlighted that "it's important in the province of Ontario to have an Emergency Management and Civil Protection Act that has clear cut consequences for municipalities that don't comply (Participant 14 2018, 9)." Therefore some supported a further expansion of the Act to include mechanisms to ensure the compliance of ministries and municipalities with their legislated responsibilities. 
A key characteristic of bureaucratic governance is the existence of mandated roles and responsibilities. Participants understood and respected the mandate of the Act and expressed that the organizations they work with took their legislated responsibilities seriously. Several participants noted that EM organizations consistently comply with the Act despite coercive mechanisms not being in place to ensure that compliance, providing evidence that the top-down mandate of the Act not only exists in theory but also in practice. The authority of the Act is a societal construction, which seems to be meaningful to EM organizations. It is therefore important to note that while Raikes and McBean observed that the protocols and practices mandated by EM legislation in the provinces are not as prescriptive as they could be, an analysis of the EMCPA indicates that there has been a movement toward more prescriptive EM legislation in Ontario (Raikes and McBean 2016, 17). The expansion of the mandated roles and responsibilities of these key actors over time is evidence of a bureaucratization of EM in the province.

\section{Mandated Standards and Procedures}

The mandated standards and procedures of ministries and municipalities were also expanded following the adoption of the Emergency Management Act. Ontario Regulation 380/04 sets out standards for ministerial and municipal EM programs (The Ministry of Community Safety and Correctional Services 2005, 7). The 2005 and 2008 PERPs describe what municipal and ministerial emergency plans should provide for (The Ministry of Community Safety and Correctional Services 2005, 9). Two major aspects of these standardized procedures were the required use of an incident management system by ministries and municipalities and ministries 
were and the requirement to conduct hazard Identification and risk assessments and review them annually (The Ministry of Community Safety and Correctional Services 2005, 16).

Participants who discussed the topic stated that EM organizations adhere to and respect legislated standards and procedures, even when they are perceived to be to the detriment of their emergency planning and response. The mandated use of an incident management system was well understood by participants. Many participants discussed the use of the provincial IMS by organizations they had worked with since the system's inception while others promoted the use of other systems, such as the Incident Command System. Participants expressed the need for EM organizations to have incident management systems and widely supported the mandated use of those systems.

The use of an annual hazard identification and risk assessment mandated by the EMCPA was widely supported by participants. The requirement for hazard identification and risk assessments was promoted as being a vital development to EM in Ontario. These yearly assessments provide a continual, quantifiable, and comparable method for EM organizations to identify hazards and assess risks. Hazard identification and risk assessments aid in the distribution of resources allocated to EM in an organization, allow different organizations and communities to compare hazards they have identified and the level of risk associated with them, and allow organizations to chart the development of risk over time.

Therefore it would seem that there has been an expansion in mandated standards and procedures in EM in Ontario, primarily as a result of the adoption of the Emergency Management Act and Regulation 380/04. The mandated procedures in the Act are understood and implemented by professionals in the province, demonstrating that the mandate of the Act is translating into practice and not merely existing in theory. The adoption of these new standards 
and procedures are further evidence of development toward a bureaucratic system of governance as discussed by Junki, and Considine and Lewis (Junki 2006, 21).

\section{A Reliance on Hierarchies and Top-down Decision-Making and Goal Articulation}

A reliance on hierarchies and top-down decision-making and goal articulation, characteristic of bureaucratic governance, was apparent in the responses of participants. The importance of senior leadership in EM planning and programming was widely expressed by participants and was consistent regardless of organization being discussed. One participant noted "without senior management buy in it is extremely difficult to run a successful program (Participant 102018 , 3)." Similarly, another participant stated "the Chief Administrative Officer, Vice President, or CEO are the ones that really set the pace (Participant 14 2018, 5)." This reliance on senior leadership extends to provincial ministries, with one participant noting that "if direction came down from a Minister or Deputy Minister the ministries would work well and get that done. If it was any sort of initiative that employees themselves were trying to push forward there seemed to be hesitation as to relationship building and getting those types of initiatives done (Participant 11 2018, 2)." Participants from both governmental and non-governmental organizations discussed the importance of having champions in key leadership positions to forward EM in the province, with several noting that when this occurs there have been substantial developments in the field. The views of participants therefore did not support the shift in emphasis away from hierarchies toward informal, horizontal exchanges as discussed by Pierre and Peters (Pierre and Peters 2000, $15)$.

A lack of leadership at the provincial level has been noted to be to the detriment of the province's EM program. In the 2008 PERP the structure of the provincial emergency program 
was altered so that the Cabinet Committee on Emergency Management would itself direct the Deputy Minister of Emergency Planning and Management/Commissioner of Emergency Management, creating a clear line of authority directly from the Cabinet Committee to the Deputy Minister of Emergency Planning and Management (The Ministry of Community Safety and Correctional Services 2008, 41). This hierarchical decision making structure is characteristic of bureaucratic governance as discussed by Pierre and Peters (Pierre and Peters 2000, 81).The Cabinet Committee would develop the overall provincial emergency response strategy, brief appropriate ministries, engage in strategic issues management, and ensure the continuity of critical government services (The Ministry of Community Safety and Correctional Services 2008, 42).

However, the 2017 Auditor General's report found no evidence that the Cabinet Committee had met in the last five years. The Auditor General's report states that "without meeting regularly, the Committee cannot provide proper oversight and strategic direction for the Province or a government-wide focus for emergency management, and cannot demonstrate that the Province is prepared to address an emergency situation (The Office of the Auditor General of Ontario 2017, 235)." The gradually disintegrating leadership on the part of the province since the adoption of the EMCPA was noted by several participants, who found it to be to the determent of EM planning and programming in the Province.

The support for EM by senior leadership in communities varies considerably throughout the province. Some communities may have Heads of Council and CAOs who are highly supportive of EM in their communities, while others may be less so. Support from leadership and senior officials can have a large effect on EM. Participants expressed that when commitment from senior officials and leadership wanes EM planning suffers, regardless of the level of 
government. One participant noted that 'if you don't get the support from your municipal leaders your plans only go so far (Participant 06 2018, 7)." Several participants noted that it was often difficult to obtain buy-in from senior management due to the diffuse benefits of EM planning and programming, in line with Henstra's observation (Henstra 2010, 250). An example of the negative effects of the inability to obtain buy-in was recounted by one participant "it was so bad that at one point we went to do our exercise. I had my field officer here from Emergency Management Ontario, I couldn't get a council member to show up and they knew I needed somebody there and no one could show up for it (Participant 09 2018, 9).” Another participant noted "I've been through four mayors and the mayor I have now is the first mayor I've ever had whose read the emergency plan and actually attended emergency training (Participant 06 2018, 7)." EM planning and programming is therefore dependent to some extent on senior leadership. The impotence of executive control described by Hammond is therefore not supported by the responses of participants (Hammond 1986, 384).

Many participants expressed the importance of accountability to senior leadership in collaborating with other organizations. Participants noted that EM organizations are in most cases governmental departments and agencies whose resources ultimately belong to governments. One participant described the complexities surrounding resource- sharing: "we don't own those resources. They belong to the municipal government, or provincial government (Participant 04 2018, 5)." They carried on to say that "there has to be vetting, there has to be accountability, we're using taxpayers' money so we are accountable (Participant 04 2018, 5).” The participant's response culminated in the statement "there are possibilities of sharing with other communities and generally there is an openness to that but it doesn't necessarily rely on the emergency management community, it relies on the will of the whole political organization 
(Participant 04 2018, 5).” Therefore mechanisms of accountability traditionally found in a representative democracy, as discussed by Rhodes, were expressed as existing in governmental departments and agencies in EM in Ontario by participants (Rhodes 1997, 21). The separation of the control of a sector from those who are perceived as responsible for it by the broader community who hold stake in it, discussed by Pierre and Peters as a result of networked governance, does not seem characteristic of EM in Ontario (Pierre and Peters 2000, 20).

Leadership can have a significant impact on the relationships and partnerships an EM organization engages in. The recent push toward greater communication, collaboration, and stakeholder engagement on the part of OFMEM was attributed by many participants as occurring as the result of changes in senior leadership within that Office, which shows a connection between the role of senior leadership in decision-making and goal articulation and the development of networks. EM organizations in Ontario seem to have a continued reliance on hierarchies and top-down decision-making and goal articulation to be successful, consistent with a bureaucratic system of governance.

\section{Decentralized Power and Authority}

While EM organizations may rely on hierarchies and top-down decision making there is a continued decentralization of power and authority in EM networks characteristic of networked governance. The need for EM systems to share responsibility, authority, and power across actors discussed by Kapucu and Graryev seems to apply to the context of Ontario (Kapucu and Garayev 2016, 954). The bottom-up structure of the graduated response system discussed in the 1991 PEP supports the idea of community-based EM at local levels of government, as more senior levels of government become involved in an emergency they would not take control of the response but 
instead coordinate and collaborate horizontally with the affected municipalities (The Ministry of the Solicitor General 1991, 5).

Broad-based coordination and collaboration is required among EM actors as an emergency may affect more than one municipality or a regional municipality as well as its regional government. The 1991 PEP states that EM plans of these actors must be harmonized to the extent that these actors do not, at minimum, interfere with each other's response (The Ministry of the Solicitor General 1991, 5) . The 1991 PEP states that changes in jurisdictional arrangements are "nearly always disruptive and never more so than during the stress that accompanies an emergency (The Ministry of the Solicitor General 1991, 5) ." While more senior levels of government may take on the jurisdictions of lower levels this is stated to be inadvisable unless completely necessary. The decentralization of authority across the province, and the need for coordination and collaboration that results from it, is characteristic of networked governance as discussed by Pierre and Peters (Pierre and Peters 2000, 39).

The adoption of the Emergency Management Act led to a centralization of authority in some aspects of EM in the province. The Ministry of the Solicitor General of Ontario was merged with the Ministry of Correctional Services and became the Ministry of Public Safety and Security in 2002. In 2003 the Ministry was renamed the Ministry of Community Safety and Correctional Services. Emergency Measures Ontario was restructured into EMO during this time. Whereas Emergency Measures Ontario acted as a central coordinator during the response to an emergency in the Emergency Plans Act and the 1991 PEP, the Emergency Management Act mandated EMO as the central co-ordinating authority for emergency management planning and programming of municipalities and ministries (The Ministry of Community Safety and Correctional Services 2005, 20). The Emergency Management Act states that all municipal 
emergency plans shall conform to the standards set by the Minister of Community Safety and Correctional Services (The Ministry of Community Safety and Correctional Services 2005, 7). The Chief of EMO was made responsible for ensuring the compliance of ministry and municipal EM programs in the province, which shows a centralization of authority characteristic of a bureaucratic conceptualization of governance discussed by Junki (The Ministry of Community Safety and Correctional Services 2005, 21; Junki 2006, 21).

EM in Ontario is still structured in the 2005 and 2008 PERPs as a graduated system just as it was in the 1991 PEP (The Ministry of Community Safety and Correctional Services 2005, 3). As such authority over the response to emergencies is decentralized among ministries and communities in the province. The responsibility for an emergency remaining with the municipality that declared it was confirmed by participants, one of whom specifically stated "the province and the government have made it very clear that if you declare a disaster they're not going to take over, it is still yours to run (Participant 09 2018, 6)." Municipalities maintain authority over the response to emergencies in their jurisdictions, and ministries maintain authority over emergencies in their designated areas of special responsibility.

The power to prepare for and respond to emergencies is decentralized to an even greater extent. When discussing collaboration in emergency response one participant noted "it's a whole of society response - we need to involve private industry, NGOs, and other organizations into the fold and make sure everything we do is in line together (Participant 13 2017, 2)." The need to engage a multi-sector network of organizations for effective EM discussed by participants supports the view that power in regard to EM in Ontario is decentralized across a range of organizations. One participant stated "when it comes to emergency management that to me is community-based. When an emergency hits a specific area - the outcomes of that particular 
event have major community impacts and that is where emergency management really comes into play (Participant 01 2018, 3)." Boin and 't Hart's discussion surrounding the capacity of an EM community being determined to a large extent by the breadth and depth of the relationships between organizations in its networks was supported by participants (Boin and 't Hart 2010, 365). Multi-sector networks of organization need to share power horizontally to address the broad-based impacts of emergencies.

Interdependency between organizations can be seen in the response to various emergencies in the province over the years. The 1998 Ice Storm AAR states that organizations that were involved in the response to the emergency included ministries, municipalities, regions and counties, First Nations Communities, business associations and private industry, and a range of other local actors (SAIC Canada 1998, 10-11). The response to the 2011 Northwestern Ontario wildfires involved collaboration between the Ministry of Natural Resources, the Ministry of Community Safety and Correctional services, Health Canada, municipalities, First Nations communities, NGOs, in addition to others (The Ministry of Community Safety and Correctional Services 2012, 23). The 2015 James Bay Flood evacuation likewise required coordination and collaboration between a range of interdependent organizations (The Office of the Fire Marshal and Emergency Management 2015, 5).

Several participants noted that EMO was not granted any coercive mechanisms through which to enforce compliance with the directives of the EMCPA in line with the findings from the Auditor General of Ontario's 2017 Report (The Office of the Auditor General of Ontario 2017, 238) Today, apart from OFMEM's provision of a letter notifying a municipality there are no direct penalties for non-compliance. Participants noted that OFMEM's principle method for ensuring compliance is working horizontally with the CEMCs of municipalities to ensure they 
understand, and have the capability of fulfilling, their municipalities responsibilities in line with the Act. OFMEM would seem to use soft instruments of authority to ensure compliance as opposed to the use of coercion (Pierre and Peters 2000, 105).

As stated earlier the Auditor General's Report on Emergency Management in Ontario pointed out that there is no evidence that the Executive Cabinet Committee on Emergency Management has met in approximately five years (The Office of the Auditor General of Ontario 2017, 235). The more authoritative structure that has been put in place, while perhaps indicative of a centralization of authority in theory, seems to be absent in practice. The idea of an absence of provincial authority is supported in the comments of participants, several of which commented on a continual lack of leadership at the provincial level. This continual lack of leadership was seen as contributing to fragmentation and inconsistency in regard to EM throughout the province, which ties into Berado and Scholz's discussion surrounding network development resulting from a fragmentation of formal authority (Berardo and Scholz 2010, 632). As provincial leadership in the field becomes less prominent authority in regard to EM seems to have continued to be decentralized amongst the various communities, municipalities, and ministries of the province.

A major exception to the decentralized power and authority of EM organizations within the province is apparent during provincial emergencies. The centralization of authority in the provincial government was noticeable in the analysis of the provincial response to the 2003 SARS emergency. The Emergency Plans Act gave the Premier, or their designated minister, the authority to direct and control the administration, facilities and equipment of a municipality during a provincial emergency, which meant that the provincial executive authority could directly activate and control the resources of the municipalities as necessary during the course of the emergency (J.A. Pirie \& Associates 2003, 8-9). Following the declaration of the provincial 
emergency the City of Toronto, the Regional Municipalities of Durham, Halton, Peel, and York, and Simcoe County were issued a directive that explained that their community emergency operations centres were to "provide a coordinated and centralized response with each community to support its Public Health Department. Community Control Groups (were to) consider measures required to address immediate, short term and long term needs, related to SARS (J.A. Pirie \& Associates 2003, 9).” The outright issuing of directives to municipalities is a clear example of command and control EM in line with bureaucratic governance. Pierre and Peters state: "Governance highlights the extent to which collective goals can be articulated and direction can be given under the constraints present in the environment of those who govern." During this provincial emergency the executive authority clearly directed the response of certain municipalities, which otherwise seemed to maintain a horizontal relationship with the province in regard to EM (Pierre and Peters 2000, 7). The response to the 2003 SARS Emergency provides an example of the centralization of authority in EM in the province during a provincial emergency. However, the vast major of emergencies in the province do not require the declaration of a provincial emergencies. In these cases, authority and power seem to continue to be shared between networks of interdependent organizations as is in line with a networked conceptualization of governance.

\section{Varying Levels of Coordination and Interdependency}

The decentralized power and authority of EM organizations and their diverse roles and responsibilities contribute to the need for varying levels of coordination and interdependency between these organizations. Some mandated relationships are apparent in the analysis of PERPS, AARs, and the responses of participants. However, the bulk of coordination between 
EM organizations varies based on their different needs, environments, leadership, resources, and a plethora of other factors. Several participants highlighted that the relationships, partnerships, and arrangements that they engaged in varied widely depending on the organization or community they worked with.

The varying levels of coordination and interdependency between EM organizations discussed by participants can be illustrated through a discussion of the varied relationships communities in the province form. Communities experience different hazards and vulnerabilities depending on their environment. One participant described the differences in pandemic planning between a host community and the community they were hosting during an evacuation. They stated "the H1N1 outbreak in 2009 - those communities were very much impacted by it, more so than a lot of other communities and they took their pandemic planning to a whole other level than what a lot of us did (Participant 01 2018, 6)." The varying EM priorities of these two communities led to the need for coordination and collaboration between them.

The resources of EM organizations were also described as a major factor in the type of relationships EM organizations create and maintain. Several participants noted that municipalities that cannot draw from as substantial a pool of resources for their EM programming may work more directly with OFMEM to draw on their resources and expertise of to supplement their planning and programming. Communities that do not experience as substantial resource scarcity may maintain more of a reporting-compliance relationship with the Office.

The jurisdictions in the environment of EM organizations also influence the relationships, partnerships, and arrangements they engage in. Communities were described by participants as forming tight, consistent relationships with ministries that held responsibilities in that 
community’s environment. For instance, the Ministry of Natural Resources will work more closely with communities who may be potentially affected by forest fires and the Ministry of Transportation will work with communities near major highways. Communities were discussed as forming sophisticated and formalized relationships with other neighboring communities. In areas like southern Ontario, where many communities may be within a short distance of one another, communities often have a diverse range of partnered communities who they engage with in the development of plans and the delivery of programs. In some cases a community's closest neighbors may be in another province or in the United States of America, so some of their most highly developed relationships may be in jurisdictions outside of the province. Communities that experience greater geographic isolation may engage in less coordination and collaboration as they have fewer neighbors.

Participants described municipalities as developing varied relationships with NGOs and private industry in their communities for the purpose of EM. One community may work closely with the Salvation Army and Canadian Red Cross while another may work primarily with Samaritan's Purse and St. John Ambulance. Similarly, one community may work closely with local chemical industry while another works with local finance industry or educational institutions. While there are mandated organizations in EM networks in Ontario that maintain a high level of coordination, in general there are varying levels of coordination and interdependency based on a wide range of factors between EM organizations in the province. The varying level of coordination and interdependency between EM organizations in Ontario seems to have remained fairly constant over time and points toward a networked system of governance. 


\section{CHAPER EIGHT - DISCUSSION AND CONCLUDING REMARKS}

This chapter discusses the findings from the analysis of the data collected from participants, PERPs, and AARs and identifies major patterns and trends in the four key themes outlined in the methodology. The findings of this thesis are compared with the major themes and concepts discussed in the literature review chapter. Suggestions for future policy, the limitations of the findings of this thesis, and avenues for future research are then discussed.

\section{Discussion}

The analysis of PERPs, AARs, and perceptions of participants show that there has been a continual need for networks in EM in Ontario between the period of 1991 and 2018. The varying roles and responsibilities of EM organizations within to the graduated response system used in the province as well as the decentralized power and authority of EM actors has meant that communication, coordination, collaboration, the sharing of resources and expertise, and trust and confidence between EM organizations has been necessary throughout this period. The importance of characteristics associated with comprehensive networks is highlighted as far back as the $1991 \mathrm{PEP}$.

The extent of the need for comprehensive EM networks has expanded considerably since 1991 from being focused on emergency response to EM's other aspects such as preparation and mitigation. There is also an increased need for more inclusive and expansive networks between different fields, demonstrated by the increased communication and collaboration between EM and fields such as healthcare, conservation, and social services. The need for more comprehensive and inclusive networks has been driven in part by an expanding risk 
environment, the increased severity and frequency of natural disasters, and the increased vulnerability and expectations of the public.

As stated by Kapucu and Garayev a network is: "an aggregation of structural arrangements due to the belief that structure - whether horizontal or vertical—affects outcome (Kapucu and Garayev 2016, 933).” The arrangements that comprise a network are goal oriented instruments used by rational actors (Pierre and Peters 2000, 41). The increased comprehensiveness and formalization of networks in the Province of Ontario over this time can be understood to be a rational response wherein EM organizations have learned from and responded to these changing circumstances. Potential developments in the mutual trust and confidence between EM organizations are difficult to track due to the varied relationships between organizations in the province. While trust and confidence between EM organizations is undoubtedly vital to the field there is not enough evidence to make inferences as to the development of this concept on a provincial scale.

Changes in legislation seem to have been a major vehicle for the development of more comprehensive, formalized networks in EM in the province and have led to clearer roles and responsibilities, the development of more sophisticated information-sharing systems, increased coordination between EM organizations, and the introduction of standardized systems and procedures. The growth of the field itself over time, in part influence by the mandated requirements of the EMCPA, has also facilitated increased communication, coordination, and collaboration between EM organizations and professionals as there is a greater pool of actors to form networks with. Trends in the development of the comprehensiveness of EM networks in the province can be seen in Table 4 and trends in the formalization of EM networks can be seen in Table 5. 
TABLE 4, Developments in the Comprehensiveness of Emergency Management Networks

\begin{tabular}{|c|c|c|c|c|}
\hline 1991 & Trend & 2018 & Major Influences & Implications \\
\hline $\begin{array}{l}\text { Less information- } \\
\text { sharing }\end{array}$ & Strong & $\begin{array}{l}\text { Greater effective } \\
\text { information- } \\
\text { sharing }\end{array}$ & $\begin{array}{l}\text { - The implementation of more substantive } \\
\text { provincial information-sharing systems. } \\
\text { - The growth of the size and } \\
\text { comprehensiveness of the field. } \\
\text { - Technological advancements. }\end{array}$ & $\begin{array}{l}\text { - Greater information- } \\
\text { sharing provincially is } \\
\text { indicative of more } \\
\text { comprehensive structural } \\
\text { arrangements between } \\
\text { EM organizations. }\end{array}$ \\
\hline $\begin{array}{l}\text { Less clear roles } \\
\text { and } \\
\text { responsibilities }\end{array}$ & $\stackrel{\text { Moderate }}{\longrightarrow}$ & $\begin{array}{l}\text { Clearer roles and } \\
\text { responsibilities }\end{array}$ & $\begin{array}{l}\text { The adoption of legislation and PERPs } \\
\text { that more clearly and comprehensively } \\
\text { set out the roles and responsibilities of } \\
\text { provincial ministries and municipalities. }\end{array}$ & $\begin{array}{l}\text { - Clearer roles and } \\
\text { responsibilities are } \\
\text { indicative of more } \\
\text { comprehensive EM } \\
\text { networks in the province. }\end{array}$ \\
\hline $\begin{array}{l}\text { Less coordination } \\
\text { and collaboration }\end{array}$ & Strong & $\begin{array}{l}\text { Greater } \\
\text { coordination and } \\
\text { collaboration }\end{array}$ & $\begin{array}{l}\text { - The expanding risk environment. } \\
\text { - The adoption of legislated central } \\
\text { coordinating structures for provincial } \\
\text { and municipal emergency programs. } \\
\text { - Changes in public needs and } \\
\text { perceptions. } \\
\text { - Cutbacks in provincial and federal } \\
\text { support for municipal emergency } \\
\text { programs. }\end{array}$ & $\begin{array}{l}\text { - Greater coordination and } \\
\text { collaboration is indicative } \\
\text { of more comprehensive } \\
\text { networks. Significant } \\
\text { gaps exist in this } \\
\text { development due to } \\
\text { resource scarcity and } \\
\text { isolation. }\end{array}$ \\
\hline $\begin{array}{l}\text { Mutual trust and } \\
\text { confidence is vital }\end{array}$ & Unknown & $\begin{array}{l}\text { Mutual trust and } \\
\text { confidence is } \\
\text { vital }\end{array}$ & $\begin{array}{l}\text { - Mutual trust and confidence is } \\
\text { inaccessible through the analysis of } \\
\text { PERPs and AARs. Participants } \\
\text { expressed uncertainty regarding the } \\
\text { development of mutual trust and } \\
\text { confidence on a provincial scale. }\end{array}$ & $\begin{array}{l}\text { Further research is } \\
\text { necessary in this area. }\end{array}$ \\
\hline
\end{tabular}


TABLE 5, Developments in the Formalization of Emergency Management Networks

\begin{tabular}{|c|c|c|c|c|}
\hline 1991 & Trend & 2018 & Major Influences & Implications \\
\hline $\begin{array}{l}\text { Less } \\
\text { prescriptive } \\
\text { legislation }\end{array}$ & Strong & $\begin{array}{l}\text { More prescriptive } \\
\text { legislation }\end{array}$ & $\begin{array}{l}\text { - The expanding risk } \\
\text { environment. } \\
\text { - Increases in the occurrence } \\
\text { and severity of natural } \\
\text { disasters. } \\
\text { - The adoption of the } \\
\text { Emergency Management Act } \\
\text { and EMCPA. }\end{array}$ & $\begin{array}{l}\text { More prescriptive legal structures } \\
\text { contribute to more formalized connections } \\
\text { between EM organizations. } \\
\text { More prescriptive legislation and } \\
\text { regulations can cause difficulties if } \\
\text { flexibility is not adequately incorporated } \\
\text { to account for the different circumstances, } \\
\text { needs, and environments of different EM } \\
\text { organizations. }\end{array}$ \\
\hline $\begin{array}{l}\text { Emergent } \\
\text { partnerships and } \\
\text { arrangements }\end{array}$ & Strong & $\begin{array}{l}\text { Increased use of } \\
\text { agreements and } \\
\text { MOUs }\end{array}$ & $\begin{array}{l}\text { - The expanding risk } \\
\text { environment. } \\
\text { - Increases in the occurrence } \\
\text { and severity of natural } \\
\text { disasters. } \\
\text { - Public perceptions and } \\
\text { needs. }\end{array}$ & $\begin{array}{l}\text { - Agreements and MOUs formalize the } \\
\text { expectations between EM organizations } \\
\text { and harmonize their operating procedures. } \\
\text { - MOUs may reduce the perceived } \\
\text { vulnerability of the public. }\end{array}$ \\
\hline $\begin{array}{l}\text { Few standards } \\
\text { and procedures }\end{array}$ & Strong & $\begin{array}{l}\text { Common } \\
\text { standards and } \\
\text { procedures }\end{array}$ & $\begin{array}{l}\text { The need for harmonized } \\
\text { standards on the part of EM } \\
\text { organizations to facilitate } \\
\text { effective emergency } \\
\text { planning and programming. } \\
\text { The adoption of the Z-1600, } \\
\text { HIRA, IMS, JEMS, and } \\
\text { other related standards and } \\
\text { procedures. }\end{array}$ & $\begin{array}{l}\text { The standards and procedures of EM } \\
\text { organizations have become increasingly } \\
\text { standardized across the province, } \\
\text { contributing to more formalized structural } \\
\text { arrangements between EM organizations. }\end{array}$ \\
\hline
\end{tabular}

Source: Data collected from participant interviews, PERPs, and AARs. 
The diversified roles and responsibilities, the decentralized power and authority, and the varying levels of interdependency between EM actors in the province indicate that the structural arrangements that they engage in differ. The graduated response system utilized by the province is by its nature a decentralized system, which has contributed to notable discrepancies in the development of EM networks in the province due to resource scarcity, environmental and geographical factors, differences in leadership, as well as a range of other contextual factors. While EM networks in general seem to have become more comprehensive and formalized this is certainly not the case for every organization in the province.

The mandated roles, responsibilities, standards, and procedures introduced in the Emergency Management Act and the enhanced position of the Cabinet Committee on Emergency Management introduced in the EMCPA would appear to indicate that EM in Ontario has been moving to be more in line with a system of bureaucratic governance. EM organizations also exhibit a reliance on top-down decision making and goal articulation consistent with a bureaucratic system of governance. Several participants also expressed the use of checks and balances to ensure the accountability of governmental EM organizations to the broader public also indicative of bureaucratic governance.

While OFMEM is assigned as the authority to ensure compliance with the stipulations in the EMCPA coercive mechanisms are not included to do so (The Office of the Auditor General of Ontario 2017,238). OFMEM works horizontally with municipalities to ensure compliance. The power to exercise more coercive tools to enforce this authority may not be necessary on the part of OFMEM. Structures of authority are shared constructions of individuals. Participants who commented on this area expressed that they took their legislated responsibilities seriously and 
worked to meet compliance. This structure appears to be meaningful to the professionals operating within it.

While the Cabinet Committee on Emergency Management is given the authority to provide direction for the province's EM program there is no evidence that the Committee has met in the last five years (The Office of the Auditor General of Ontario 2017, 235). The lack of cohesion makes the authority of the Committee appear absent in practice, contributing to the view that there is a continued decentralization of power and authority between EM organizations in the province. This situation may be reflective of Clarke's theory of fantasy planning, with the existence of the Cabinet Committee serving more as a symbol of control, order, and stability than actually translating into a mechanism for high-level strategic policy making and leadership (Clarke 1999). Decentralization is particularly apparent regarding the power to respond and prepare for emergencies. While authority over emergencies in different jurisdictions is held by governments, the power to respond and prepare for emergencies is often spread across a multisector network of governmental actors, NGOs and not-for-profit organizations, and private industry. While EM organizations seem to rely on top-down decision making and goal articulation many also rely on horizontal collaboration and partnerships in all aspects of EM. EM organizations also experience varying levels of interdependency, in line with a system of networked governance. While some mandated organizations may maintain a high degree of coordination, often the partnerships and relationships that EM organizations form vary widely across the province based on a range of contextual factors.

It is important to note that there are aspects of EM in Ontario that clearly do not align with a system of networked governance. Henstra's theory of policy communities dictating EM policy does not seem to be in line with a system of networked governance, as these policy 
communities do not appear to operate in the absence of top-down structures of authority. While the findings from participant responses indicated that representatives from government agencies, NGOs, and private industry could certainly contribute to the formulation of EM planning and programming government policy in the field did not seem divorced from hierarchical power structures and top-down goal articulation. Horizontal collaboration was evident in the response of participants but it does not seem to have displaced top-down decision-making in government departments and agencies. The centralization of authority during provincial emergencies was also evident during the 2003 SARS Emergency, when the provincial government issued directives to municipalities to prepare for and respond to the emergency. Trends in the development of governance in EM can be seen in Table 6.

The increased comprehensiveness and formalization of EM networks in Ontario has been accompanied by an expansion in legislated roles, responsibilities, standards, and procedures and the centralization of authority. The EMCPA has contributed to network development while also contributing to a movement towards a system of governance that is more bureaucratic. While EM in Ontario has become increasingly networked between 1991 and 2018, governance has become less so. A timeline of these developments can be seen in Table 7. 
TABLE 6, Developments in Emergency Management Governance

\begin{tabular}{|c|c|c|c|c|}
\hline 1991 & Trend & 2018 & Major Influences & Implications \\
\hline $\begin{array}{l}\text { Decentralized } \\
\text { power and } \\
\text { authority }\end{array}$ & Weak & $\begin{array}{l}\text { More } \\
\text { centralized } \\
\text { authority }\end{array}$ & $\begin{array}{l}\text { - The introduction of more authoritative } \\
\text { legislation. } \\
\text { - OFMEM's authority in ensuring } \\
\text { compliance with the EMCPA. } \\
\text { - The creation of the Cabinet Committee } \\
\text { on Emergency Management. }\end{array}$ & $\begin{array}{l}\text { The centralization of authority } \\
\text { is characteristic of movement } \\
\text { toward bureaucratic } \\
\text { governance. EM governance } \\
\text { remains decentralized due to the } \\
\text { graduated response system. }\end{array}$ \\
\hline $\begin{array}{l}\text { A lack of } \\
\text { legislated } \\
\text { mandates }\end{array}$ & Strong & $\begin{array}{l}\text { Increased } \\
\text { legislated } \\
\text { mandates }\end{array}$ & $\begin{array}{l}\text { The inclusion of more expansively } \\
\text { mandated roles, responsibilities, } \\
\text { standards, and procedures in the } \\
\text { Emergency Management Act and } \\
\text { EMCPA. }\end{array}$ & $\begin{array}{l}\text { - The increase in legislated } \\
\text { mandates over time is indicative } \\
\text { of more a more bureaucratic } \\
\text { system of governance. }\end{array}$ \\
\hline $\begin{array}{l}\text { A reliance on } \\
\text { hierarches and } \\
\text { partnerships }\end{array}$ & $\mathrm{n} / \mathrm{a}$ & $\begin{array}{l}\text { A reliance on } \\
\text { hierarchies and } \\
\text { partnerships }\end{array}$ & $\begin{array}{l}\text { - A continual reliance on senior leadership } \\
\text { to support emergency programming and } \\
\text { a notable expansion in partnerships } \\
\text { between EM organizations between } \\
1991 \text { and } 2018 \text {. }\end{array}$ & $\begin{array}{l}\text { This characteristic of } \\
\text { governance has remained } \\
\text { bureaucratic in some ways and } \\
\text { networked in others. }\end{array}$ \\
\hline $\begin{array}{l}\text { Varying levels } \\
\text { of } \\
\text { interdependency }\end{array}$ & $\mathrm{n} / \mathrm{a}$ & $\begin{array}{l}\text { Varying levels } \\
\text { of } \\
\text { interdependency }\end{array}$ & $\begin{array}{l}\text { EM organizations experience varying } \\
\text { levels of interdependency based on their } \\
\text { unique needs, circumstances, and } \\
\text { environments due to the decentralized } \\
\text { nature of the graduated response system. }\end{array}$ & $\begin{array}{l}\text { This characteristic of } \\
\text { governance has remained } \\
\text { networked between } 1991 \text { and } \\
2018 \text {. }\end{array}$ \\
\hline $\begin{array}{l}\text { Varying policy } \\
\text { processes }\end{array}$ & $\mathrm{n} / \mathrm{a}$ & $\begin{array}{l}\text { Varying policy } \\
\text { processes }\end{array}$ & $\begin{array}{l}\text { - The decentralized nature of EM in the } \\
\text { province contributes to varying policy } \\
\text { processes between actors. }\end{array}$ & $\begin{array}{l}\text { - This characteristic may be more } \\
\text { or less bureaucratic depending } \\
\text { on the organization in question. }\end{array}$ \\
\hline
\end{tabular}

Source: Data collected from participant interviews, PERPs, and AARs. 
TABLE 7, The Development of Emergency Management Networks and Governance in Ontario between 1991 and 2018

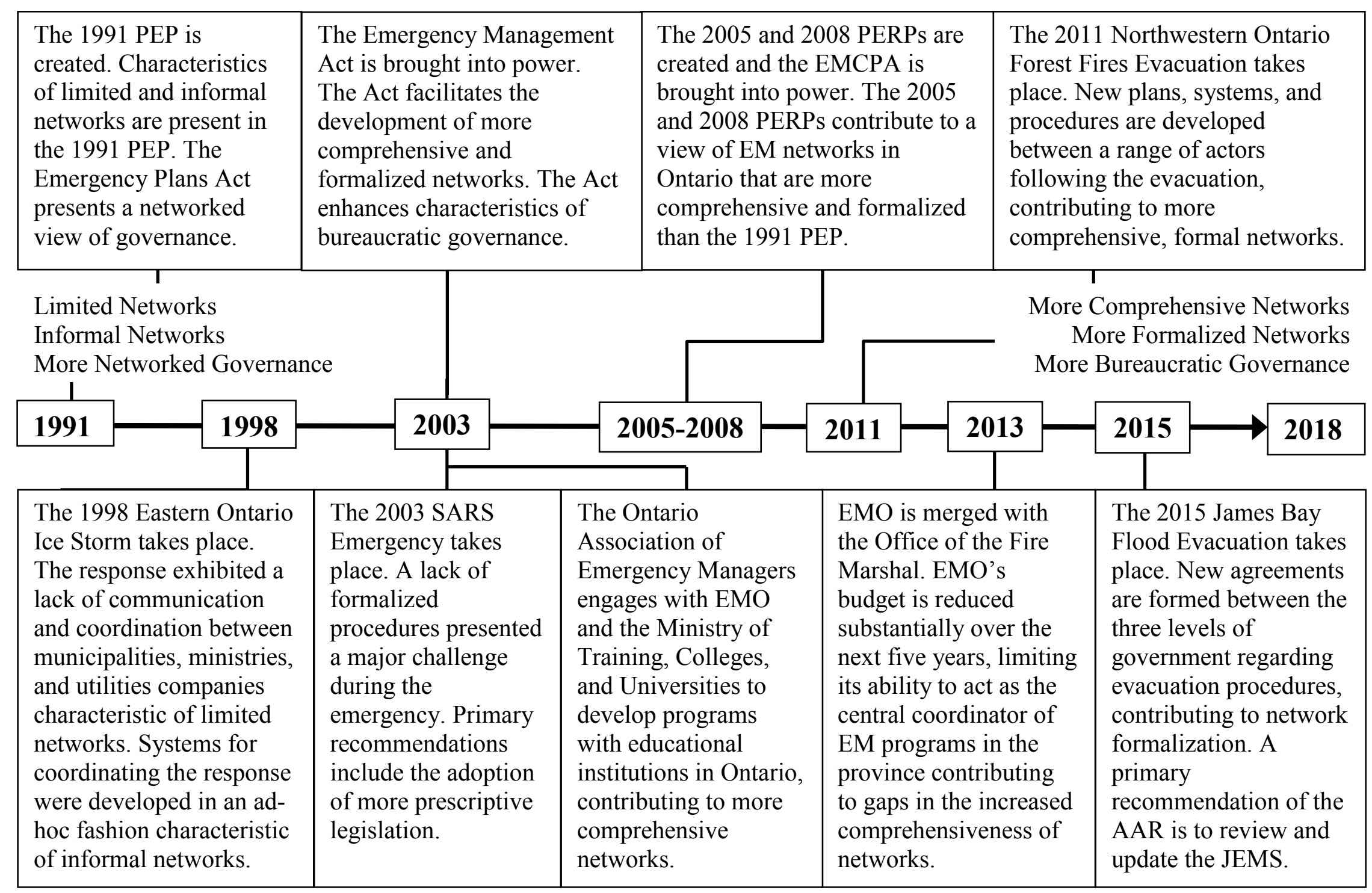

Source: Data collected from participant interviews, PERPs, and AARs. 
The findings from this thesis contribute to the understanding of how EM networks and governance in the Province of Ontario have developed over time, contributing to the study of the concepts of networks, governance, and public management in a field of increasing importance in Canadian society. The findings of this thesis present the view that the bureaucratization of governance can accompany the development of more comprehensive networks and that the increased use of horizontal partnerships and arrangements do not necessarily indicate the subversion of hierarchical structures of authority. Several areas for consideration have been revealed by this thesis, which should be taken into account when engaging in further study in the field of EM. First, the capacity for EM organizations to engage in networks decreases as resources become scarcer. It should therefore be understood that while some municipalities can fill the gap with network building following provincial and federal cutbacks in EM support, others will become more isolated. Measures should be taken by the province to develop and implement centralized information-sharing systems that can increase connectivity between all municipalities in the province and reduce isolation when cutbacks occur. Both a provincial web emergency operations centre and a secure centralized sharing system were highlighted by participants as major areas for development.

The significant cutbacks on the funding and staffing of the Office of Emergency Management in OFMEM have directly affected its ability to act as the central coordinator of EM in the province, which has reduced the Office's ability to share information, build relationships, and support the EM planning, programming, and training of municipalities. Reduced resources on the part of the Office have also inhibited its ability to develop plans and systems to enhance the coordination of EM actors in the province. The impact of these cutbacks have been felt 
particularly because the Office's duties have become more expansive due to the Province's expanding risk environment and the increases in the severity and frequency of natural disasters. Further support should be allocated to the Office to ensure it can effectively engage in its duties. The development of the NGO Alliance was widely acknowledged as beneficial to EM in Ontario due to its ability to act as a central point of contact to connect governmental actors with NGOs and not-for-profits. Developments like the NGO Alliance should be supported by provincial, regional, and municipal EM actors due to the centralized structures they create being beneficial for network development in EM. Organizations like the NGO Alliance may be able to act as central coordinators between governmental and non-governmental organizations in the province, providing a system for communities in the province to maintain connectivity during times of austerity.

The EMCPA has been beneficial to the development of EM networks in the Province of Ontario. A further expansion of the Act should be considered as a potential vehicle to further network development in the province. However, expanded requirements on the part of municipalities should be accompanied by the development of systems to support them in meeting compliance with those requirements. Care should also be taken to include the input of EM organizations such as municipalities in the development of legislation, regulations, and standardized systems. It is ultimately the network of actors involved in EM in the province that makes these developments meaningful. Without their commitment these structures may not function effectively in practice.

The formalization of EM networks in the province seems to have been a positive development. Roles and responsibilities are more clearly defined, there is a greater harmonization of standards and procedures, and there are clearer expectations between EM 
organizations outlined in MOUs and shared agreements. However, network formalization may have negative effects if it does not account for the unique needs, circumstances, and environments of those within the network. In the case of the development of further regulations or standardized systems and procedures at the provincial level care should be taken to ensure that flexibility is built in to account for the different circumstances of EM organizations in the province.

The scope of this thesis is limited due to its focus on the EM networks in the Province of Ontario. Care must therefore be taken before applying these findings to other jurisdictions or fields of study. The decentralized nature of EM in Ontario and the varying systems, environments, and priorities of EM actors also implies that the applicability of the trends highlighted by this thesis may not be consistent across all organizations. It is important to note that the PERPs, AARs, and perceptions of EM professionals used as sources of data for this thesis are not perfect representations of EM in the Province of Ontario. Likewise, the AARs and participants have been chosen at the discretion of the researcher based on a variety of factors and are not as exhaustive or as representative as they could be.

Despite its limitations, this thesis lays the groundwork for many avenues for further research. A comparative analysis of the EM networks in different communities in the province would be beneficial to understanding how local networks in the province form and develop and identifying discrepancies in this development. The current rise in emergencies with prominent social and mental health aspects also presents an opportunity to examine how these aspects are being incorporated in EM in the province. A study focusing on the development of trust and confidence between EM organizations would help to identify how these concepts relate to the development of EM networks. EM in First Nations communities was a topic raised by several 
participants as an important area that warranted academic research, a study on EM in First Nations communities in northern Ontario would be beneficial for the understanding how these communities, as well as provincial ministries and federal departments, are approaching the topic.

\section{Concluding Remarks}

This thesis provides evidence that rise in the prominence of EM networks in other jurisdictions is occurring in the Province of Ontario in the form of more expansive, comprehensive, and formalized networks. The findings indicate that network development does not necessarily equal movement toward networked governance. The adoption of the Emergency Management Act and the EMCPA enhanced characteristics associated with both bureaucratic governance and comprehensive, formalized networks. The decentralized nature of EM in Ontario has contributed to discrepancies in the development in these networks. The development of networks also does not seem to have subverted traditional structures of government power and authority in the province. Network development has been beneficial to EM in the Province of Ontario and the increased attention that EM is currently experiencing in the province presents an opportunity to encourage that development to further enhance the effectiveness and consistency of EM in the province. 


\section{BIBLIOGRAPHY}

Abraham, Marilyn, Anneleis Eckert, Jessica Isaac, Logan Juffermans, Amy Lejcar, Eric Marr, Shannon McIntyre, et al. 2012. "Guidelines for Engaging the Public Post-Disaster: Key Success Factors for Your Community." School of Environmental Design \& Rural Development, University of Guelph.

Berardo, Ramiro, and John T. Scholz. 2010. "Self-Organizing Policy Networks: Risk, Partner Selection, and Cooperation in Estuaries." American Journal of Political Science 54 (3): 632-49.

Boin, R. A., and P. 't Hart. 2010. "Organising for Effective Emergency Management: Lessons from Research." Australian Journal of Public Administration 69 (4): 357-71. https://doi.org/10.1111/j.1467-8500.2010.00694.x.

Brinkerhoff, Jennifer M. 2002. "Government-non-profit Partnership: A Defining Framework." Public Administration and Development 22 (1): 19-30. https://doi.org/10.1002/pad.203.

Brooks, JoAnn M., Deb Bodeau, and Jane Fedorowicz. 2013. "Network Management in Emergency Response: Articulation Practices of State-Level Managers-Interweaving Up, Down, and Sideways." Administration \& Society 45 (8): 911-48.

Caprole, Rocco. 2000. "The May 1998 Landslides in the Sarno Area in Southern Italy: Rethinking Disaster Theory." Quick Response Report \#131. St. John's University.

Chipangura, Paul, Dewald Van Niekerk, and Gerrit Van Der Waldt. 2016. "An Exploration of Objectivism and Social Constructivism within the Context of Disaster Risk." Disaster Prevention and Management 25 (2): 261-74. https://doi.org/10.1108/DPM-09-2015- 0210.

Clarke, Lee Ben. 1999. "Mission Improbable: Using Fantasy Documents to Tame Disaster." Chicago: University of Chicago Press.

Collier, David. 2011. “Understanding Process Tracing." PS: Political Science and Politics 44 (4): 823-30. https://doi.org/10.1017/S1049096511001429.

Considine, Mark, and Jenny M. Lewis. 2003. "Bureaucracy, Network, or Enterprise? Comparing Models of Governance in Australia, Britain, the Netherlands, and New Zealand." Public Administration Review 63 (2): 131-40. https://doi.org/10.1111/1540-6210.00274.

Creswell, John W. 2003. Research Design: Qualitative, Quantitative, and Mixed Methods Approaches. New Dehli: Sage Publications Inc.

-- - 2007. Qualitative Inquiry and Research Design - Choosing from Amoung Five Approaches. London: Sage Publications Inc.

Fasenfest, David. 2011. "Government, Governing, and Governance." Critical Sociology 36 (6): 771-74.

Gilbert, Claude. 1995. "Studying Disaster: A Review of the Main Conceptual Tools." International Journal of Mass Emergencies and Disasters 13 (3): 231-40.

Hammond, Thomas H. 1986. "Agenda Control, Organizational Structure, and Bureaucratic Politics." American Journal of Political Science 30 (2): 379-420.

Henstra, Daniel. 2010. "Explaining Local Policy Choices: A Multiple Streams Analysis of Municipal Emergency Management." Canadian Public Administration 53 (2): 241-58. https://doi.org/10.1111/j.1754-7121.2010.00128.x.

- - . 2011. "The Dynamics of Policy Change: A Longitudinal Analysis of Emergency Management in Ontario, 1950-2010." Journal of Policy History 23 (3): 399-428.

J.A. Pirie \& Associates. 2003. "A Report on the Management of the SARS Emergency by Emergency Management Ontario." J.A. Pirie \& Associates Inc. 
Joakim, Erin, and Brent Doberstein. 2013. "Policy Recommendations for Reducing Vulnerability to Disasters in Canada: Perspectives From Practitioners in Waterloo Region, Ontario." Risk, Hazards \& Crisis in Public Policy 4 (4): 274-91.

Jordan, A. Grant. 1981. "Iron Triangles, Woolly Corporatism and Elastic Nets: Images of the Policy Process." Journal of Public Policy 1 (1): 95-123. https://doi.org/10.1017/S0143814X00001379.

- - . 1990. "Policy Community Realism versus 'New' Institutionalist Ambiguity." Political Studies 38 (3): 470-84. https://doi.org/10.1111/j.1467-9248.1990.tb01082.x.

Junki, Kim. 2006. "Networks, Networked Governance, and Networked Networks." International Review of Public Administration 11 (1): 19-34. https://doi.org/10.1080/12294659.2006.10805075.

Kapucu, Naim, and Vener Garayev. 2016. "Structure and Network Performance: Horizontal and Vertical Networks in Emergency Management." Administration \& Society 48 (8): 931-61.

Keller, Lisa A. 2010. "Unit of Analysis." In Encyclopedia of Research Design, 2-4. Thousand Oaks: Sage Publications Inc.

Klijn, Erik-Hans. 2008. "Governance and Governance Networks in Europe: An Assessment of Ten Years of Research on the Theme." Public Management Review 10 (4): 505-525. https://doi.org/10.1080/14719030802263954.

Lansdowne Technologies Inc. 2017. "Emergency Management Review." https://www.emergencymanagementontario.ca/english/insideemo/EmergencyManagementRe view.html.

Laycock, Katherine, James. P Mahone, and Glen Filson. 2014. "The Impact of Natural Disaster on Community Engagement and Connection in Goderich, Ontario." Canadian Journal of Urban Research 23 (1): 39-54.

McCarthy Dan, Sarah Michaels and Nancy. P Goucher. 2006. "Policy Windows, Policy Change, and Organizational Learning: Watersheds in the Evolution of Watershed Management." Springer: Environmental Management. 38: 983-992.

McNabb, David E. 2008. Research Methods in Public Administration and Non-Profit Management Quantitative and Qualitative Approaches. Second Edition. Armonk: M.E Sharpe Inc.

Murphy, Brenda L. 2004. "Emergency Management and the August 14th, 2003 Blackout." Series 40. ICLR Research Paper Series. Brantford: Wilfrid Laurier University.

Natural Resources Canada. 2014. "Canada in a Changing Climate: Sector Perspectives on Impacts and Adaptation." The Government of Canada. http://www.nrcan.gc.ca/environment/resources/publications/impactsadaptation/reports/assessments/2014/16309.

Nirupama, Niru, and David Etkin. 2012. "Institutional Perception and Support in Emergency Management in Ontario, Canada." Disaster Prevention and Management 21: 599-607.

O'Sullivan, Tracey L., Wayne Corneil, Darene Toal-Sullivan, and Craig E. Kuziemsky. 2013. "Unraveling the Complexities of Disaster Management: A Framework for Critical Social Infrastructure to Promote Population Health and Resilience." Social Science \& Medicine 93: 238-46.

Participant 01. January 16, 2018. EM Thesis Transcript - Participant 01.

Participant 02. January 20, 2018. EM Thesis Transcript - Participant 02.

Participant 03. January 16, 2018. EM Thesis Transcript - Participant 03.

Participant 04. January 24, 2018. EM Thesis Transcript - Participant 04.

Participant 05. January 24, 2018. EM Thesis Transcript - Participant 05.

Participant 06. January 22, 2018. EM Thesis Transcript - Participant 06.

Participant 07. January 19, 2018. EM Thesis Transcript - Participant 07.

Participant 08. January 24, 2018. EM Thesis Transcript - Participant 08.

Participant 09. January 22, 2018. EM Thesis Transcript - Participant 09.

Participant 10. January 19, 2018. EM Thesis Transcript - Participant 10. 
Participant 11. January 26, 2018. EM Thesis Transcript - Participant 11.

Participant 12. January 26, 2018. EM Thesis Transcript - Participant 12.

Participant 13. January 27, 2017. EM Thesis Transcript - Participant 13.

Participant 14. January 29, 2018. EM Thesis Transcript - Participant 14.

Participant 16. January 31, 2018. EM Thesis Transcript - Participant 16.

Participant 17. February 1, 2018. EM Thesis Transcript - Participant 17.

Participant 18. February 1, 2018. EM Thesis Transcript - Participant 18.

Participant 19. February 5, 2018. EM Thesis Transcript - Participant 19.

Participant 20. February 7, 2018. EM Thesis Transcript - Participant 20.

Participant 22. February 20, 2018. EM Thesis Transcript - Participant 22.

Perry, Ronald W. 2004. "Disaster Exercise Outcomes for Professional Emergency Personnel and Citizen Volunteers." Journal of Contingencies and Crisis Management 12 (2): 64-75. https://doi.org/10.1111/j.0966-0879.2004.00436.x.

Pierre, Jon, and B. Guy Peters. 2000. Governance, Politics and the State. Hong Kong: St. Martin's Press. Plato, and Allan Bloom. 1991. The Republic of Plato. Second Edition. Library of Congress: Basic Books.

Porter, Jody. 2017. "First Nations Say Suicide Crisis Requires Same Response as Natural Disasters - 'Social Emergencies Summit' Aims to Create Template for Government Response in First Nations." CBC News, March 24, 2017.

Public Safety Canada. 2011. "Federal Emergency Response Plan." The Government of Canada. https://www.publicsafety.gc.ca/cnt/rsrcs/pblctns/mrgnc-rspns-pln/index-en.aspx.

- - . 2016. "Public Safety Canada Report on Plans and Priorities 2016-17." The Government of Canada. https://www.publicsafety.gc.ca/cnt/rsrcs/pblctns/rprt-plns-prrts-2016-17/.

Raikes, Jonathan, and Gordon McBean. 2016. "Responsibility and Liability in Emergency Management to Natural Disasters: A Canadian Example." International Journal of Disaster Risk Reduction 16: 1218. https://doi.org/10.1016/j.ijdrr.2016.01.004.

Rhodes, R.A.W. 1997. Understanding Governance - Policy Networks, Governance, Reflexivity and Accountability. Glasgow: Open University Press.

Robinson, Scott E., Warren S. Eller, and Brian J. Gerber. 2013. "The Core and Periphery of Emergency Management Networks." Public Management Review 15 (3): 344-62.

Robinson, Scott, Haley Murphy, and Angela Bies. 2014. "Structured to Partner: School District Collaboration With Nonprofit Organizations in Disaster Response." Risk, Hazards \& Crisis in Public Policy 5 (1): 77-95.

SAIC Canada. 1998. "Assessment of Provincial Preparedness and Response to the 1998 Ice Storm in the Province of Ontario." Science Applications International Corporation.

Saldaña, Johnny. 2009. The Coding Manual for Qualitative Researchers. Book, Whole. London Sage Publications Inc.

Strauss, Anselm L. 1987. Qualitative Analysis for Social Scientists. Cambridge: Cambridge University Press.

The Canadian Red Cross. 2017. "Alberta Fire Response 2016." 2017. http://www.redcross.ca/in-yourcommunity/alberta/alberta-major-disaster-responses/alberta-fires-response-2016.

The Government of Canada. 1909. The Canadian Red Cross Society Act. http://lawslois.justice.gc.ca/eng/acts/C-22.4/index.html

The Government of Ontario. The Emergency Management and Civil Protection Act. 1990. https://www.ontario.ca/laws/statute/90e09.

The Government of Ontario Newsroom. 2017. "Ontario Strengthens Emergency Management Program." The Government of Ontario. https://news.ontario.ca/mcscs/en/2017/12/ontario-strengthensemergency-management-program.html. 
The Ministry of Community Safety and Correctional Services. 2016. "Emergency Management Legislation and Regulation." Accessed 2017-08-07.

https://www.emergencymanagementontario.ca/english/insideemo/legislationandregulation/ha ndbook_EMCPA.html.

- - . 2005. "2005 Province of Ontario Emergency Response Plan." The Government of Ontario.

- - . 2008. "2008 Province of Ontario Emergency Response Plan." The Government of Ontario. https://www.emergencymanagementontario.ca/english/emcommunity/response_resources/pl ans/provinicial_emergency_response_plan.html.

- - - 2012. "A Review of Ontario's Response to the 2011 Northwestern Ontario Forest Fires." The Government of Ontario.

The Ministry of the Solicitor General. 1991. "1991 Province of Ontario Emergency Plan." The Government of Ontario.

The Auditor General of Ontario. 2017. "The Office of the Auditor General of Ontario 2017 Annual Report - Volume 1." The Government of Ontario.

The Office of the Fire Marshal and Emergency Management. 2015. "After-Action Report \& Improvement Plan, James Bay Flood Evaluation 2015." The Government of Ontario.

Waugh, William L ., and Gregory Streib. 2006. "Collaboration and Leadership for Effective Emergency Management." Public Administration Review, Special Issue: 131-40.

Weichselgartner, Juergen. 2001. "Disaster Mitigation: The Concept of Vulnerability Revisited." Disaster Prevention and Management 10 (2): 85-94. 